



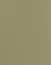









FIRST LESSONS IN BATIK 




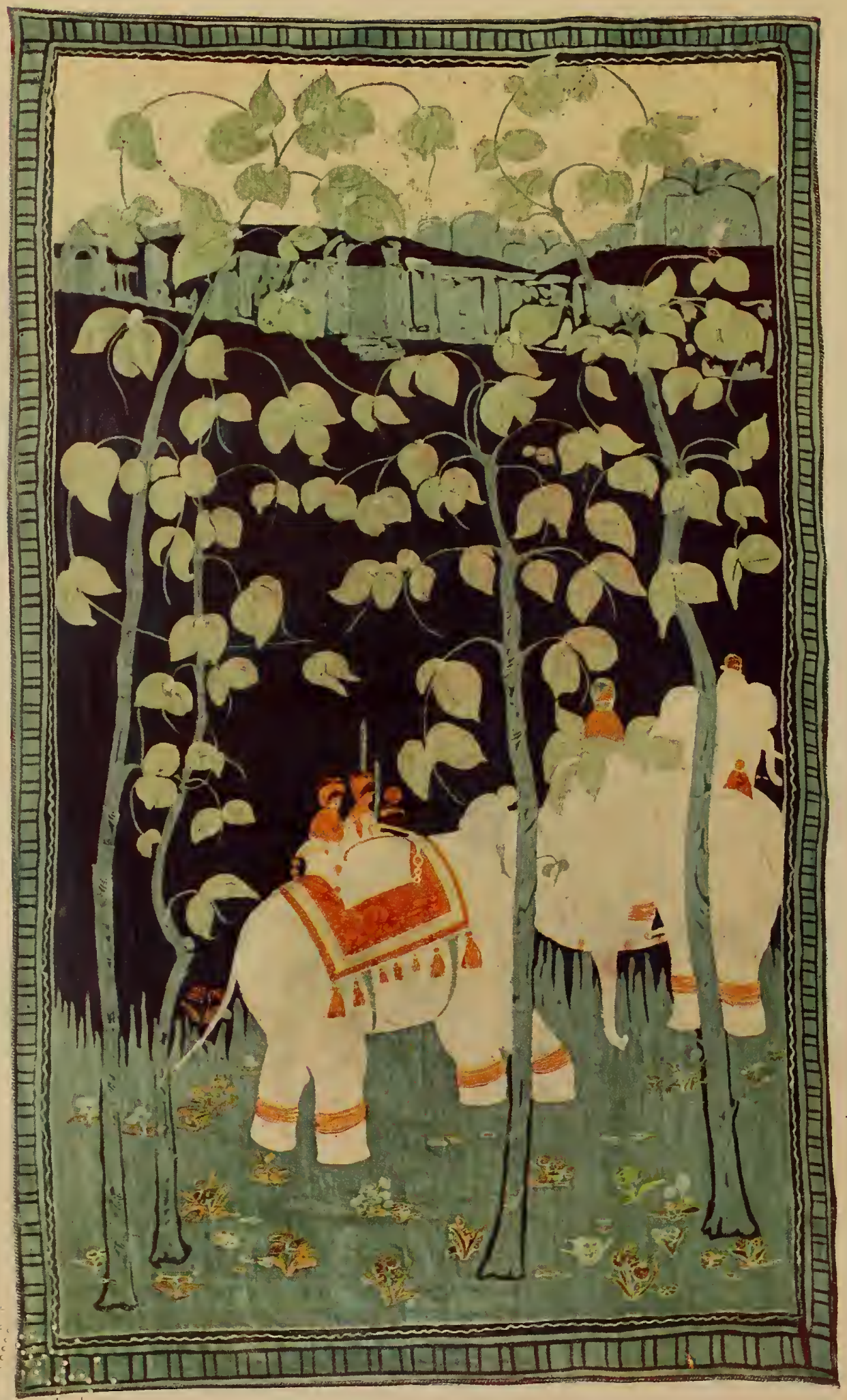

A'B'ATIK WALL HANGING. BY ANNA TYRELL. ART INSTITUTE 


\section{FIRST \\ LESSONS IN BATIK}

A HANDBOOK IN BATIK, TIE-DYEING

AND ALL PATTERN DYEING

By

GERTRUDE CLAYTON LEWIS

Instructor in Art, Lindblom High School, Chicago

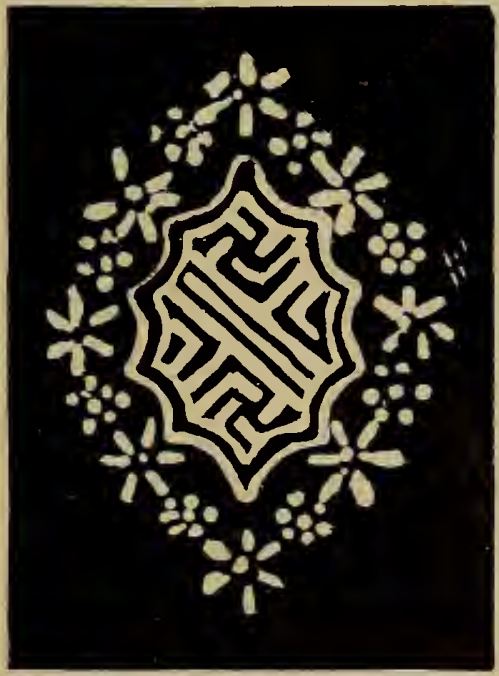

A Javanese Motif

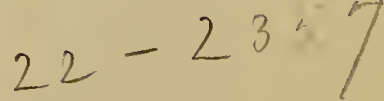

\section{THE PRANG COMPANY}


64384

$11<$
9503
$14 x$

M

747

$2674 \mathrm{~F}$

Copyright, 1921

By THE PRANG COMPANY 


\section{THE PREFACE}

7 HE growing interest in "Batik" leads the author to believe that this Handbook, describing the various processes and illustrating a number of definite problems, will meet the need of many artists, teachers, and craft workers who wish to try their hand at this new and fascinating oriental art.

The book does not attempt to present a historical or critical study of "Batik," but to give detailed directions for doing the work under American conditions. "Batik" presents many new and interesting problems for art workers who have wearied of china painting, metal work, embroidery, etc. It not only permits the worker to produce exquisite gowns, scarfs, table covers, bags, curtains, and many other articles that will express her own individuality, and be exactly suited to the color scheme and design of their surroundings, but it also will enable the worker to produce articles of commercial value which are readily salable. As the beauty and value of "Batik" depends almost wholly upon the personal touch and artistic taste of the worker who produces it, there is little likelihood of its being commercialized or produced by mechanical processes. This promises to keep it an individual craft.

While "Batik" offers large opportunities for home workers, it also presents an interesting field for industrial art problems for students in art schools, high schools, normal schools, and colleges. Many progressive art teachers are offering courses in "Dyes and Dyeing" in connection with their scientific study of "Color," and relating them also to the work in "Costume Design," "Interior Decoration," and "Domestic Art."

"Bateeko Powder Dyes" are recommended for Batik work. These dyes can be prepared and kept in bottles in strong solution, ready for immediate use. It is not necessary to boil the goods in the dyes, as they work successfully in tepid water and without constant stirring. These dyes are recommended as unusually beautiful and brilliant, yet soft in tone.

Mr. Albert Buell Lewis, Assistant Curator of the Department of Anthropology in the Field Museum, Chicago, has furnished interesting historical data and supplied a number of illustrations from his private collection of "Batiks."

Photographs have been kindly loaned by the following: The Art Institute of Chicago; Professor Albert W. Heckman of Teachers College, Columbia University; the "Keramic Studio;" the "Industrial Arts Magazine;" Mrs. Helen Reed of New York City; Mrs. Caroline Kohl; Miss Amy Swisher of Miami University, Oxford, Ohio; Lieutenant Jean Paul Slusser of the U. S. General Hospital, Fort McHenry, Ind.; Miss Rose Buhlig of the Lindblom High School, Chicago; Miss Anna Tyrell.

The publishers are under special obligation to Miss Mary C. Scovel, Head of the Normal Department of the Art Institute of Chicago, who prepared the outline and first draft of this book, and gave many practical suggestions.

"They would be glad to receive suggestions or interesting photographs of "Batik" suitable for use in connection with future editions of this book. 


\section{The Table of Contents}

The Preface

Chapter I. The History of Batik . . . . . . . . . 7

Chapter II. The Method in Java . . . . . . . . . 10

Chapter III. The Possibilities of Batik . . . . . . . . 20

Chapter IV. Processes of Batik Dyeing . . . . . . . . 36

Chapter V. Crackle in Batik . . . . . . . . . . 44

Chapter VI. Color and How to Use It . . . . . . . . 50

Chapter VII. "Tied and Dyed" Work . . . . . . . . 60

Chapter VIII. Dyeing Suggestions. . . . . . . . . . 74 



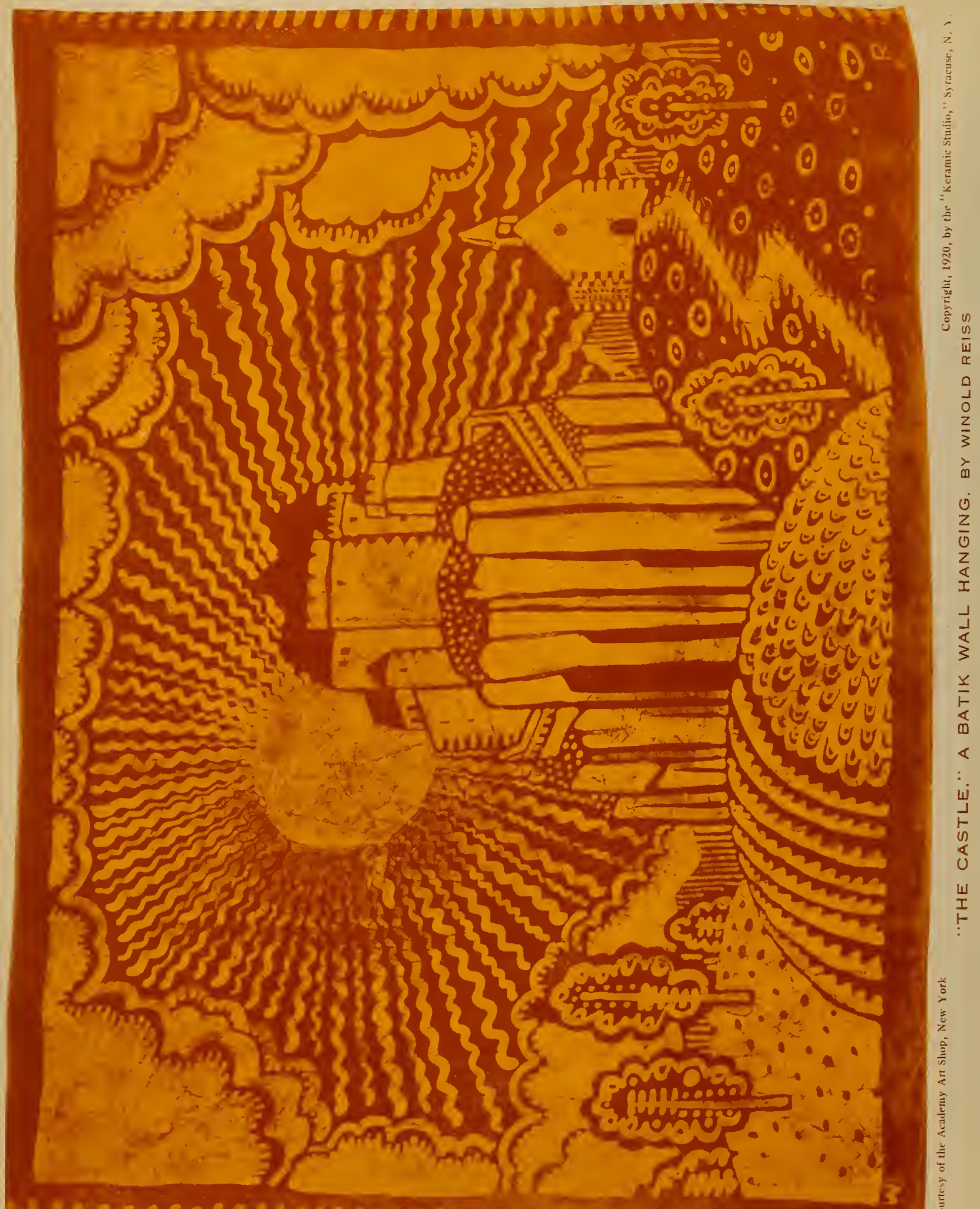




\section{FIRST LESSONS IN BATIK}

\section{CHAPTER I \\ THE HISTORY OF BATIK}

7 HE word "Batik" is Javanese, and means to paint or draw or design with wax on textiles so that when placed in the dye the wax prevents the part covered from taking the color. The wax is then removed by hot water or gasoline, leaving the parts thus covered of the original color.

From early times and in many places designs have been made in this manner on various kinds of objects, but the process reached its highest development in its application to woven fabrics. Wax seems to have been used in this manner in southern India and probably in some other parts of southeastern Asia for centuries. Early Buddhistic books of the ninth or tenth century refer to a wax painting process, and there are preserved in Japan ancient Indian cloths which have been colored in this manner.

This process of wax painting, horvever, reached its highest development in Java, where it was probably introduced about the twelf th century. The earliest written record we have states that in 1518 , there was a flourishing industry of this sort at Cheribon, Java, which showed certain remarkable resemblances to the processes employed on the Coromandel coast of southern India. The work was done by men, and plant and animal motives were largely used in the designs. At that time, that portion of the island had not yet been Mohammedanized, as we see by the designs used.

After Mohammedanism spread over the island, the industry developed rapidly, and many new and original patterns were added to those formerly used. The highest development was in central Java, where "Batik" flourished especially during the seventeenth and eighteenth centuries. Here the work was carried on by women, especially by those of the leisure class, who could give the time and care necessary to the production of the finest work. Some designs were so elaborate and difficult that only the nobility could afford them and a few designs were reserved for the use of royalty. In these designs, indigoes or browns are the predominating colors.

The first detailed account of Batik making was by Raffles in 1817 . At that time the "tjanting," an instrument which will be explained later, was in universal use. How long it had been used and when it superseded the brush, which was doubtless used earlier, as it was in India, is not known. About I860, a new process was introduced by means of which the wax was transferred to the cloth by a metal stamp dipped in the melted wax and then pressed on the cloth. This stamping process is known as "tjap" and is done by men, while in Batik work the designing and painting are always done by women. It is doubtless an adaptation of the color printing process of India to the wax process. In some cases after stamping, the opposite side is Batiked, but this is not common. These tjap cloths are, of course, much cheaper than true Batiks. 
The designs used in Javanese Batik work show much variation in different parts of the island, and certain designs are characteristic of particular regions. The motives are of various origins. Some are old weaving patterns, or adapted from basket or plaited designs. Some are evidently of Indian origin, similar to those on the cotton prints of southern India. It is interesting to find the same designs on some of the old Buddhistic sculptures that are found on certain Batik pieces. Other designs are of Chinese origin, and recently modern European designs are being adopted. Most of the designs, however, are either modifications of the old Indian plant and flower motives or geometric figures developed by the Javanese themselves.

The Javanese women employ the "Batik" process largely for the decorations of textiles used in their personal costume. This costume is simple, consisting of an oblong piece of cloth about three to four and one-half yards long by forty-two inches wide, generally called a "sarong." It is worn wrapped around the waist and tucked in the belt. This costume is worn by both men and women.

A cotton scarf, generally about three yards long by eighteen inches, is also worn, and is used by the women as a "carry-all." Silk is occasionally used by the nobility for scarfs.

The turban is made of a square piece of cloth twisted around the head in a different fashion in each district.

Each district has its own characteristic color schemes. Djokjakarta and Surakarta, which are semi-independent principalities in the interior, do the finest work and use largely indigo and soga-brown dyes, which give a range of color from cream through the yellow browns and blues to a very dark color, practically black, made by dyeing strong blue over a strong brown.

In certain places on the north coast of Java, notably Pekalongan and Samarang, much gayer colors, such as red, blue, green, etc., are used, and floral designs are common.

Prices in Java vary from one to twelve dollars, and even as much as tiventy-five dollars may be paid for a very fine piece. Two to four dollars will buy an excellent turban square.

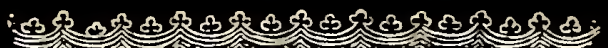

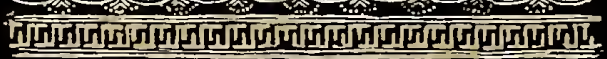

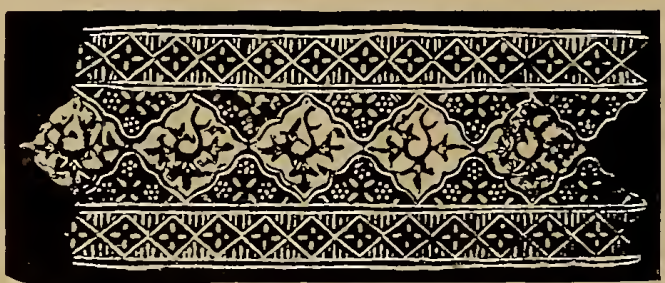

Motifs from Javanese Batik in the Field Museum of Natural History 

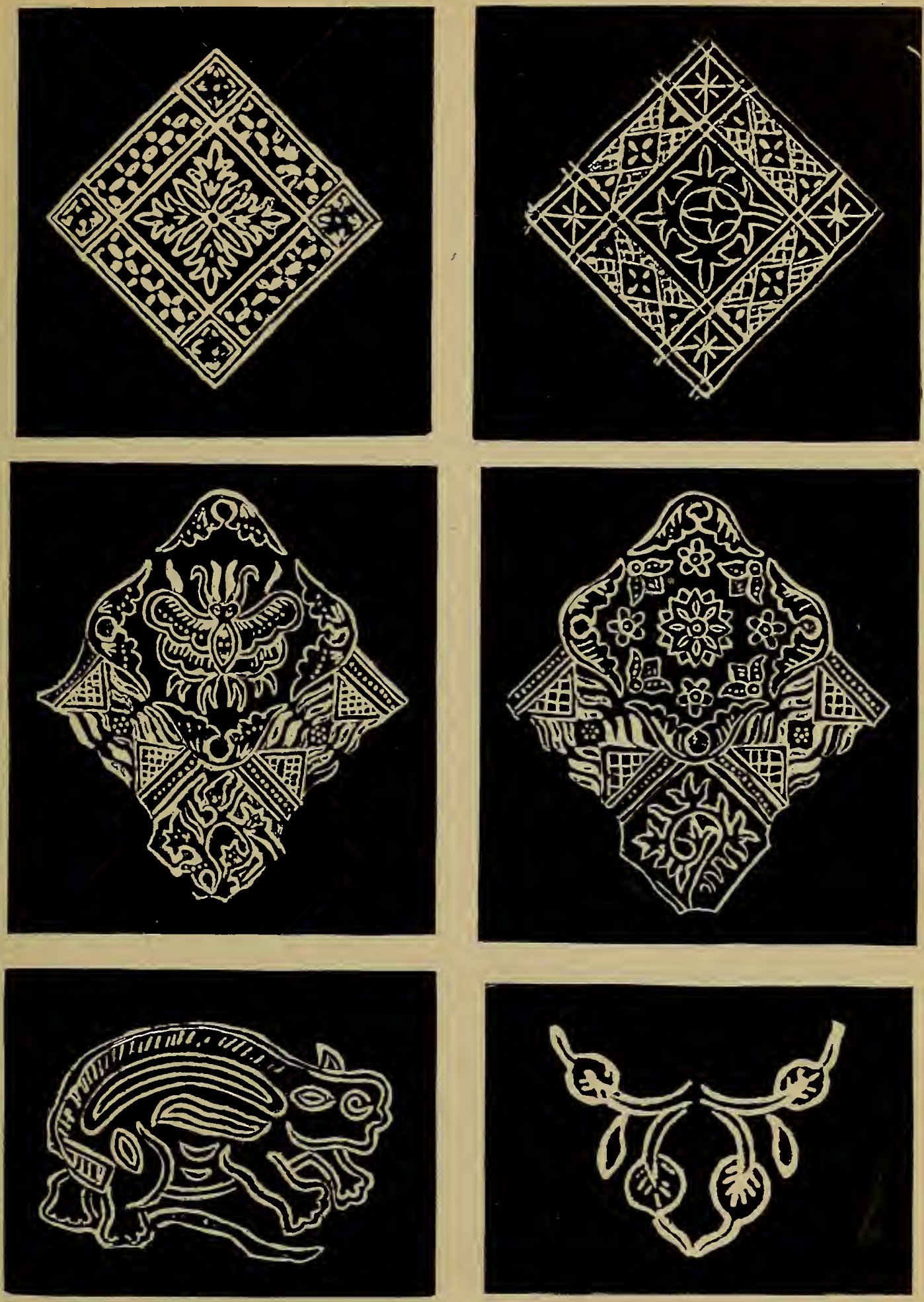

Designs from "tjap" stamps used in Java for repeating units. The Field Museum of Natural History, of Chicago, has a collection of these 


\section{CHAPTER II}

\section{THE METHOD IN JAVA}

7 HE work of Batik making is definitely divided, in Java, between the men and the women. The women do the designing and waxing, while the men do the dyeing.

In Java, in the earlier days, Batik was largely a home industry, but like all such it is being taken out of the home and transferred to primitive factories, where the workers come together to work, but continue the old methods and technique. Even in that far-off land, machine imitations of Batik are flooding the country, and it is difficult today to be sure that a given piece is a genuine example of the hand process, unless the individual history of the piece is known, since the old designs are still used, and the native work is imitated in the printed cloths even to the crackle and irregularity of the designs.

In former times they wove their own cloth, but now the cloth used is largely muslin woven in England or Japan. Several qualities are used for different grades of work. Practically all Batik work is done on muslin, though occasionally a silk scarf may be colored in this way. The cloth is prepared before using, first, by thorough washing to remove all starch and filling; second, by soaking it in cocoanut oil, and third, removing the oil with ashes. This removes the dead-white look and gives the creamy color with which we are familiar in Batik pieces. Next, the cloth is starched with a rice starch made by boiling rice in water until it is a thin paste. The cloth is then dried and rolled up. In a primitive fashion, it is then softened or ironed by pounding with a wooden pestle until it is smooth. The cloth is now ready. The wax used is a mixture of rosin, animal fat and beeswax. The proportion of each has been worked out by long experience. A little iron pan or stone jar holds the melted wax. The tjanting, which is the characteristic tool of Batik work, is used to apply the wax. This is a little oval cup made of very thin copper with a slender curved spout projecting from the base of the cup. For a handle, a short piece of reed with a soft pith is used. Tjantings vary in the size and number of spouts. A tjanting with a fine slender spout is used for very narrow lines and small dots. Then comes a series of others, each with a little larger spout for the purpose of covering more surface. One kind is made with two spouts and is used to draw parallel lines. Others have from three to six spouts to give the little groups of dots which are quite an essential part of some designs. (See page 13.)

The remainder of the equipment consists of a wad of cotton tied to a stick, a cocoanut-shell spoon, a copper basin for boiling out the wax, a light upright frame for holding the cloth while it is being worked, a straightedge of wood, and assorted basins and vats for dyes and dyeing. These are of copper, pottery or wood.

After dyeing, the color is set, wax is boiled out and saved to be used again. It is now waxed a second time for the next color, dyed and washed. This process is repeated for each color desired. 


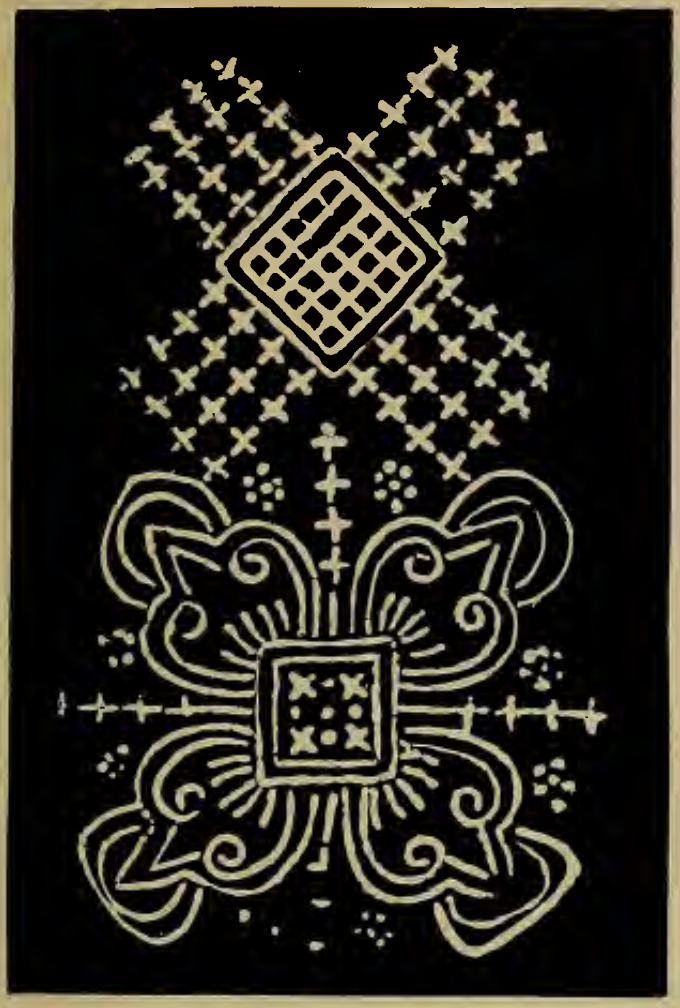

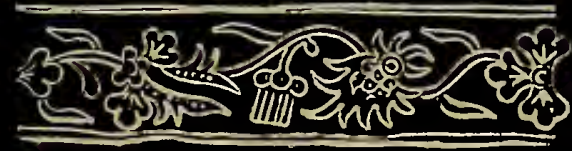

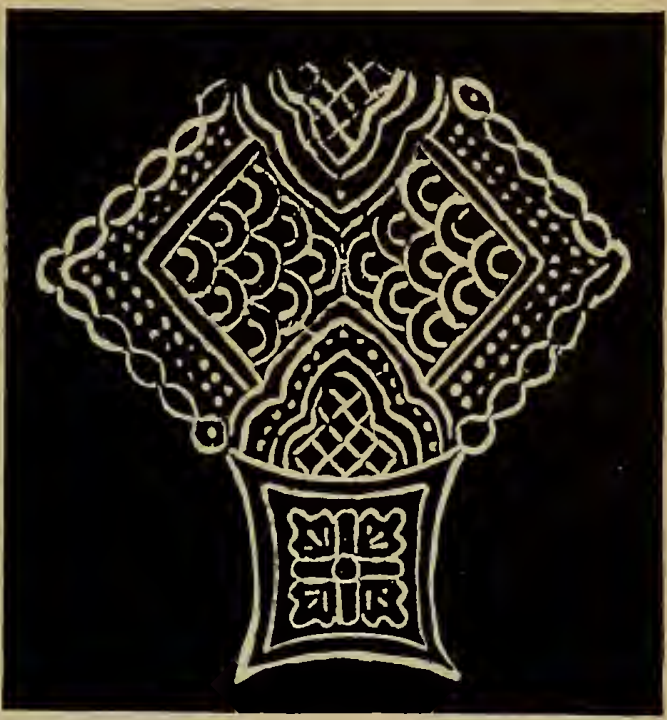

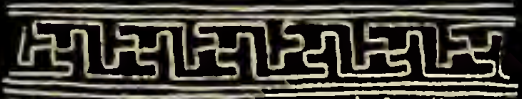

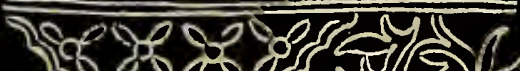

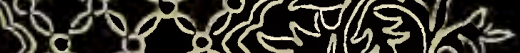

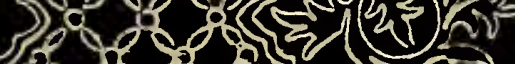

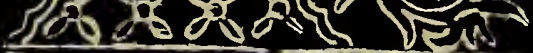

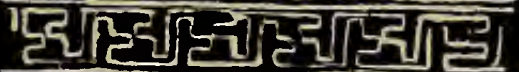
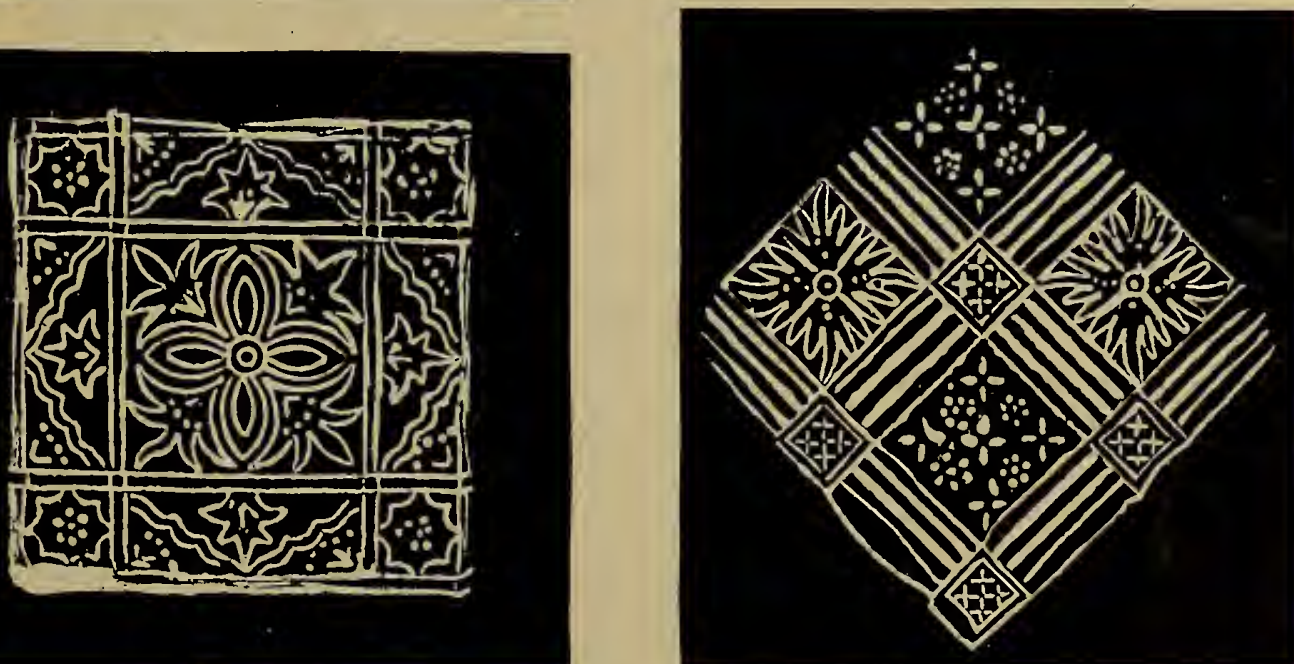

More tjap stamps giving Javanese Batik designs, from the Field Museum of Natural History', Chicago 
The use of the tjanting is the ideal method of making long even lines and for outlining large spaces. Up to the present it has been difficult to secure tjantings in America, but they will undoubtedly soon be available, since Batik has firmly established itself as a beautiful and practical artcraft for American workers.

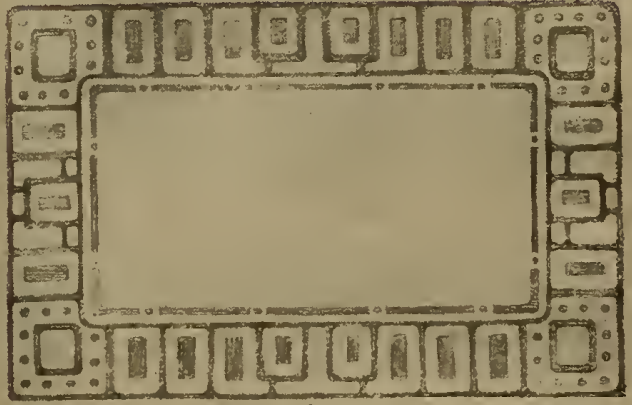

The design for this Batik Tray was done in wax and the silk then dipped in an all-over dye

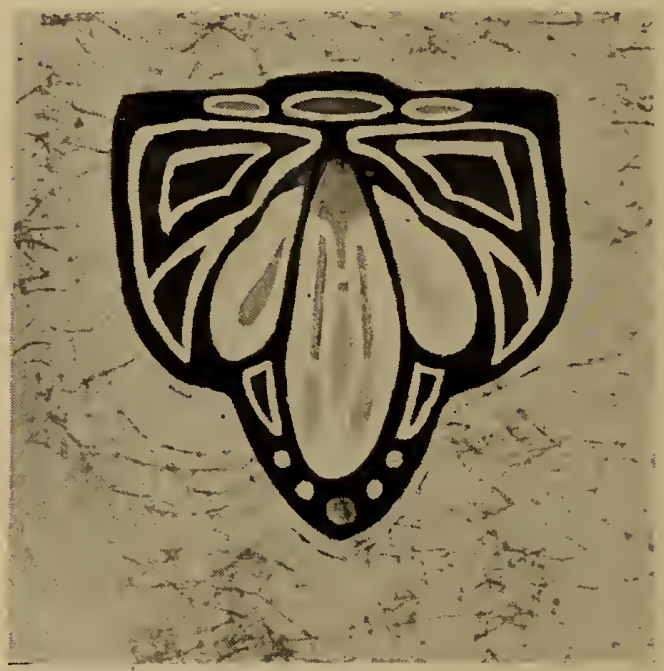

Showing design for a Batik Bag with crackle

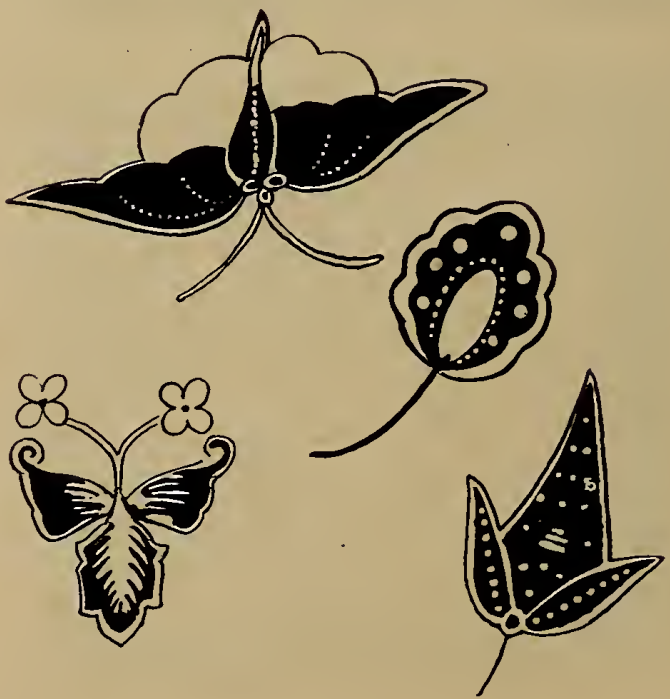

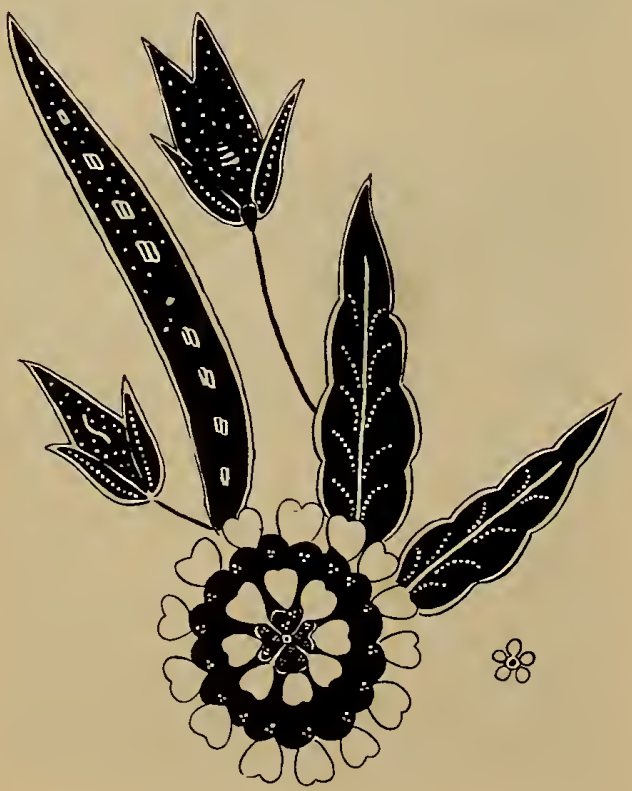

Detail drawings of units taken from Batiks in the possession of $A$. B. Lew'is 

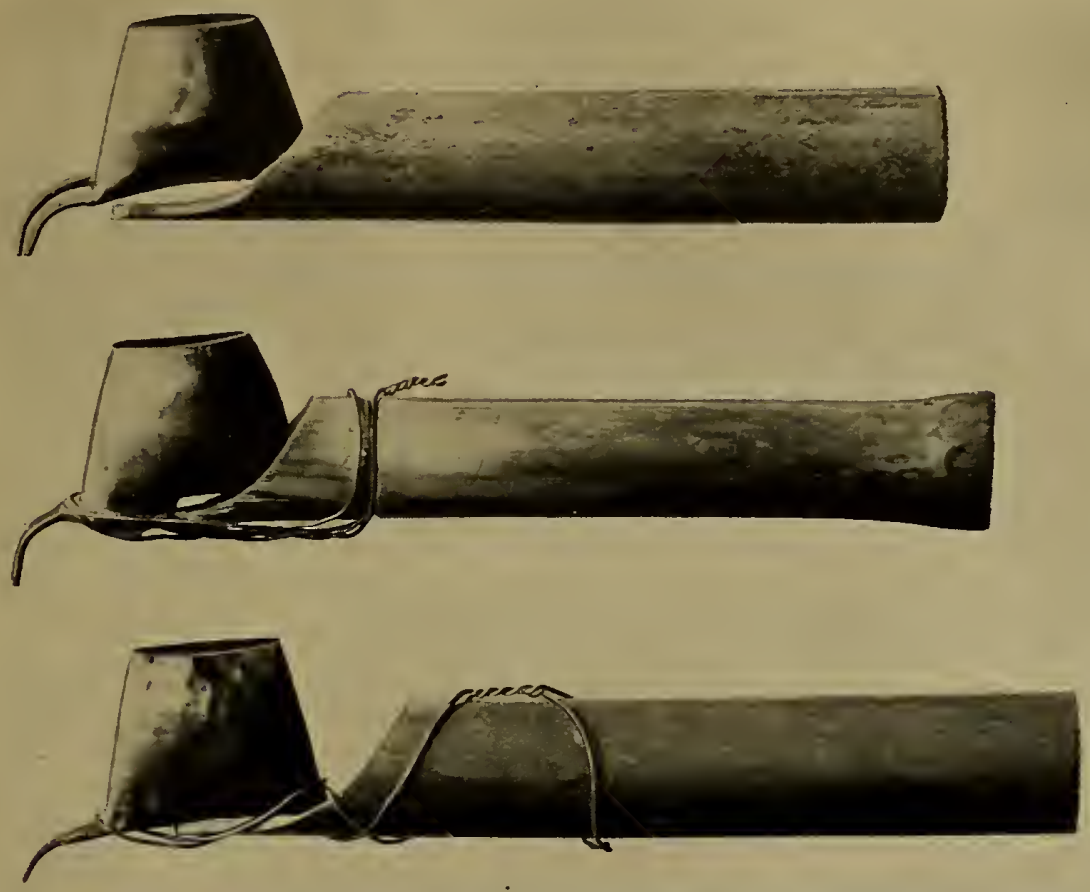

The native Javanese Tjantings, showing two sizes of single spouts and one with double spouts

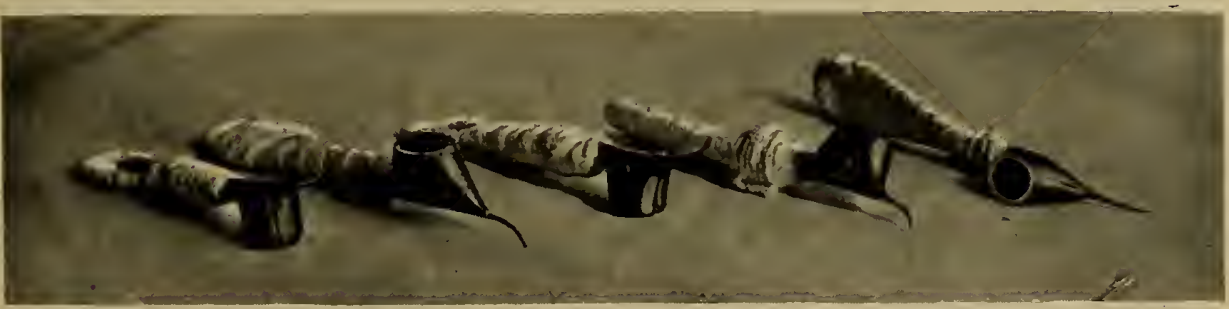

Modern Tjantings, made by R. H. Earl, New York City

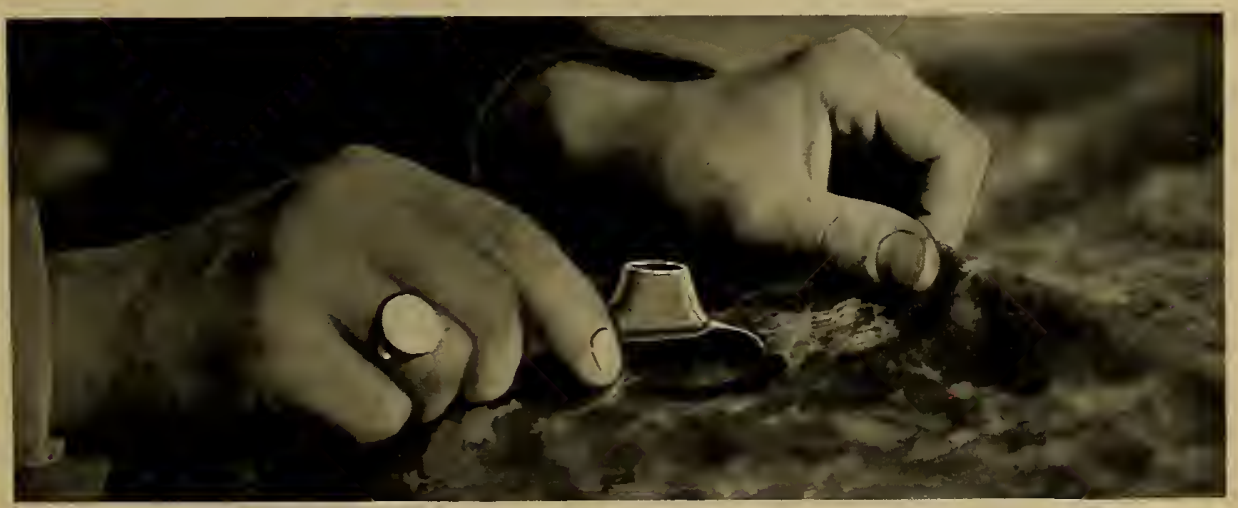

Showing the use of the Tjanting. Courtesy of R. H. Earl, New York City 


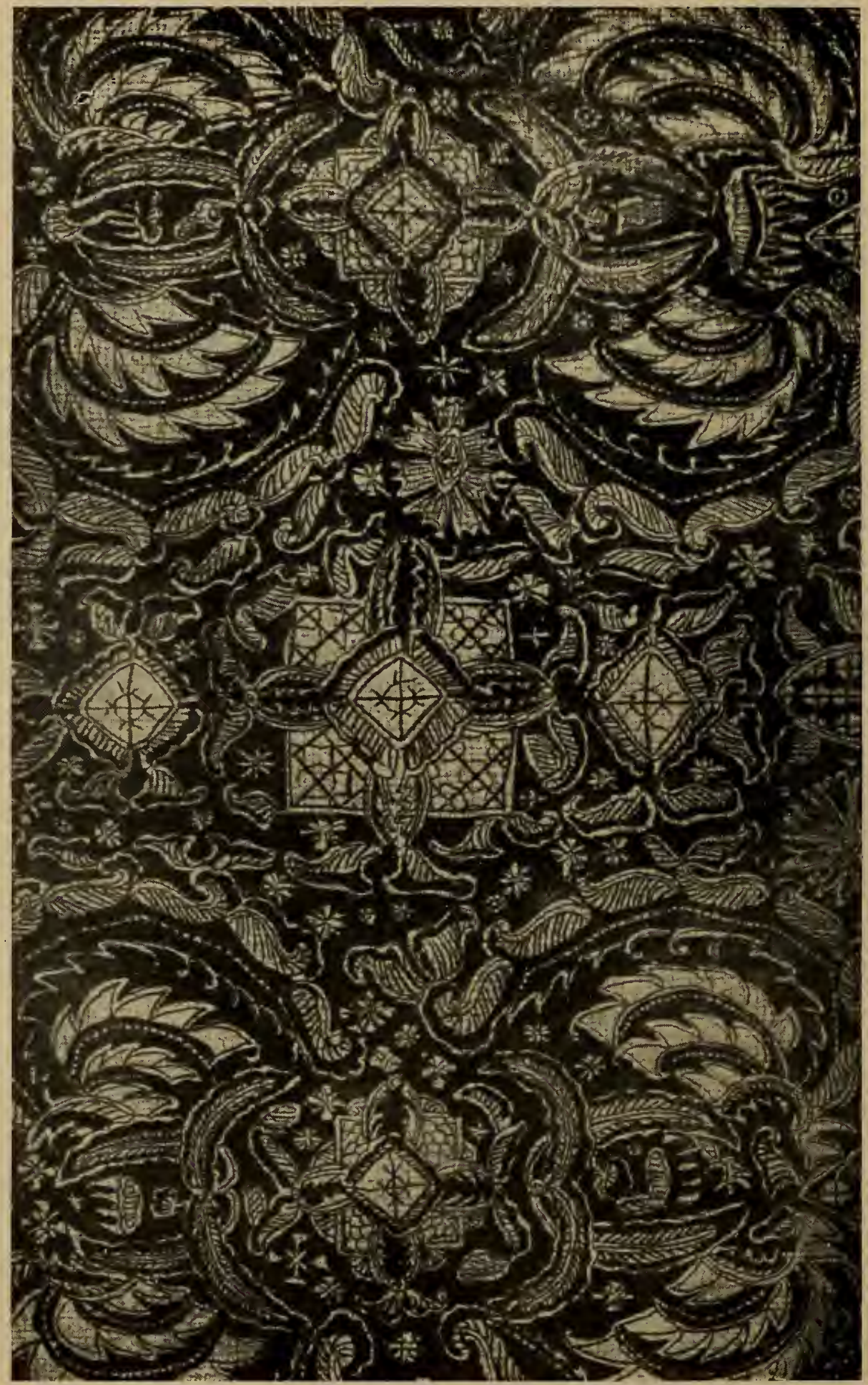

A detail of a rare Javanese Batik in the American Museum of Natural Histary, New York 


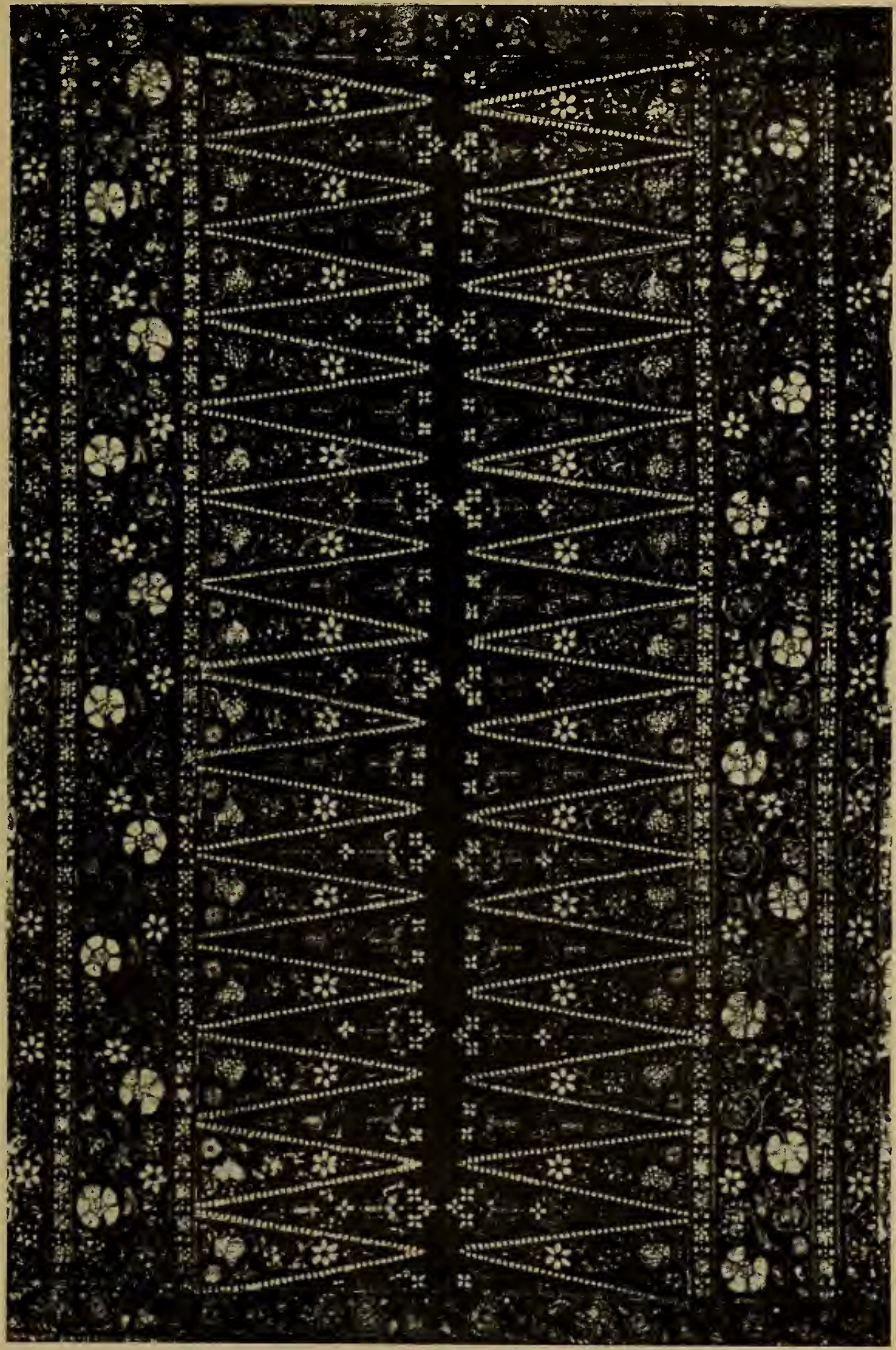

Detail of a Javanese Sarong. Property of A.B. Lez'is 
Some means of keeping the wax hot must be produced. Anything that will hold the wax at an even temperature will do, an electric stove, gas burner, or alcohol burner. A bowl of wax may be set in the top of a teakettle of boiling water and will remain hot enough to use for half an hour without reheating the water. All danger of burning the wax is eliminated by keeping the wax in a bowl set in a pan of water. If the water is kept just below the boiling point, that will give sufficient heat.

In covering a large space, it is sometimes better to begin waxing in the center and working outward toward the edge.

When the woman is ready to start her work, she sketches in the main outlines and more complicated parts of the design with charcoal; then she hangs the cloth over the little upright frame and sits down on a little mat before her work. She fills her tjanting with hot wax by means of the cocoanut-shell spoon, and, holding the cloth in her left hand, draws the design in with the tjanting by resting the tjanting lightly on the cloth or moving it gently around the outline. The small parts of the design are generally done without first drawing the design in charcoal. The cotton swab is used as a brush to wax the larger places.

The more we study the designs of the Javanese the more we realize the influence of their tools. The dots on leaves and flowers, the use of the light outline, the kind of line, the beautiful line designs used-all have been worked out with this characteristic tool and in certain ways are suggested by it.

After one side of the cloth is waxed, a good piece will be turned over and the design very carefully followed on the back. In doing this there are generally small differences in design between the back and front, which give one a means of determining whether a piece is real Batik or a print. After waxing all parts of the design not to be dyed with the first color, the piece of goods is ready to be dyed. This work is done by men. The dye is, of course, used cold, and to render it permanent the cloth must be left in the dye for several days; in the case of indigo often as long as two weeks. When removed from the dye the cloth is first hung out in the air until the color is oxidized or "fixed." The wax is then removed by steeping in hot water and is saved for use again. 


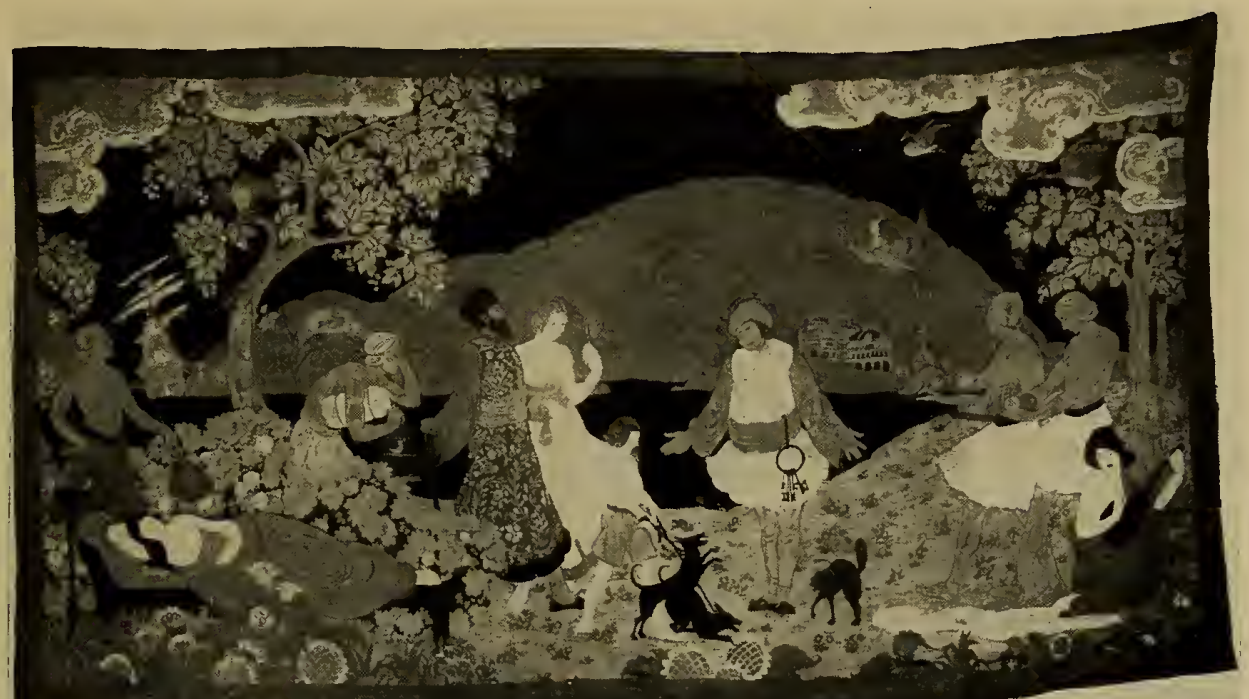

A Batik Mural Decoration by Fall

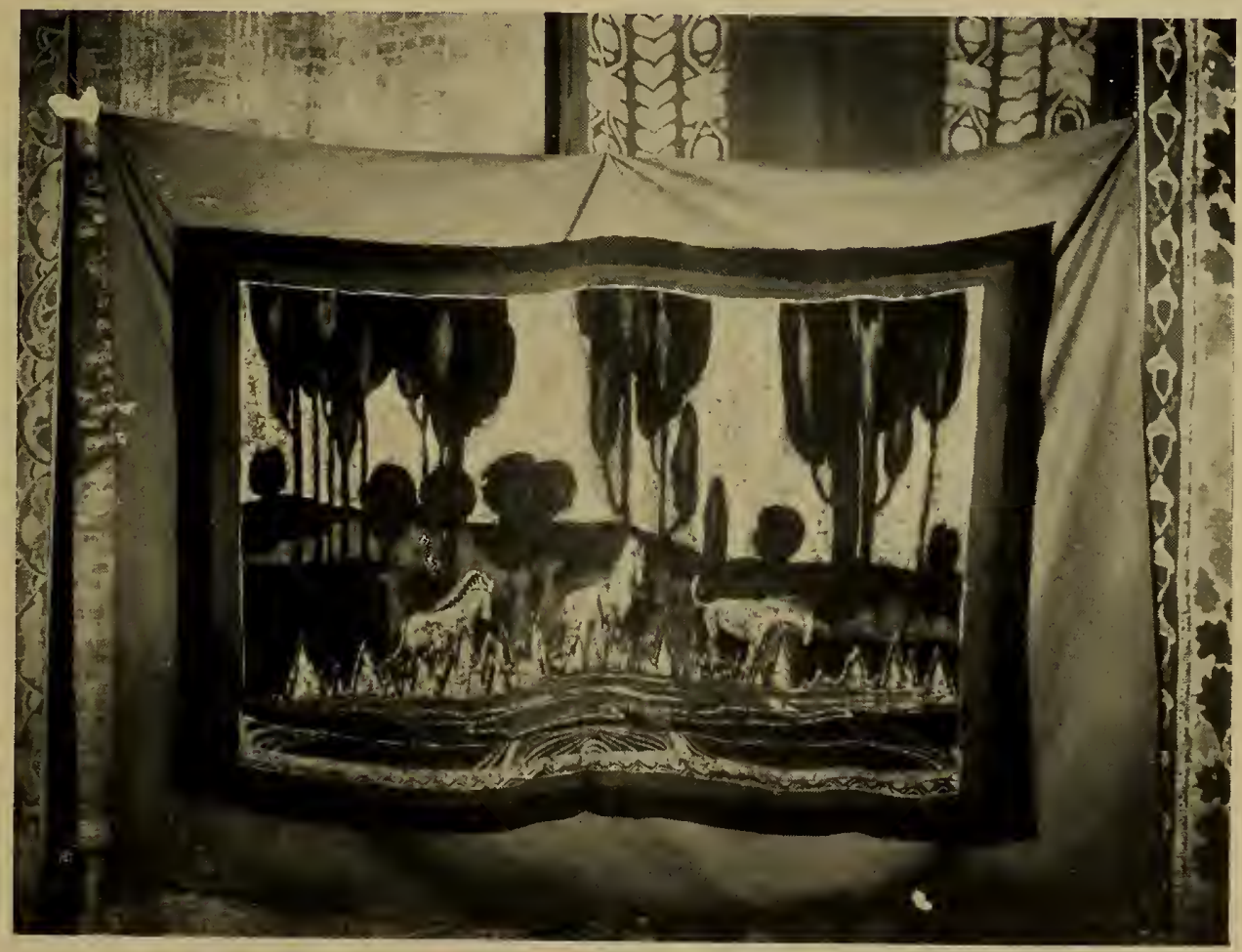

$A$ decorative Wall Hanging of modern Batik 
FIRST LESSONS IN BATIK

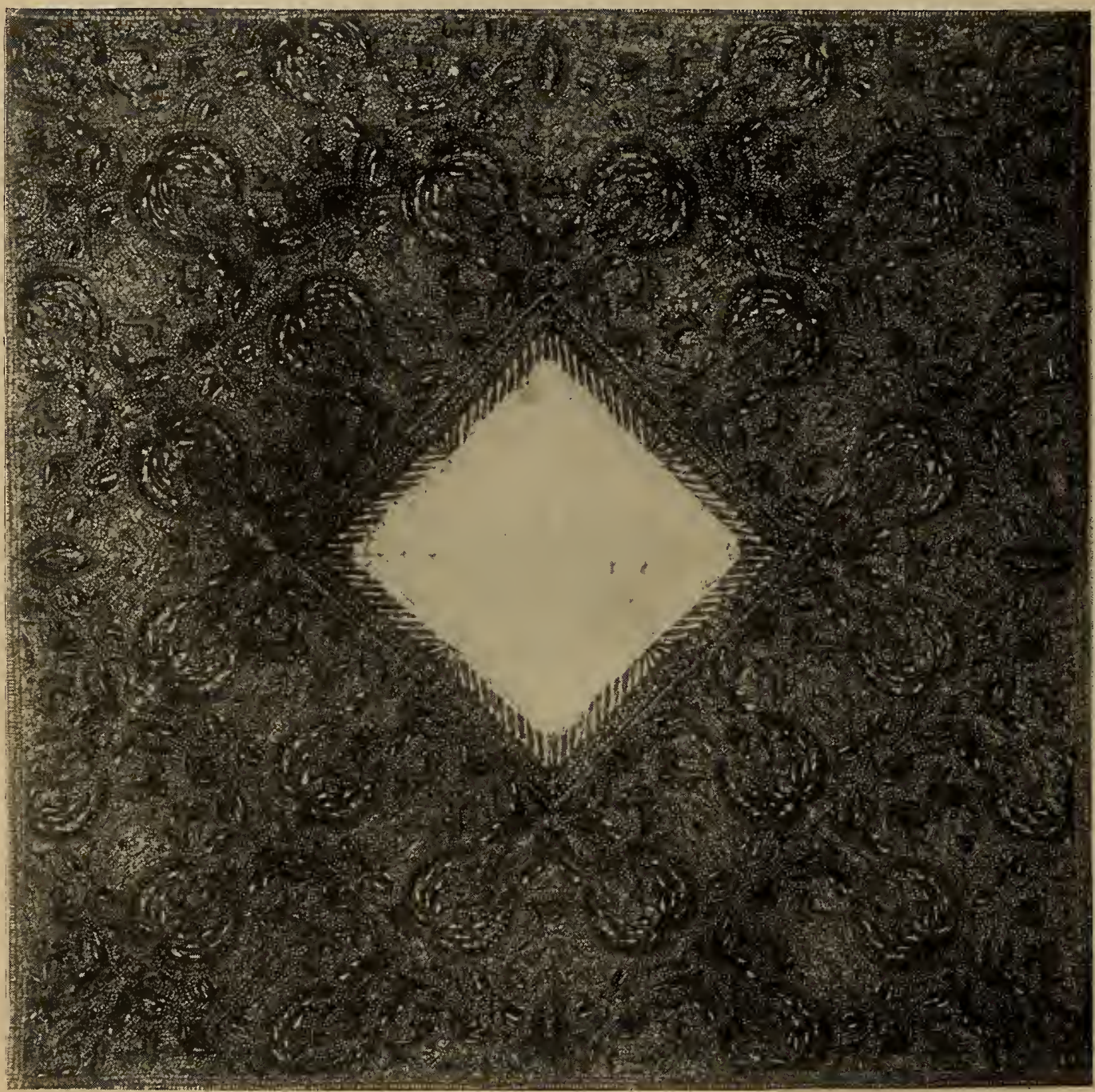

A Javanese Batik Turban. Property of A. B. Lewis 


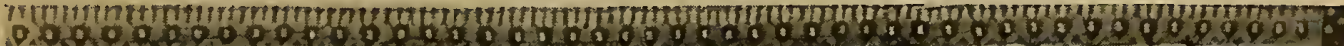

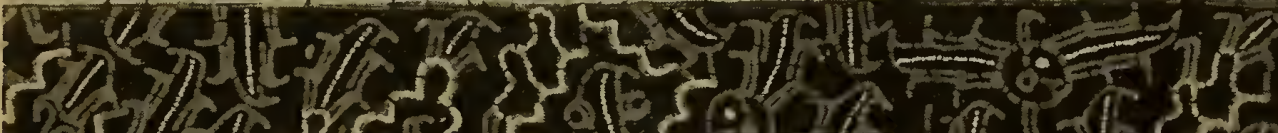

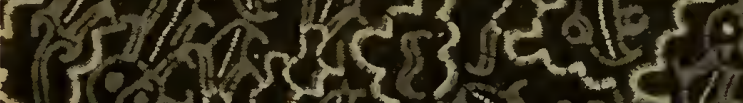

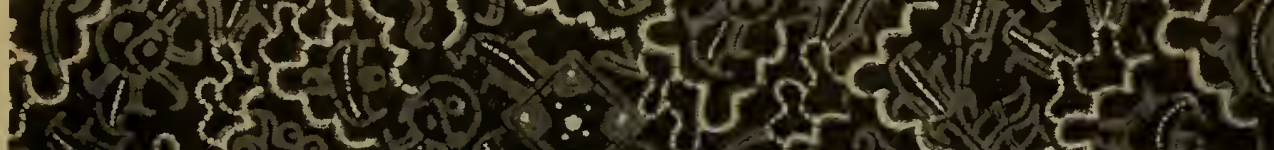

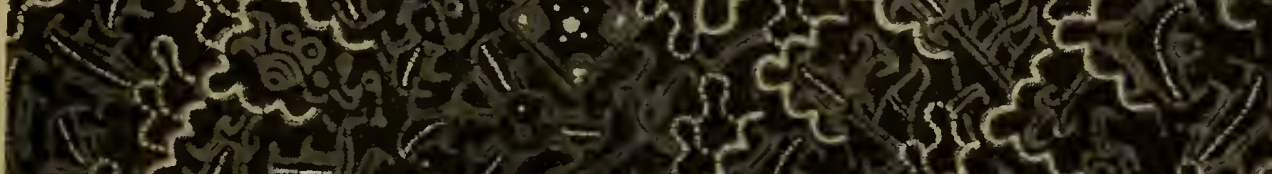

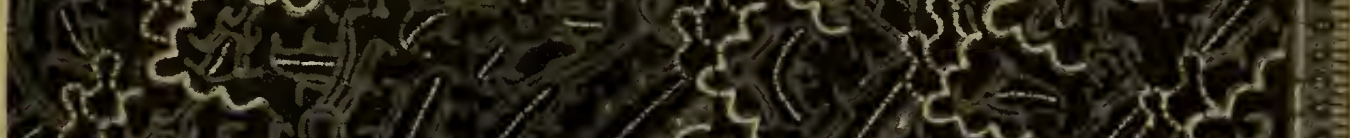

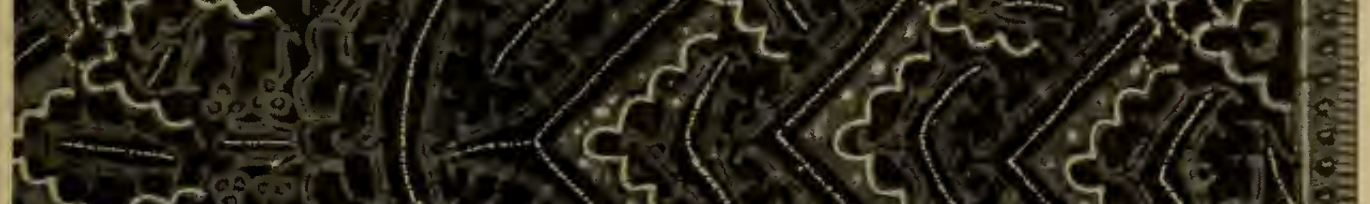
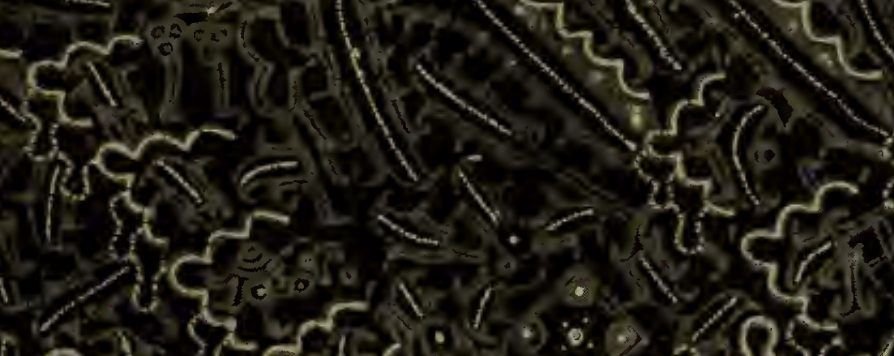

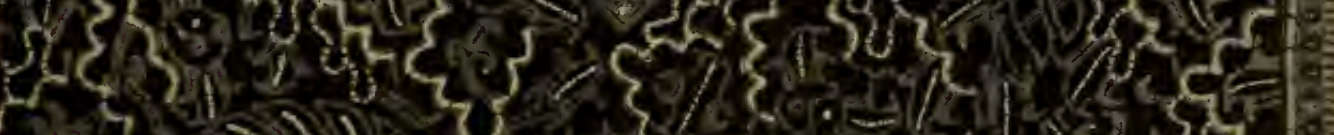

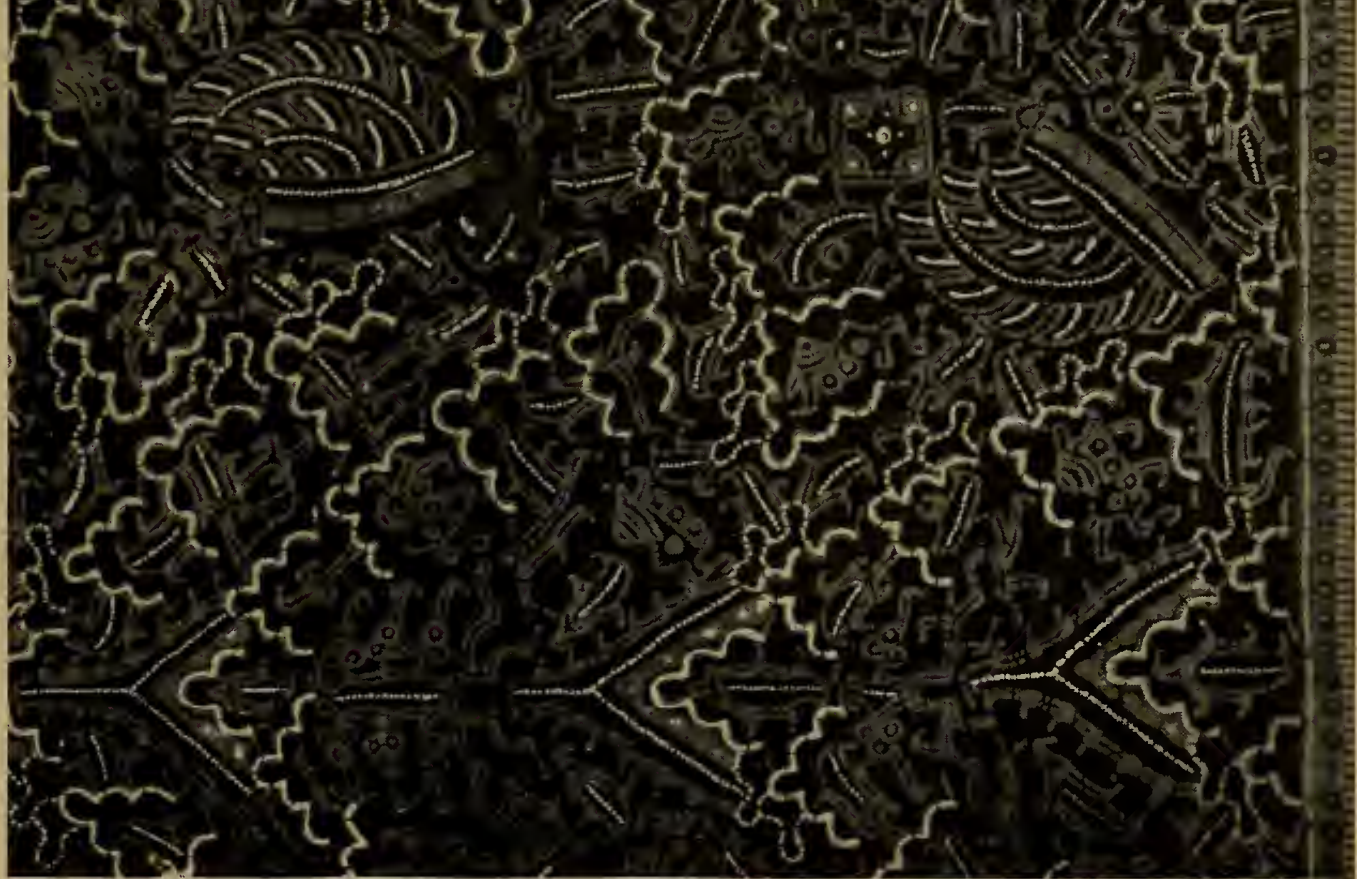

A corner of a Javanese Batik Turban. Property of A. B. Lewis 


\section{CHAPTER III \\ THE POSSIBILITIES OF BATIK}

$\Lambda^{T}$ this time of industrial and artistic development Batik dyeing comes to offer a new field for the Arts and Crafts worker.

Today the woman of leisure, as well as the artist, wishes her individuality to be shown in both the furnishings of her home and in her own personal belongings. Batik work helps to supply both these needs. In the first wave of enthusiasm over this work, it seemed as though the need of beautiful form as well as beautiful color was lost sight of. Beautiful color can hardly be avoided with good dyes. The fascination of the color and the dye is such that the need of beautiful shapes was somewhat forgotten at first, and there was a tendency to splash on a design without much regard to beauty of shape or of line and to depend upon the color to make it attractive.

The wonderful possibilities inherent in the process were the only things that saved it in this stage from the fate of stenciling, etc. Batik will rank with the art processes that are always beautiful and in use if the requirements mentioned above are adhered to. One of the chief requirements for success in this craft is a willingness to take time for careful and exact work. A successful piece of Batik must be carefully executed to be of any permanent value. Good craftsmanship is as essential in this as it is in making a good piece of embroidery or painting.

The present American method of Batik dyeing has varied somewhat from the old Javanese. It has become simpler and more direct. Time is of very little value in Java; therefore, the native artists worked without regard for the time spent.

Specimens of Batik work were carried to Holland during the seventeenth century by the Dutch East India Company as one of the interesting products of Java. The work was neither understood nor appreciated at that time, and the lack of appreciation discouraged any further importation. Somewhat later the Dutch artists, Chris Lebeau, Eachet and Dysesselhof, appreciating the beauties of this craft, studied it themselves. By their exquisite work they aroused an interest among artists. From Holland the craft spread to France, and to the alert artists of these countries we owe the increased appreciation. The work done in Europe has been applied to interior decorations rather than to costumes. This side has been left to the American designer and artist. The costumes illustrated in this volume are beautiful examples of costume designing in its broadest sense.

Both in Europe and in America considerable experimenting has been done with different kinds of tools. Various European modifications of the tjanting have been tried, but none have been received with much favor. They are, as a rule, heavy and awkward to use in comparison with the Javanese instrument. Some of the leading workers of America and Holland consider the Javanese tjanting the most desirable means of outlining. dotting, etc. 


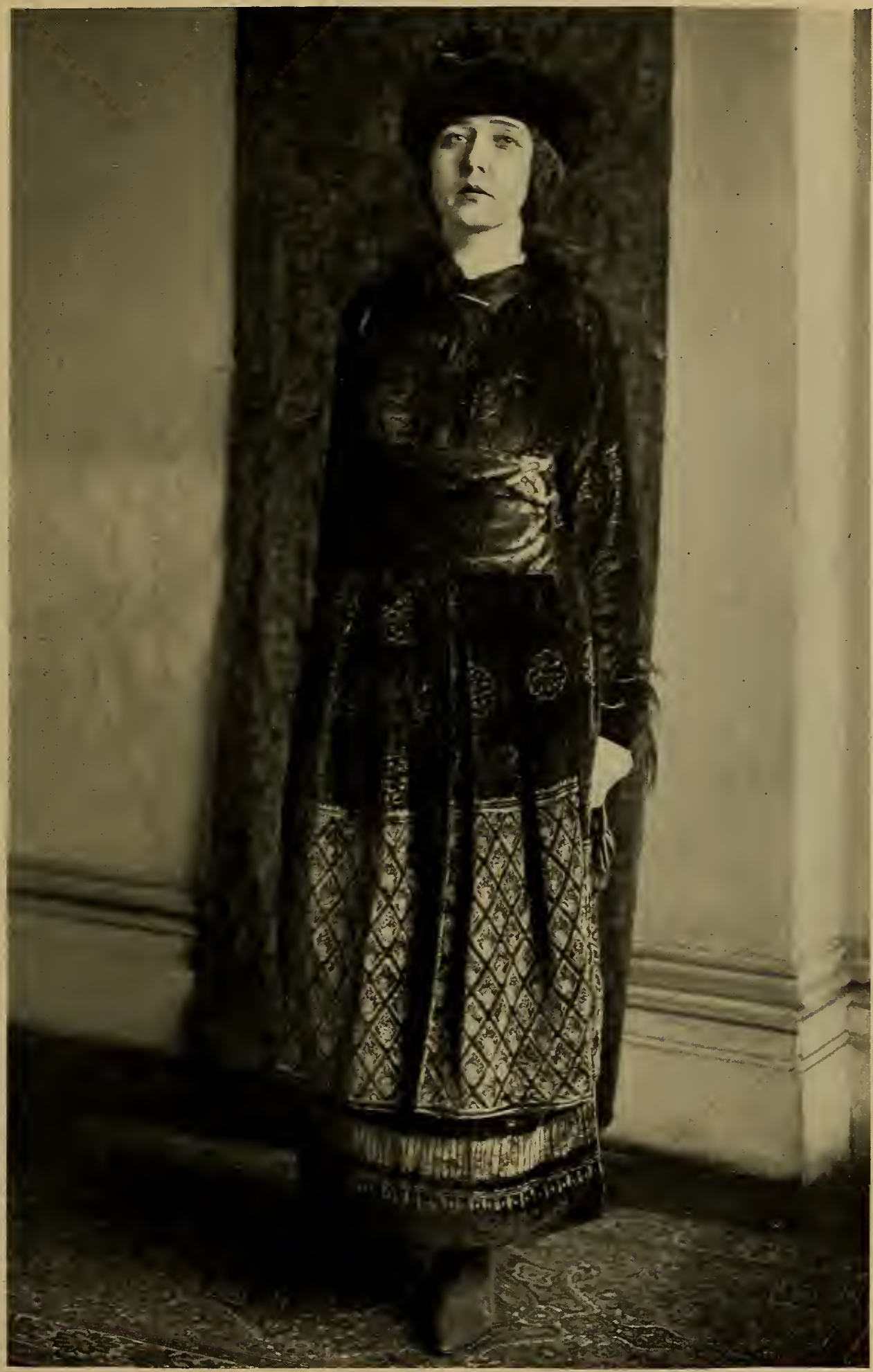


FIRST LESSONS IN BATIK

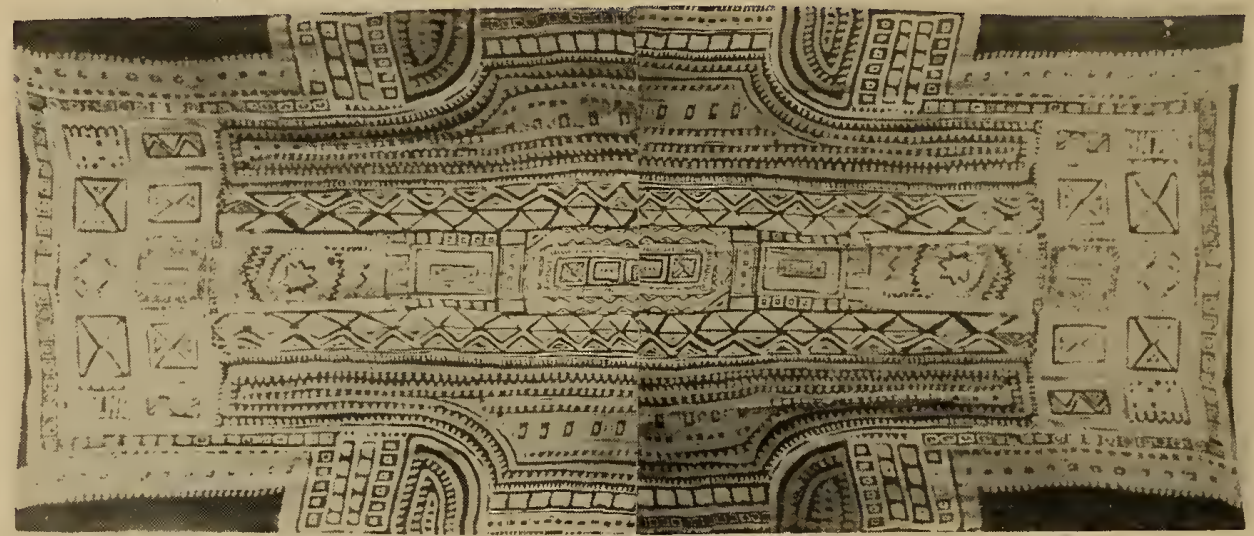

A Batik Silk Scarf, designed and executed by Helen R. Reed, Van Dyck Studios, New York

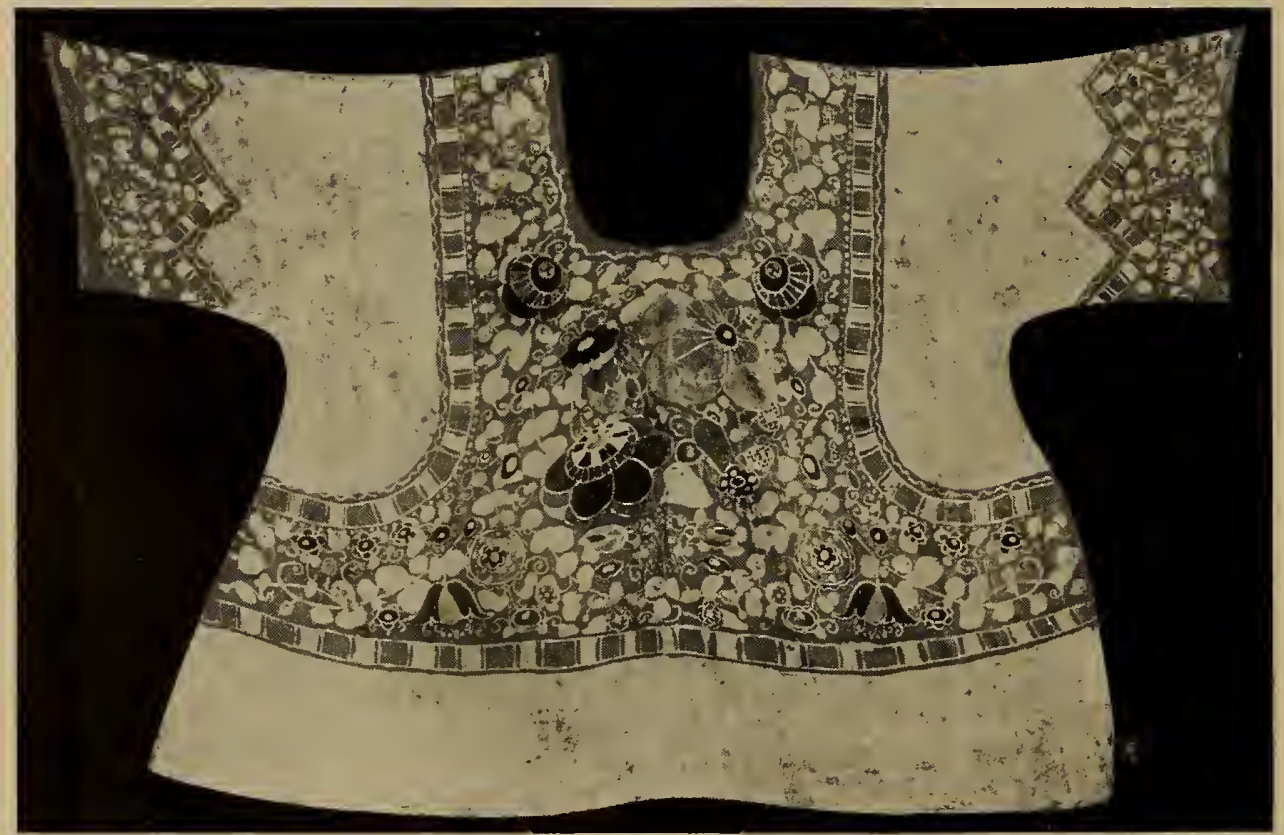

An interesting Batik Blouse, designed by Anna Tyrell, Art Department, Art Institute of Chicago 


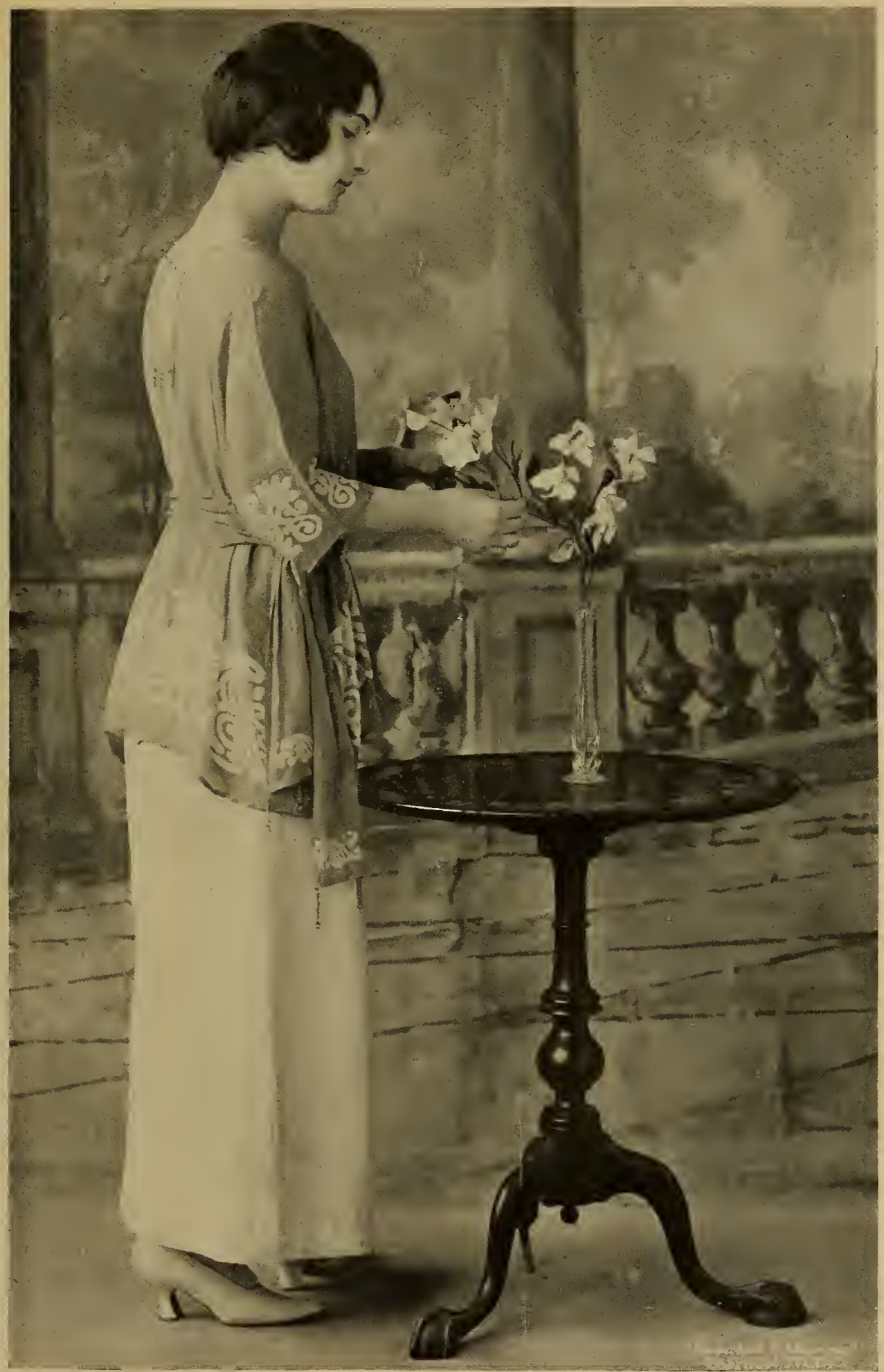

A simple, but beautiful Batik Blouse in two tones, by Noank Studio, New York 

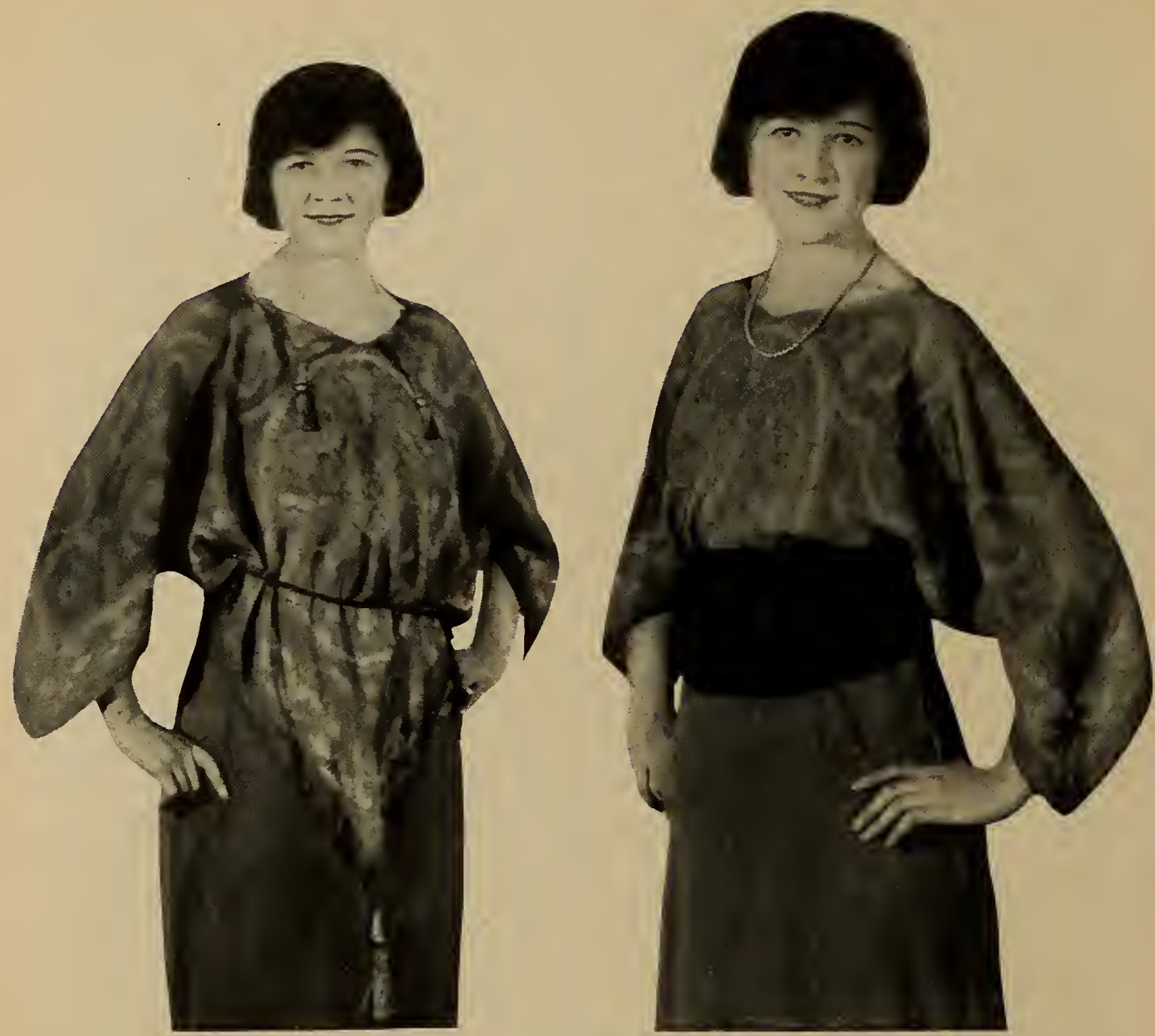

Two Batik Blouses, by Florence E. Schell, Lima, Ohio

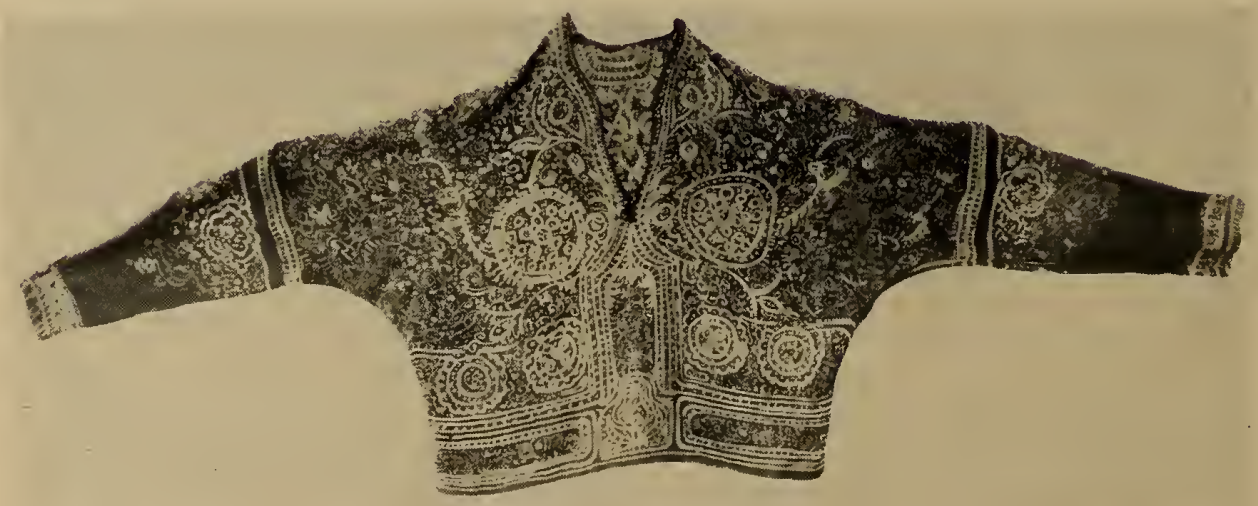

Batik Garment showing interesting treatment of tjanting and brush combined, by Helen R. Reed, Van Dyck Studios, New York 


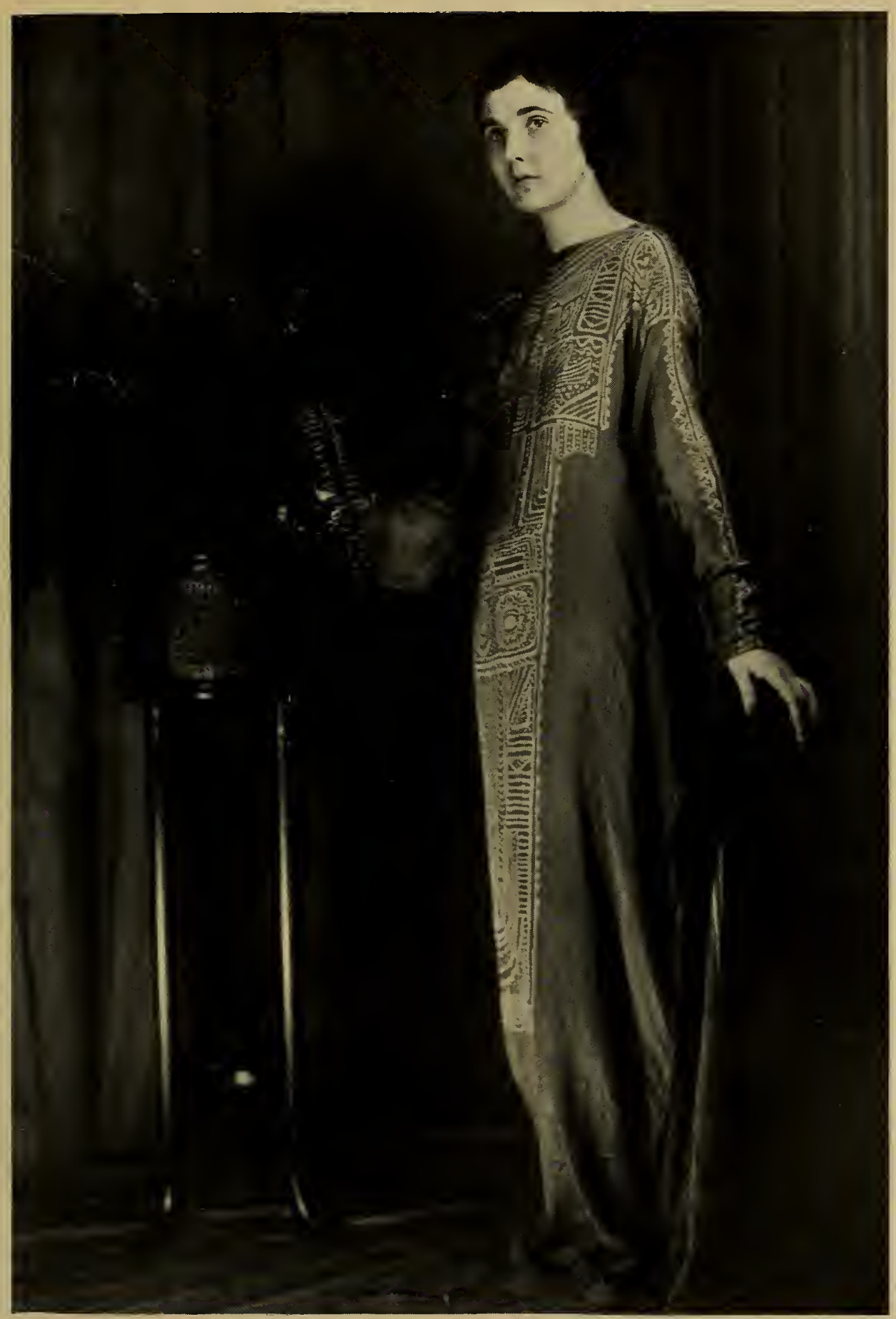

"An American Batik," by Mary Tannahill, shown at the exhibition of American textiles and costumes, held at the American Museum of Natural History

in New York. "The decoration on this graceful gown is in the spirit of South Sea Island Art." 
FIRST LESSONS IN B A TIK

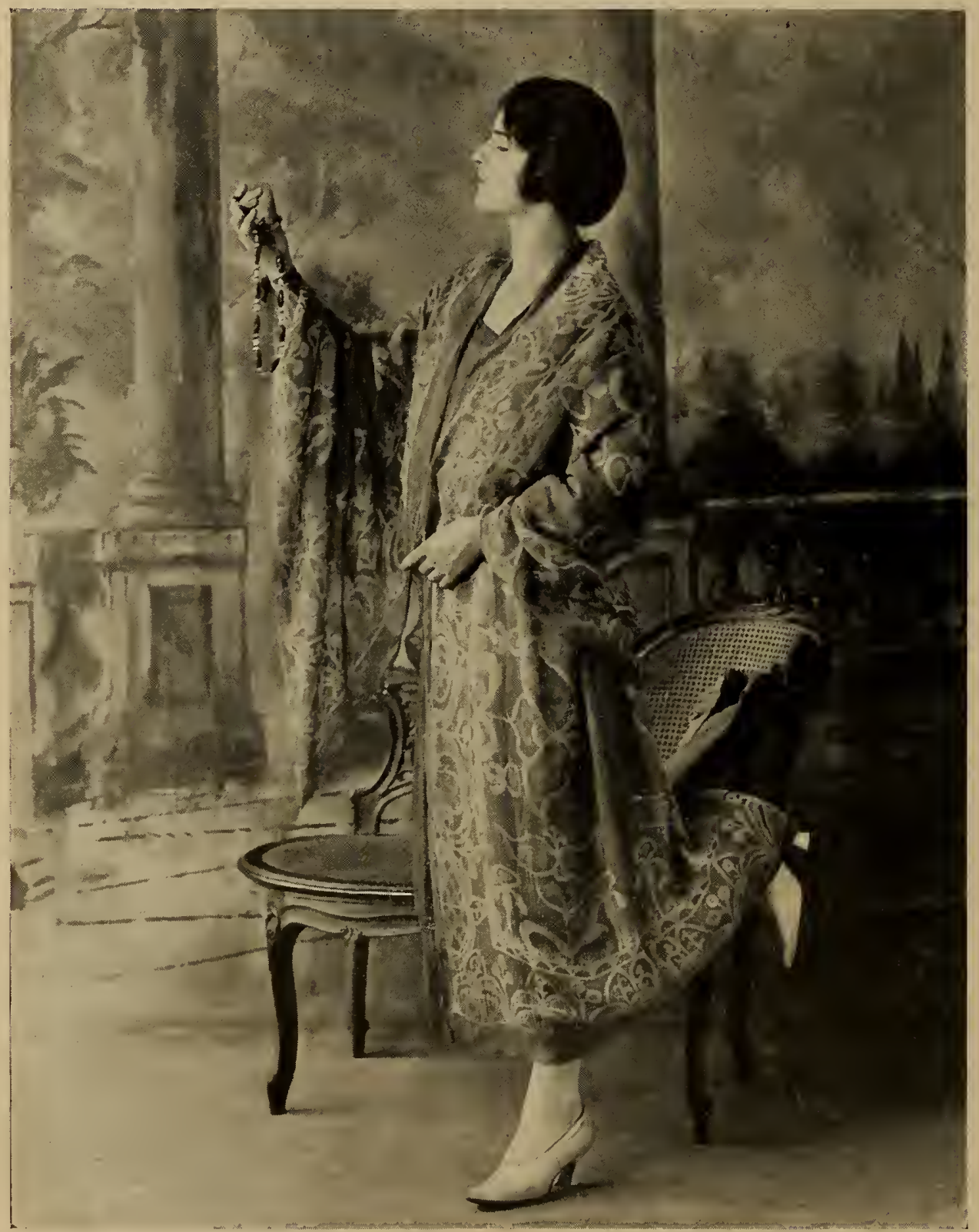

A Batik Robe, by the Noank Studio, New York 


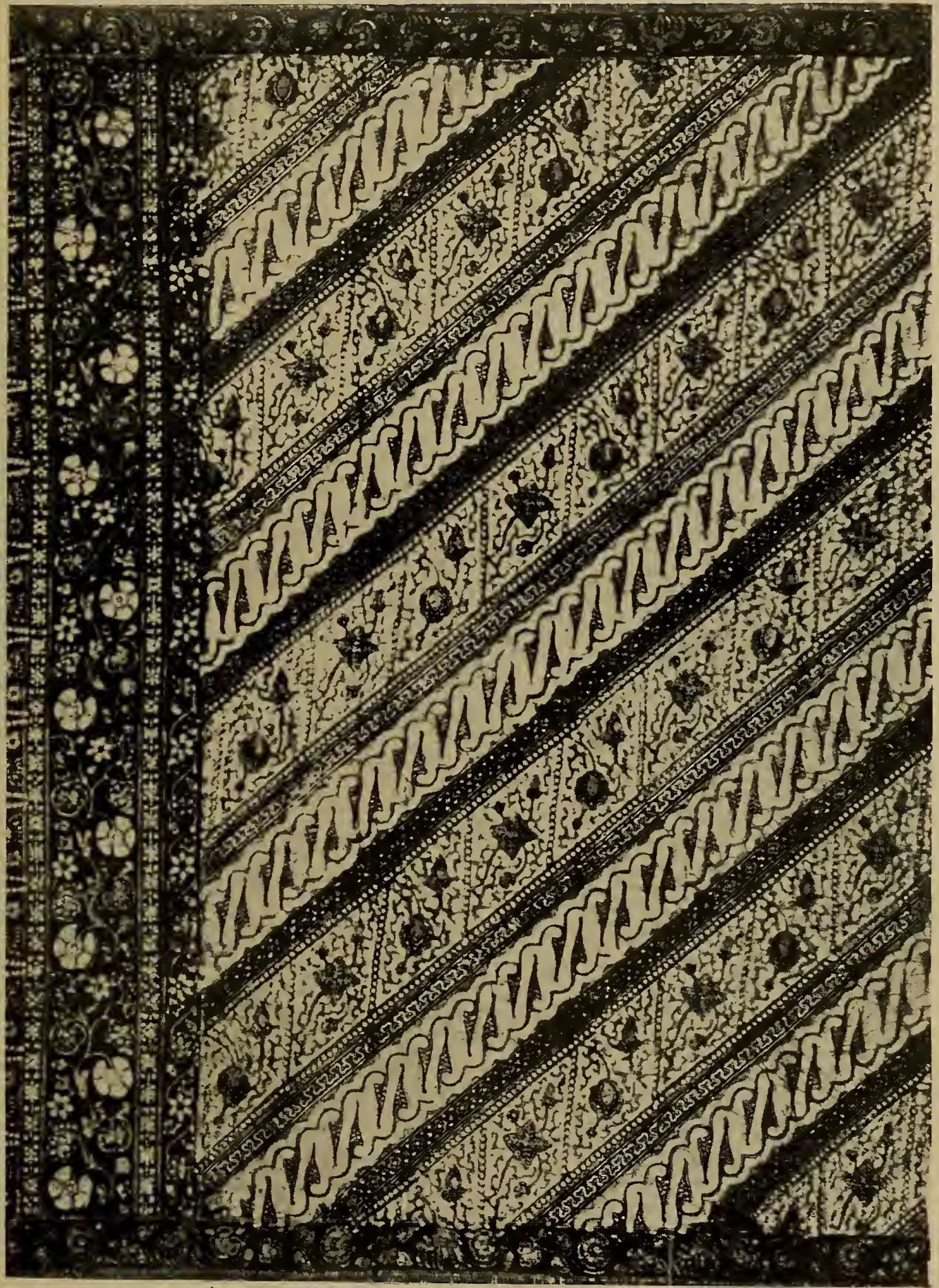

One end of a Javanese Sarong. Property of A. B. Lewis 
The brush is in much more general use than the tjanting and is preferred by many who have experimented with both. A small red sable, No. 4 , is good for outlining. If it seems to carry too much wax or does not point well, let the wax harden and trim off the projecting hairs. A No. 6 to a No. 12 brush will fill in flat surfaces rapidly. With practice, beautiful line work can be done with a small brush. In the beginning, it is safe to wipe off a little of the wax on the side of the cup instead of trying to carry to the cloth all the wax the brush will hold. It is so easy to drop a bit of wax from an overloaded brush and so troublesome to get it off that considerable caution pays. If a brush overloaded with hot wax is set on the cloth, the wax will spread in a drop or blur at the point where the brush touches the cloth, which will make the line irregular. Of course, to have an even flow of wax from the brush, the temperature of the wax must be kept the same. If the worker dips first into wax that is hot and which sinks into the cloth easily and then into wax that is so cool that it stays on top of the cloth and refuses to penetrate the fiber, the finished work will be ragged and uneven about the edges.

While applying the wax the cloth may be held up, free from the table, with the left hand. With small articles this is quite easy. A larger piece can be managed in the same way, but this is not recommended as the very best way. Instead, a wooden frame, adjustable in size at the corners and faced with cloth, to which the material can be either basted or pinned, is advised. With a Batik frame such as described the cloth is held smoothly and firmly in place, making it easy to get good edges and long smooth lines with either a tjanting or brush. If no frame is used great care must be exercised to avoid letting the wax penetrate the cloth and touch anything behind, as it will stick. In lifting it away the wax covering will be torn from the back of the threads. If this is not noticed before dyeing the dye will have a chance to penetrate these fibers and so spoil the clearness of the pattern.

If, in applying, the wax spreads too far over the pattern, it is probably too hot. To remove the overflow, it will probably be necessary to take off a larger space than is exactly needed. This will leave ragged edges, which will need rewaxing. If a drop is spilled in the wrong place while carrying the brush or tjanting, it must be completely removed or the finished product will be marred. This cannot be over-emphasized, as it is usually incompletely done. To remove the wax from a spot or part of a design, lay the spot over an absorbent pad of some kind, such as a soft towel folded. Wet the spot with gasoline, benzine or carbona. Continue wetting and very light rubbing until the wax is completely dissolved and is either absorbed by the cloth with which you have been patting, or the pad below.

Do not pile on more wax in this case, as one may have a lump of wax on top and the cloth still not be protected. Also the lumps often chip off in dyeing, exposing the fiber. Take a knife or any edge and remove the loose wax gently and rewax. Wax that is too cool will not give a smooth edge to the design. It is easy to tell by looking at the back of the cloth 


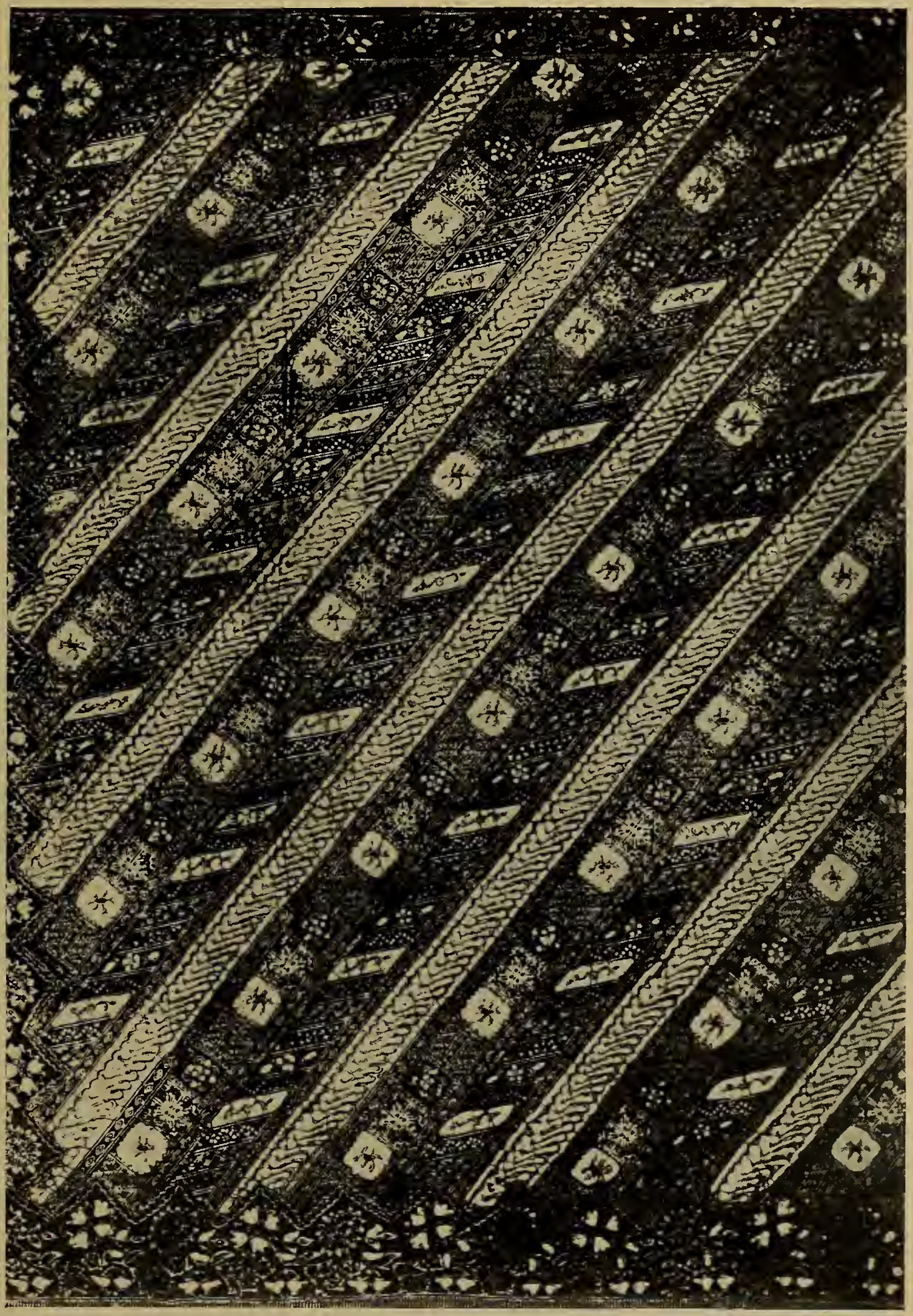

Design of a Javanese Sarong.

Property of Fay Cooper Cole 
whether the wax has penetrated. A thin silk will allow it to penetrate so easily that the design will be just as clear and distinct on the back as the front. Heavy cloth will need some retouching on the back, probably where brush strokes do not quite meet. Sometimes a drop of wax will seem to penetrate in the middle but will be loose at the edges. This means that the wax is too cool. A little practice will make the right temperature easy to estimate.

Some workers lay the cloth on a glass slab to which the wax will not stick. This cools it before it really penetrates the cloth. Sometimes it is desirable to follow the outline of the pattern with wax before filling in the solid parts. To do this, hold the brush vertically as in drawing any painted brush line. A No. 1 brush is good for very fine lines. In covering a large space, it is sometimes better to begin waxing in the center and work outward toward the edge.

Some means of keeping the wax hot must be provided. It is quite desirable also to be able to regulate the heat, so gas or alcohol, with suitable burners, are really best. A bowl of wax may be set in the top of a tea kettle of boiling water and will hold a good temperature for half an hour without reheating the water. Wax will smoke over a direct heat and will, of course, burn. The bristles of a brush will also burn if left in con-

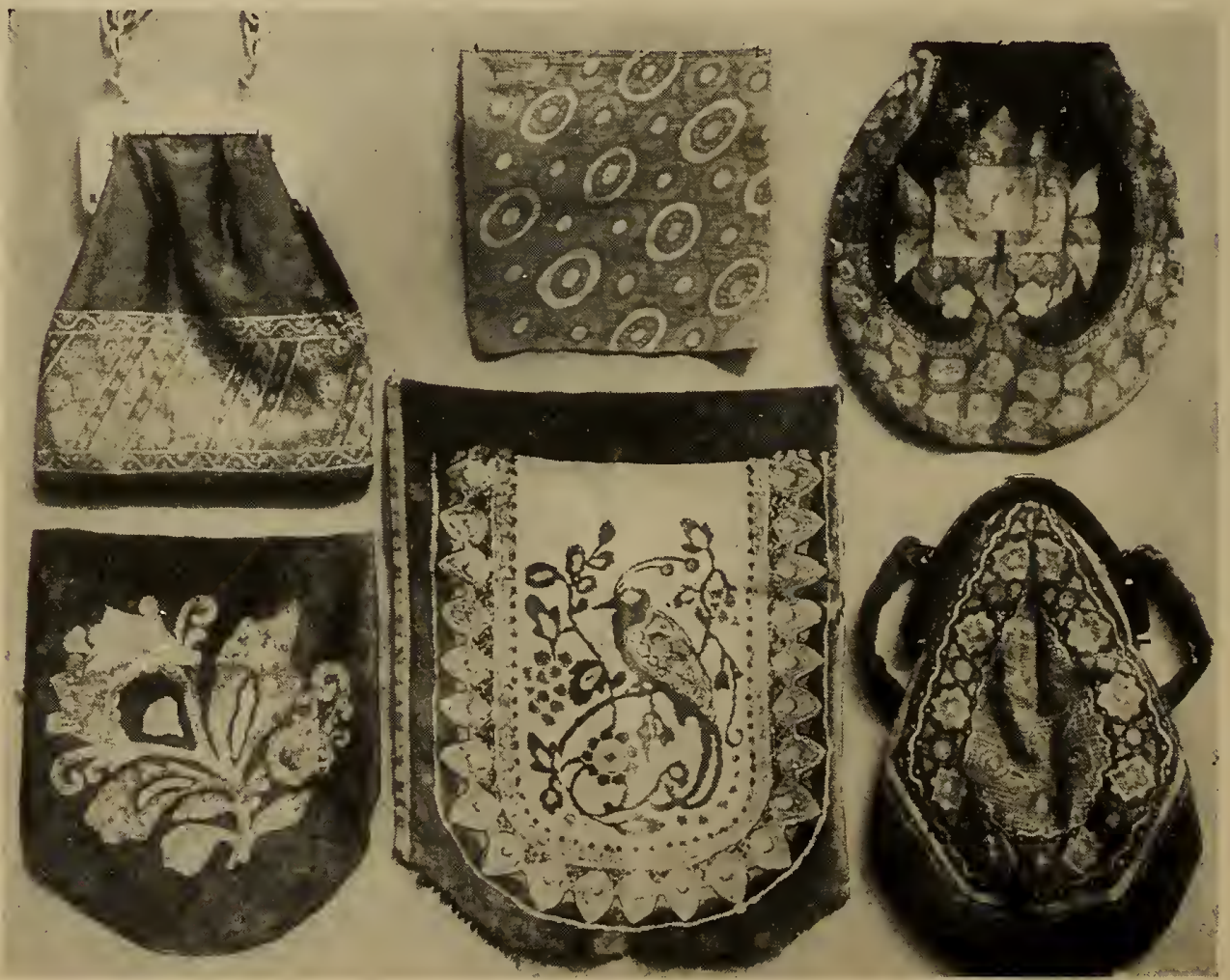

Examples of Batik, done by the students of the Design Department, Art Institute of Chicago 


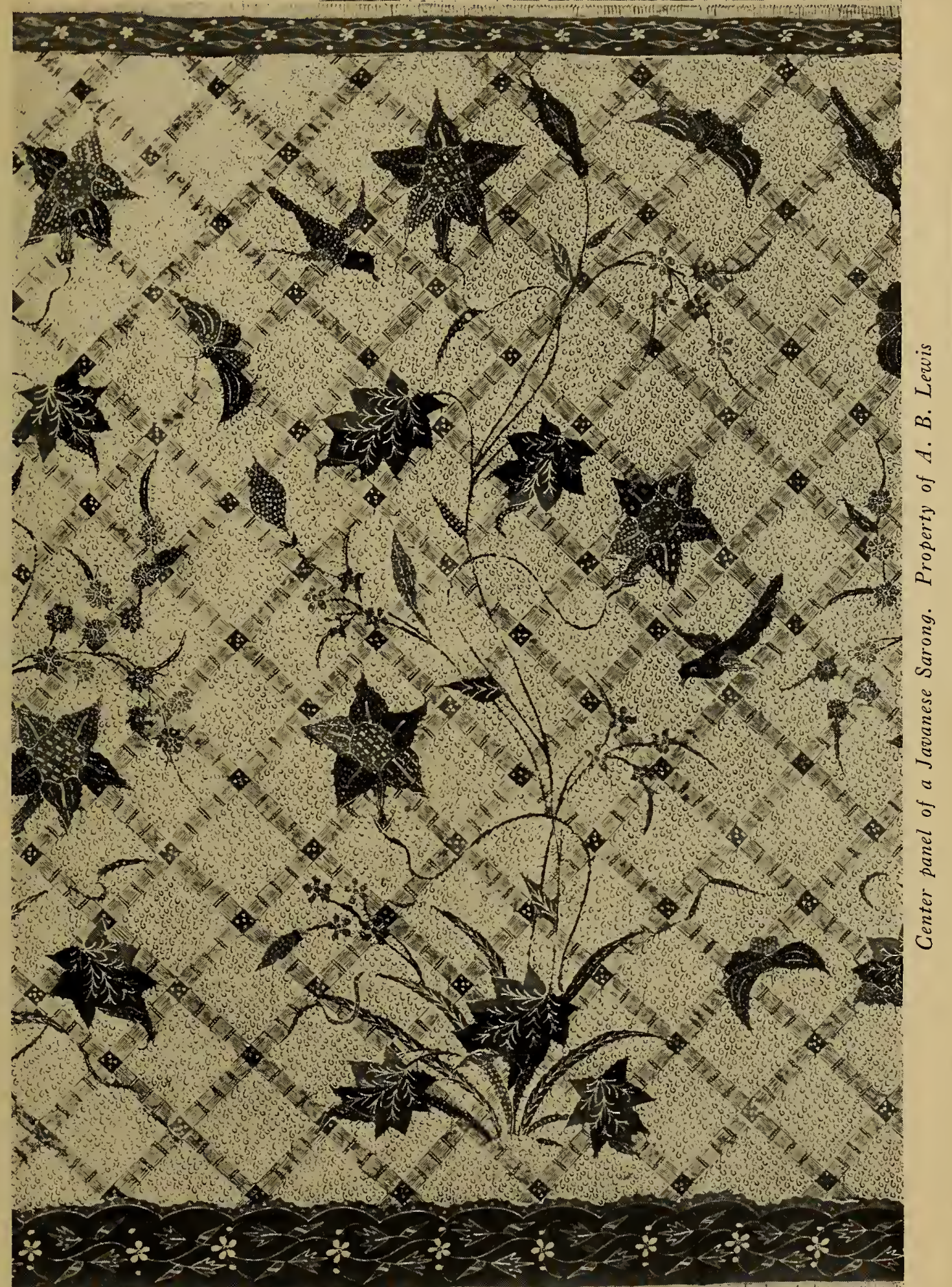


tact with the bottom of the pan over a direct fire. All bother of this kind is overcome by having the wax in a bowl set in a pan of hot water. Once some small girls who were starting this work allowed the water to splash into the inner bowl. This was afterwards set over the direct flame. There was a grand explosion and spattering of hot wax.

Various wax mixtures have been used successfully. A suitable wax must not scale off, must not get so hard as to crack too freely, and must not be affected by whatever chemicals are found in the dyes or are used as mordants. A beeswax and resin mixture, wax with mastic, paraffin with lard, paraffin and beeswax in varying proportions have all been used successfully. Paraffin alone is rather brittle and produces too much "crackle" in cold weather. Beeswax alone is rather too soft to use in warm weather and not brittle enough if any crackle is desired. Therefore, mixtures of these various substances suggested give a wax that will crackle somewhat but not too much. For the beginner it is safe to buy one of the prepared mixtures on the market and experiment later with the various possible combinations suggested, after becoming thoroughly familiar with the result wanted.

The design must, in some way, be got on the cloth. This is a place where careless work may spoil a beautiful design. The lines on the cloth must be so carefully and clearly made that the brush can follow them without the slightest hesitation. All corrections should be made before the tracing is considered finished and the waxing started. If a mistake is made with the pencil lines, "Carbona" or gasoline will remove the wrong marks. A Conte pencil, No. 2, trimmed to a sharp point, is very satisfactory, especially if the piece is to be dyed several times, as the marks will not brush off as charcoal or chalk lines will. For a simple one-process piece, charcoal sharpened carefully will serve satisfactorily.

If the material to be used is thin, which is desirable for first pieces, the cloth can be pinned carefully on top of the drawing and traced as just explained. If the cloth is too heavy for the lines of the drawing to be seen clearly, the back of the design can be rubbed with charcoal, the design laid carefully in place, charcoal side down. Then with a sharp hard pencil the lines of the drawing may be traced on the right side. When the paper is removed, the design will be on the cloth in charcoal lines. If it is to be dyed in several colors later it will be better to go over the pattern now with the Conte No. 2 very carefully, as the charcoal dusts off easily. Use the pencil lightly but clearly with even lines. The cloth must be pinned or thumb-tacked so firmly that it does not slide over the design. It is a little harder to fasten exceedingly thin material like georgette or voile firmly enough to get a good tracing, so about the weight of medium china silk or thin crepe is the easiest material to begin with.

If a design is to be repeated several times, as would be needed for the border of a curtain, the charcoal rubbing may be the most convenient. The design can be pricked with a pin and powdered charcoal dusted on the smooth upper side of the pattern. The danger in this is that too small 


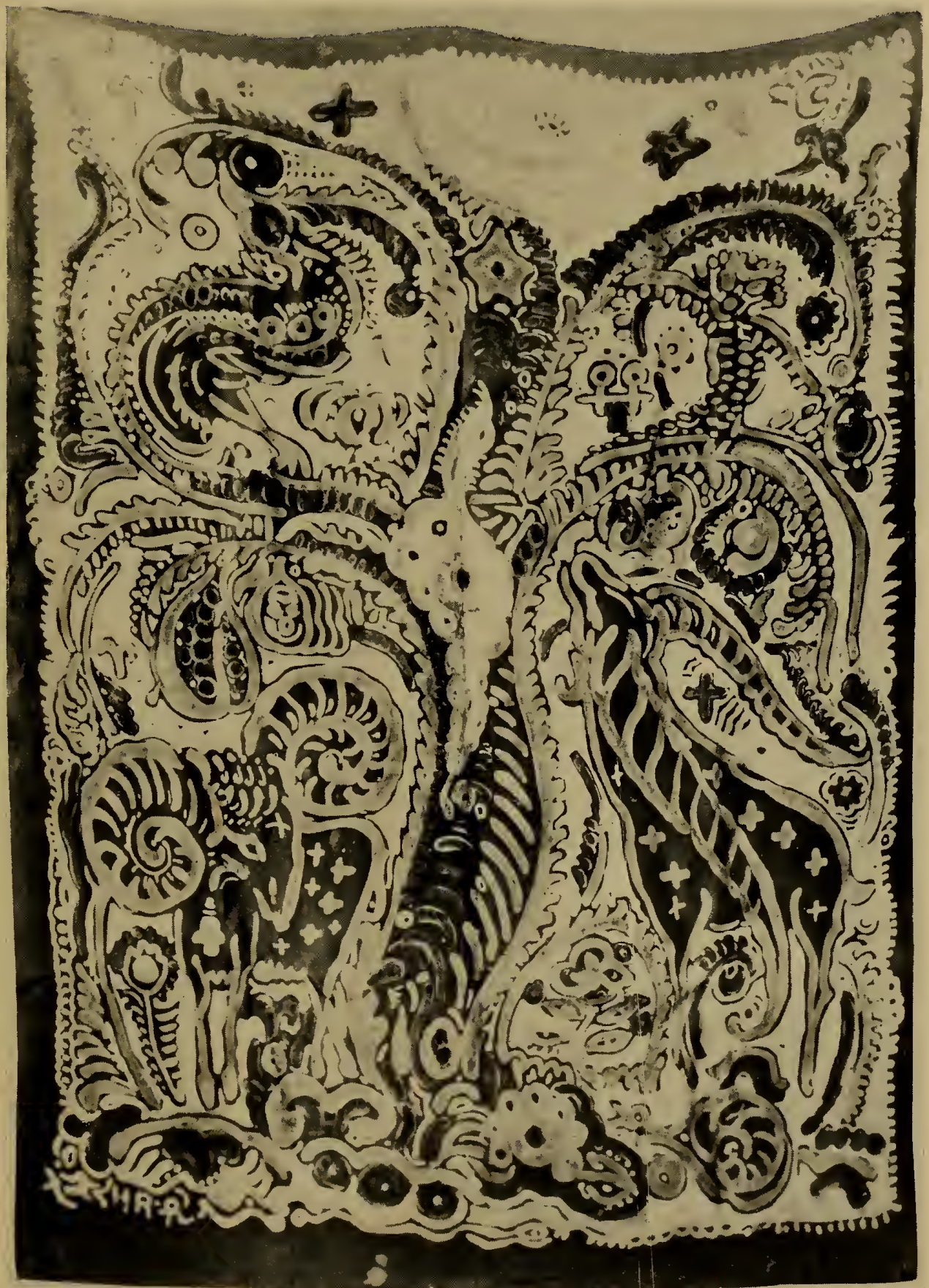

"The Sheep and the Goats." A modern Batik Wall Hanging,by Helen R. Reed, the Van Dyck Studios, New York 
a number of points will be pricked to give the design clearly. A better means of doing this is to follow the pattern with a sewing machine after removing the thread and presser foot so that the paper can be turned freely.

Some Batik workers make their design on thin paper which is pinned to the back of the cloth and the latter placed on a frame set against a window at about an angle of 45 degrees. This is somewhat on the principle of the photographers' retouching frame.

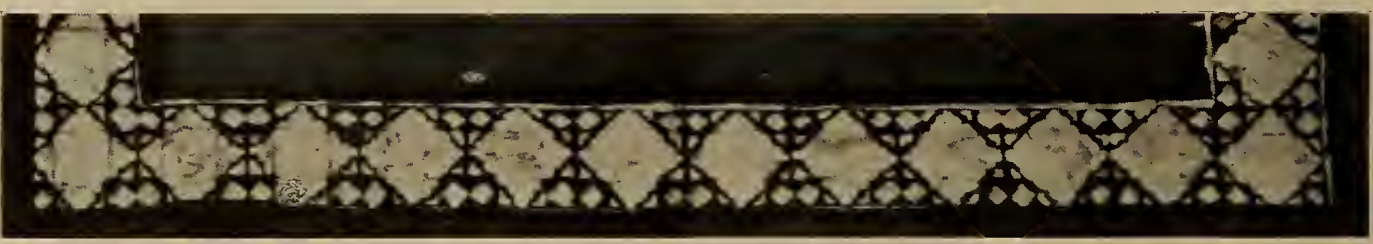

The end of a Table Cover done in one color Batik, the white design being done in wax, and the entire piece then dipped

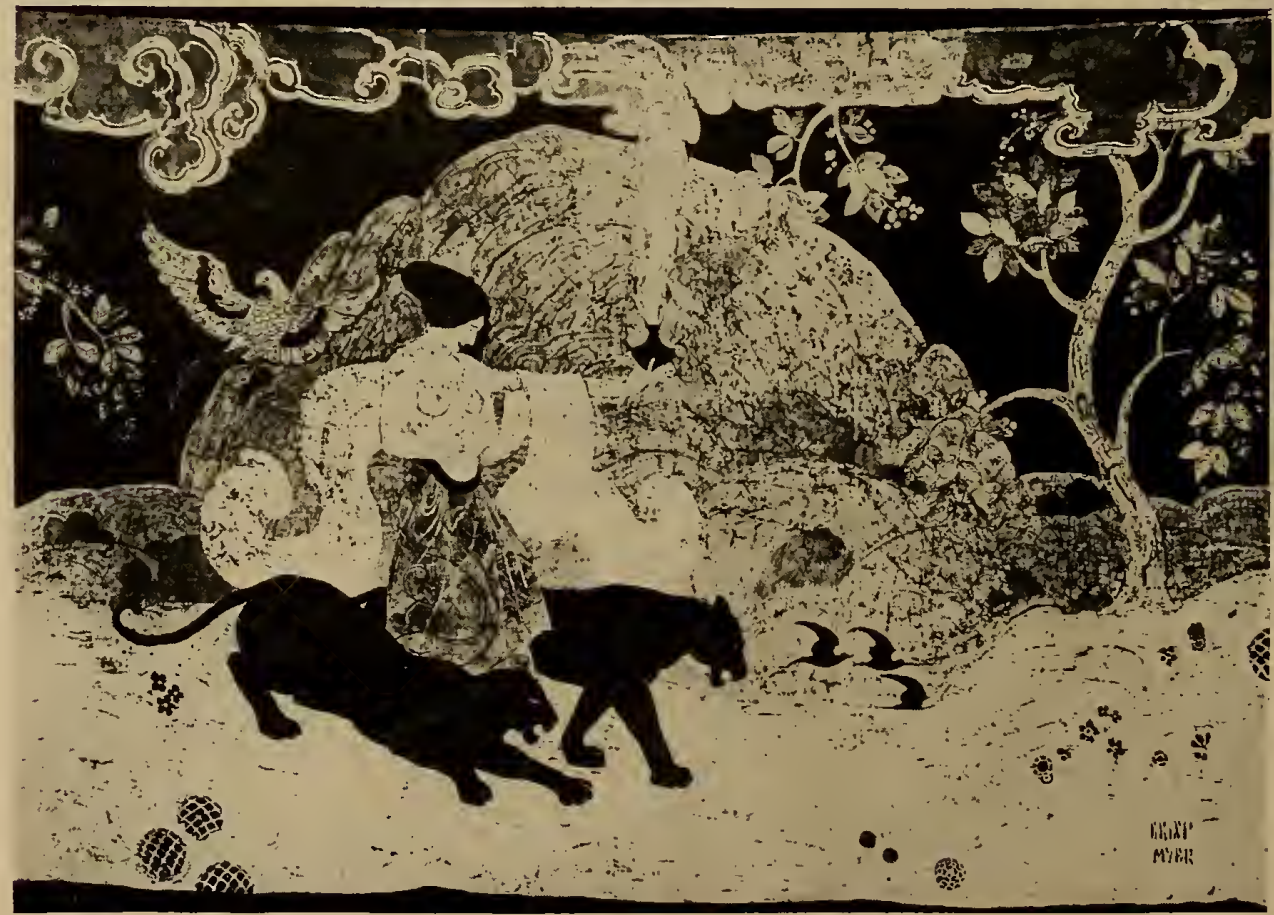

"The Sorceress." A Batik Wall Hanging, by Arthur Crisp and Peter Mijer 


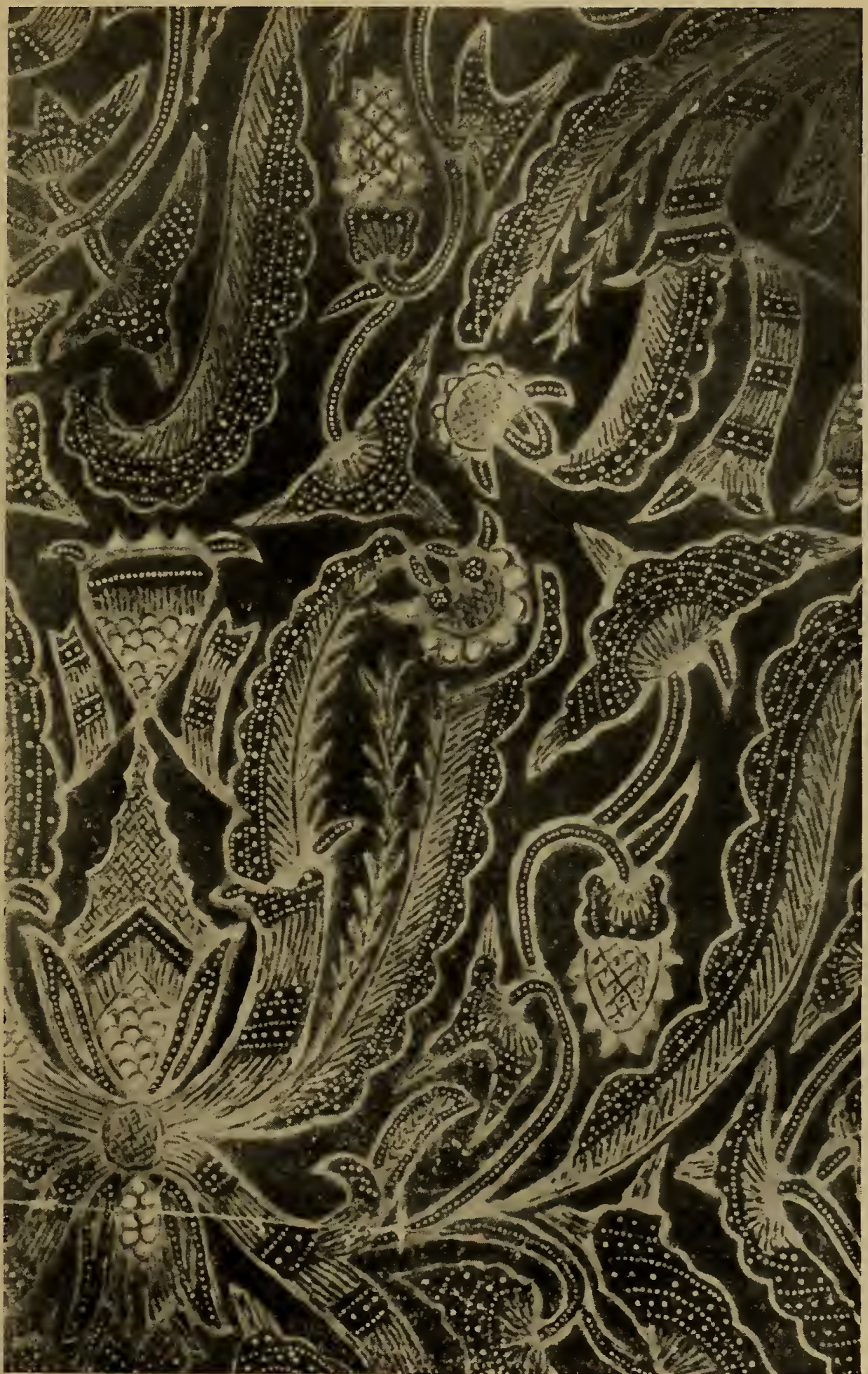

Detail of a rare Javanese Batik in the American Museum of Natural History, New York 


\section{CHAPTER IV}

\section{PROCESSES OF BATIK DYEING}

$\mathrm{T}$ HE intricacy of the design is the determining factor in the number of processes necessary for any given piece of Batik. The more colors desired, the more often will the fabric have to be immersed in the dye bath. The simplest and therefore first process for the beginner is that of dyeing the material one color with the pattern left in the original color of the cloth. For convenience, this will be referred to as the first or elementary process.

The blouse shown on page 23 was made on silk. The design was drawn out carefully on paper and then traced on the silk. The design was then waxed and dyed in a basin containing about two quarts of water, onehalf teaspoon of $36 \%$ acetic acid and a teaspoon of imperial blue dye solution. It was kept gently moving in the dye for fifteen minutes, rinsed thoroughly, dried and pressed between clean old newspapers or blotting paper and ironed dry. The ironing melts the wax out. If traces of the wax or pencil marks still adhere, the goods can be washed in gasoline or benzine. When the wax was removed, the result was a piece of two-tone Batik work of deep blue with a white design. For most Batik work, light colored fabrics are used, as designs can be successfully darkened, but cannot be made lighter on dark goods. But, on the whole, a delicate color is better as a foundation than white, because the white will often be a little out of harmony with the colors.

The designs for the two charming sashes on page 37 illustrate additional steps in more elaborate designs. The right-hand scarf was dyed first so that the ground was not white. For such a sash one-half teaspoon of dye solution in four quarts of water, with one teaspoon of $36 \%$ acetic acid, would be used for the background, with perhaps a ten-minute immersion. After it was dyed it should be rinsed thoroughly in cool water to remove all excess acid and any loose color. Rinse until the water is practically clear. Hang it up so that it will dry smoothly. When dry, wax the flowers, the connecting lines, and the broad light bands. Prepare the second dye. An agreeable color scheme is pink for the lightest, made by using scarlet dye in a weak solution, a deeper pink for the second color, and lavender for the last. If the color scheme suggested were to be used, the same dye would be used for the deeper pink and the material immersed a second time with the addition of another teaspoon of the scarlet dye solution to the basin. After the second dyeing, all the superfluous color was rinsed out, it was dried, and the parts to remain the deep pink were waxed. That left the heavy bands alone exposed to this last dye bath. For this a green solution was used which on the pink gives a beautiful grey lavender.

A color scheme of, first, orange dye; second, brown dye, and third, navy blue dye, is attractive. Some silks will ravel so as to make a good fringe; in that case a pattern for the fringe would be dyed in before raveling. With a purchased fringe the tied and dyed method will give charming bands. 


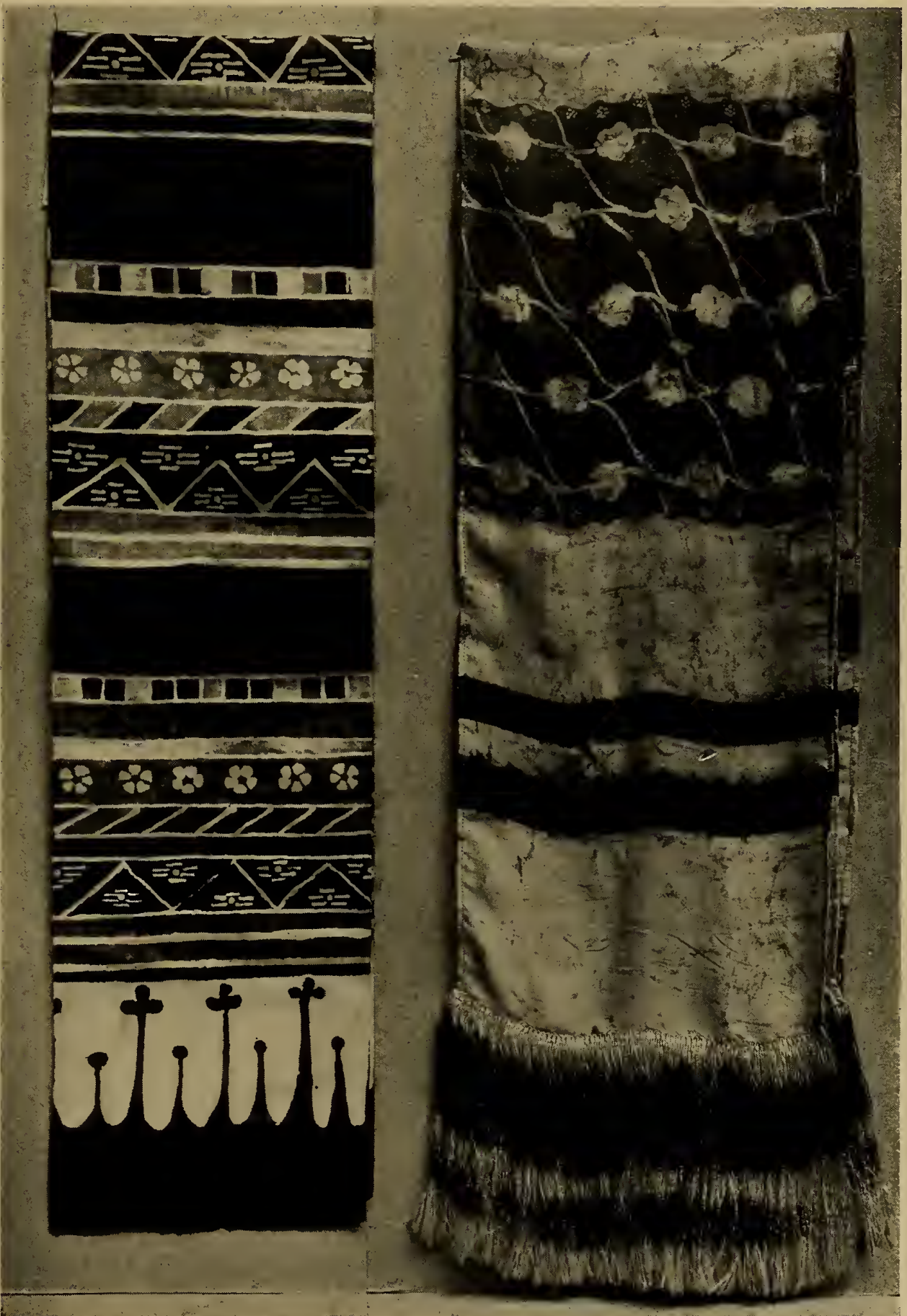

Two sashes done in Batik by the students of the Art Institute of Chicago 
The interesting sash shown on the left of the previous page is also a three-process piece in which greater contrast has been kept between the colors.

Such a place as the wing and crown of the bird figured on the velvet bag shown on page 30 could well be painted in with a brush. A blending of the colors found in some of the tropical birds-yellow, orange and blue, for instance-would be gorgeous.

The process of cleaning and finishing velvet is long and requires skill to do it successfully. The craft worker is advised to send a piece of velvet Batik to a professional if possible, rather than risk spoiling it herself.

An abbreviated outline of the process is as follows: First, remove all waxing with benzine, using several baths; second, raise the nap with dry steam, that is, steam carrying as little water as possible. Avoid touching the nap while steaming and do not crease or fold while damp. After the nap is raised by the steam, brush it gently in the direction of the nap with a bristle clothes brush.

For more elaborate work, where a combination of colors is desired in the design, the painting process may be used. As in the previous cases, the material is stretched on the Batik frame and the design outlined and then waxed in. If a combination of colors is to be used, it is best to have the design in colors on paper as a guide. It is very easy to become confused as to colors to be used on the various sections of the pattern, and mistakes in painting with dyes are serious, as the color can only be removed with a solution of ammonia or washing soda.

With the colored design before one, the dyes are mixed and tried on a scrap of the material.

This method of applying color with a brush is desirable only for small spots or surfaces. It is not possible to cover large surfaces evenly with a brush, as the color will be stronger in the spot first touched by the brush. In dyeing one color over another the result is a modified color which seldom harmonizes with spots of color that are painted in. In addition, the color is not as fast when applied in this way, as it does not have the chance to penetrate the fiber of the cloth as in dyeing.

This use of the brush is a convenient method of inserting small spots of a contrasting color that would otherwise require a re-waxing of the whole piece of goods, but is not recommended as a substitute for dipping process. 


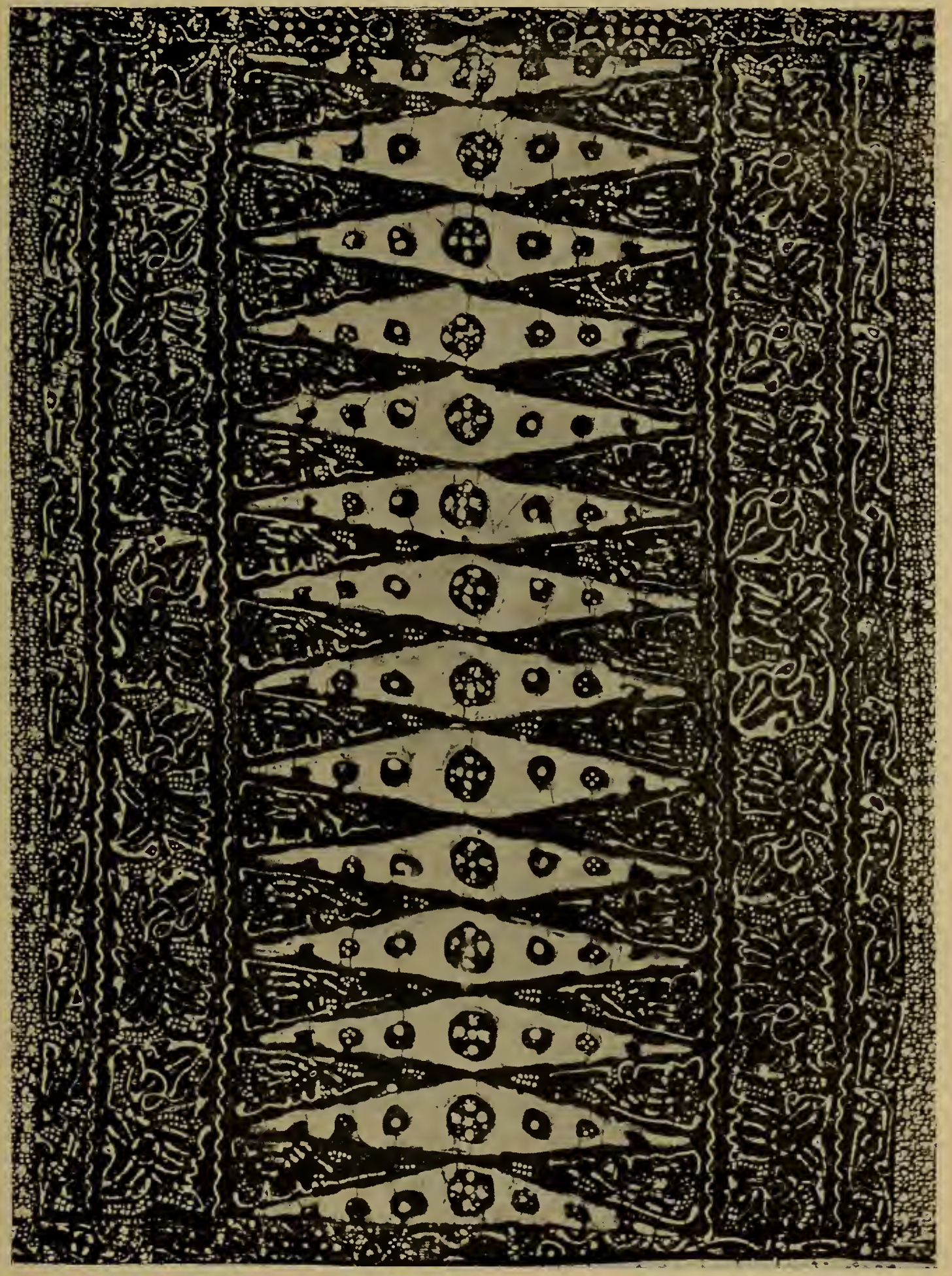

The center panel of a Javanese Batik 


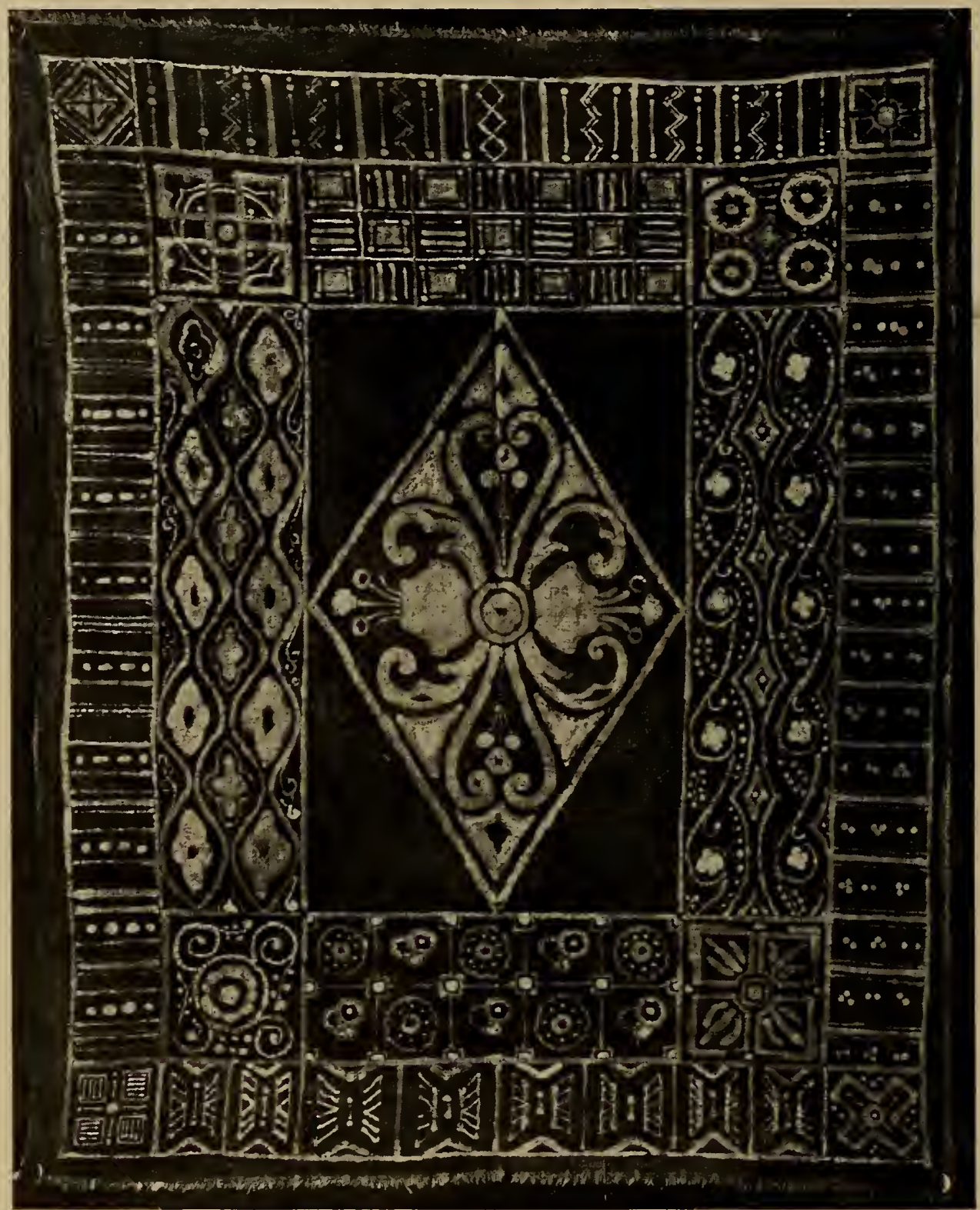

A Table Runner, by Gertrude Dandiliken, Design Department, Art Institute of Chicago 


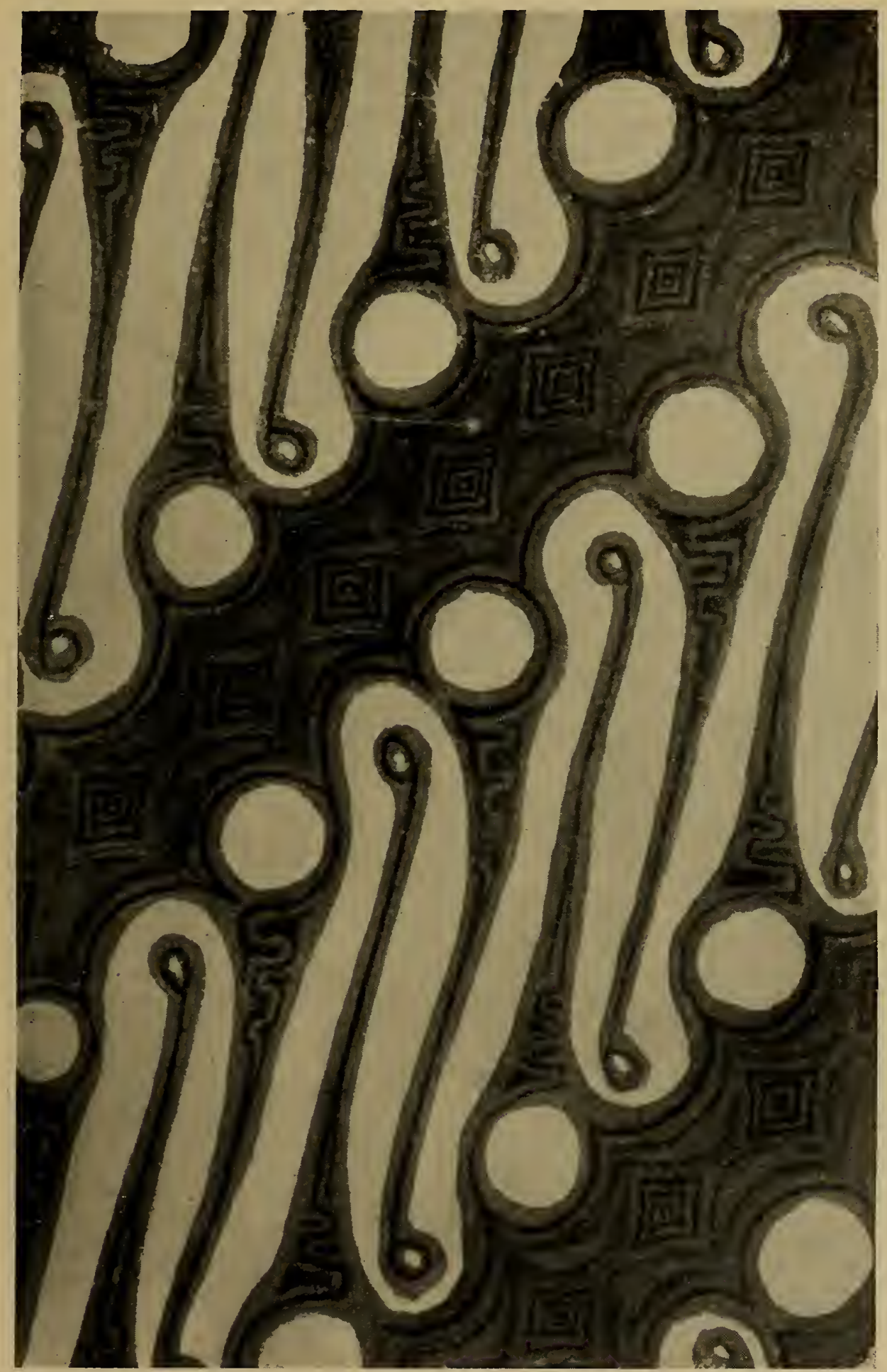

A design motif from a Javanese Sarong. Courtesy of American Museum of Natural History', New' York 
FIRST LESSONS IN BA T IK

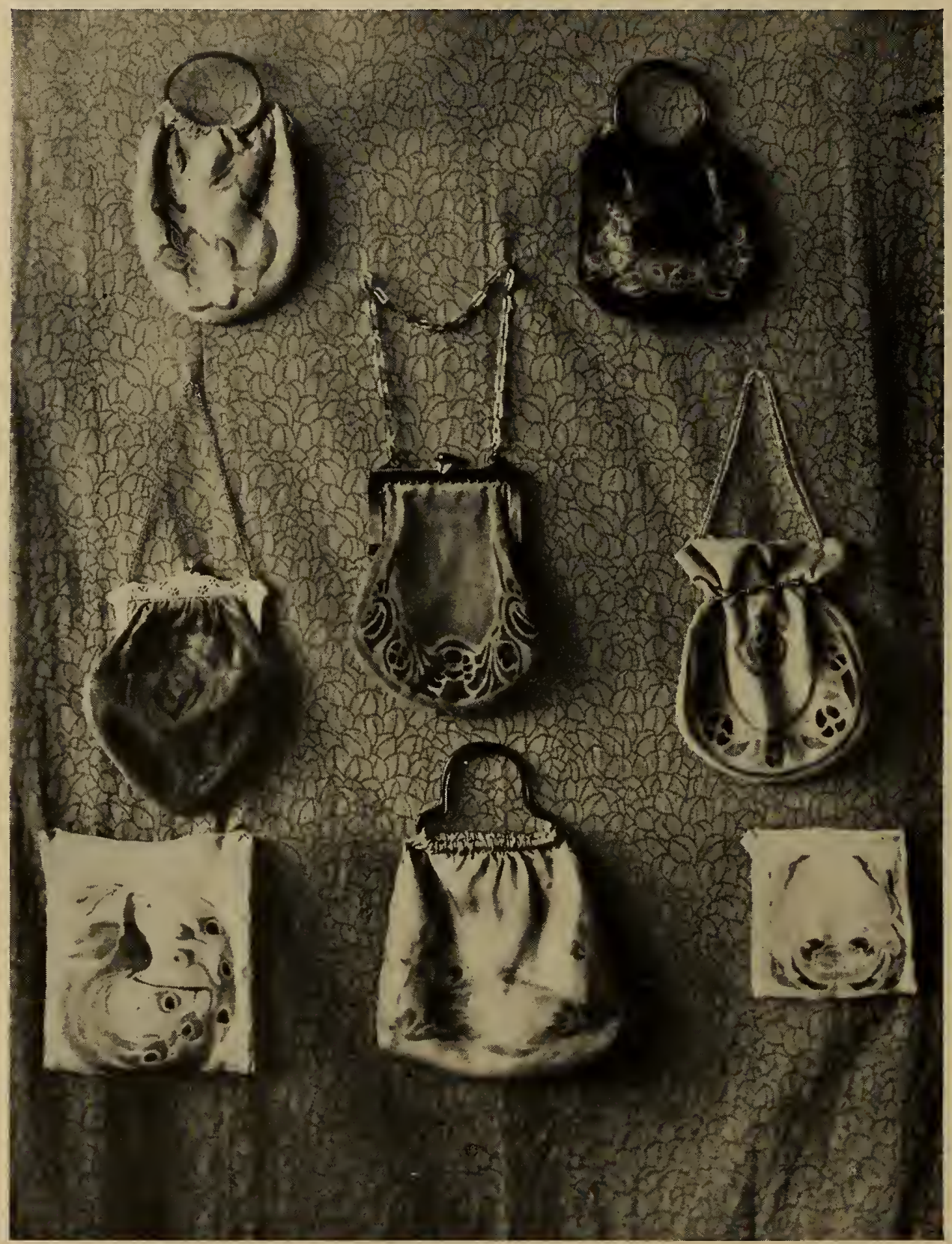

A group of Batik articles, done by the students in the Winnetka, Ill., High School 


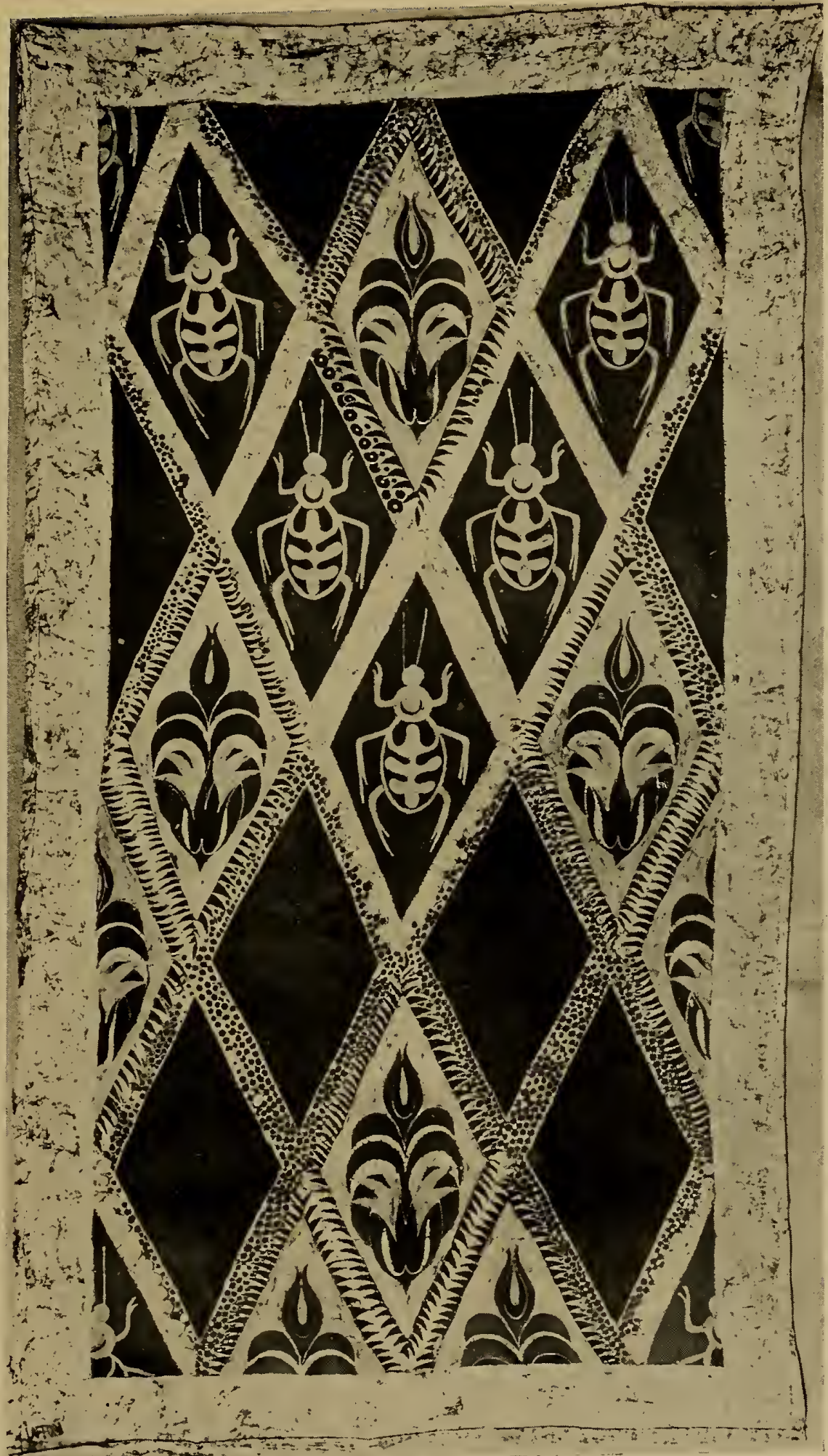




\section{CHAPTER V}

\section{CRACKLE IN BATIK}

$\triangle \mathrm{S}$ the worker in Batik dyes his material, he finds that the wax on the cloth will crack as it is handled. The dye will then penetrate these cracks in fine lines. The Javanese worker considers these lines undesirable and handles his goods with the greatest care to avoid producing them. He cannot, however, avoid them entirely even with the greatest care. He desires clear even edges no matter how fine and complicated the pattern. By looking closely at the very finest specimens, these fine cracks will always be found meandering through the pattern. To the European this is part of the charm of Batik.

As the craft workers of this country began experimenting with Batik work, they discovered the moss-like pattern produced by this crackling of the wax. This gave a quick easy method of making an all-over pattern and was immediately seized upon. At the present time, it is used to produce quick pattern effects, or to soften the effect, by putting a fine "crackle" of some harmonizing color over the whole pattern.

For instance, flowers have been left white, the background blue, and leaves green. The flowers seem too white and stand out too strongly. Crush the wax over the flower to produce fine lines of crackle in the wax and dye in the blue of the background again. This brings the white into harmony with the colors. Like many other processes it can be overdone very easily.

To make a crackle piece, stretch the material on a frame tightly. Take a broad bristle brush, No. 3 or 4 , and cover all the surface to be crackled evenly with wax. Hang the cloth on a waxed line to harden and also to allow any superfluous wax to drip off. After the wax has stiffened, the next step depends upon the weather. When it is so warm that the wax will not become brittle in the air, it may be put in the refrigerator, or it may be laid in cold water to chill. In some way the wax must be cooled until it will crack when crushed in the hands. If a fine all over pattern of crackle is wanted, crumple in the hands in such a way as to crack the wax thoroughly in every direction in fine lines. If a heavy crackle is wanted, wax and chill as before, then twist or wring the material in such a way as to give deeper, heavier cracks. A little practice will make these suggestions clear. It will sometimes be desirable to crackle certain parts or spots in a design in both of these ways. After crackling the wax, dye as in any Batik piece. Stir constantly to dye evenly in every small crack. Rinse very thoroughly to remove all extra dye from the cracks.

This process may be repeated with another color, so that the two sets of crackle lines intermingle. This adapts itself well to borders of any kind, blouses, table scarfs, and if patience allows, to all-over patterns for bags, pillow tops, etc.

The play of color that can be secured with these crackle patterns is charming, and has been used extensively as a part of the design. 


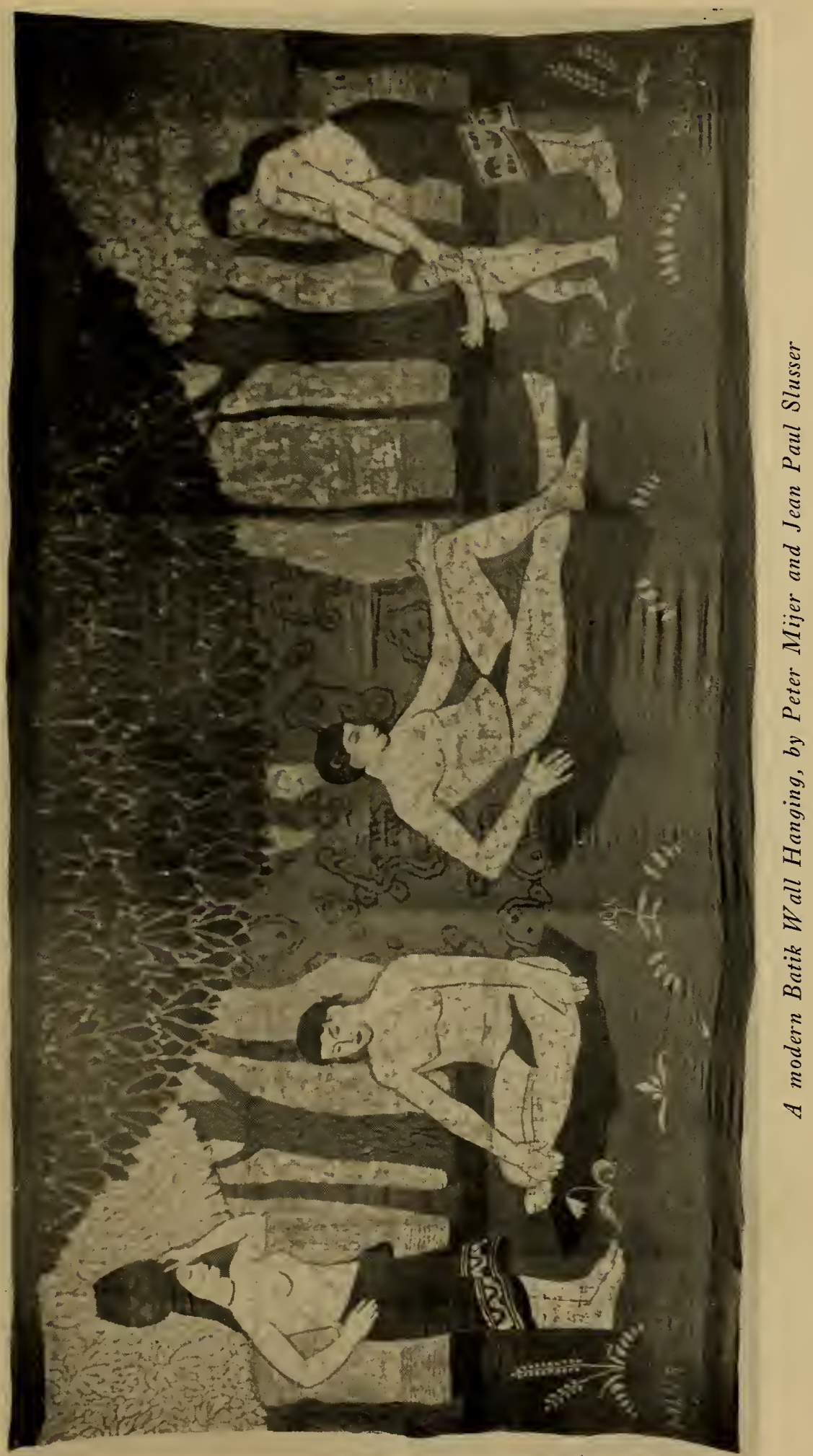


In the decorative panel by Jean P. Slusser on page 45 the figures have been treated with a rather light crackle and the background between the tree trunks with a much heavier crackle. In the memorial panel on page 48 the semi-circular framing band and the ground below the figure have been crackled carefully. Both of these uses of crackle suggested are suggestive of desirable possibilities of the crackle forms. A similar use of crackle to add variety to special plain surfaces is illustrated in the framing panel of the drapery on page 43.

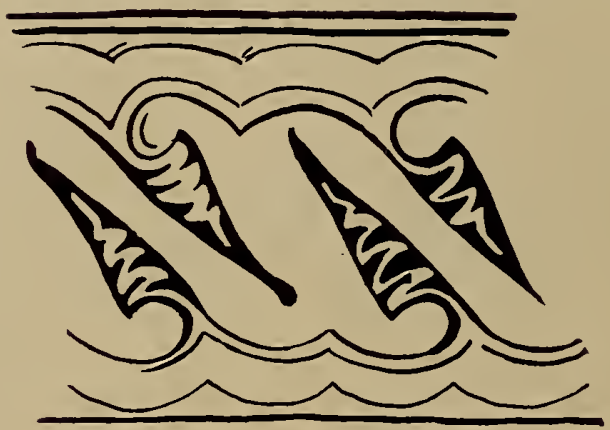




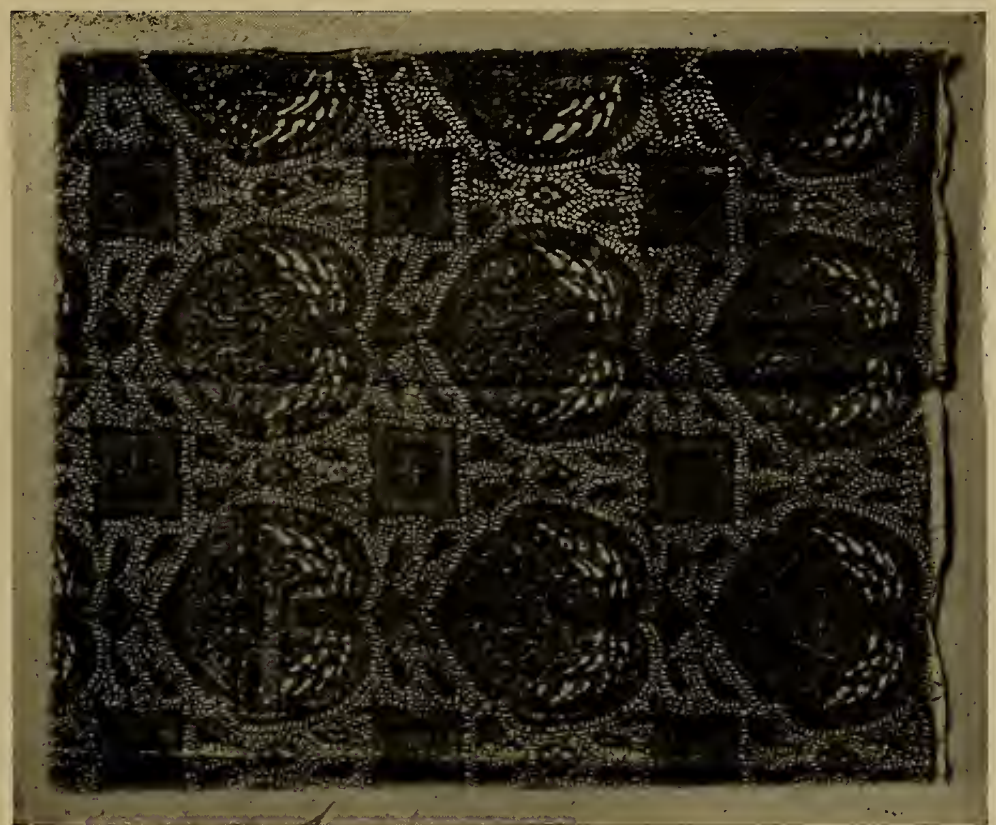

Courtesy of the Metropolitan Museum, New York.

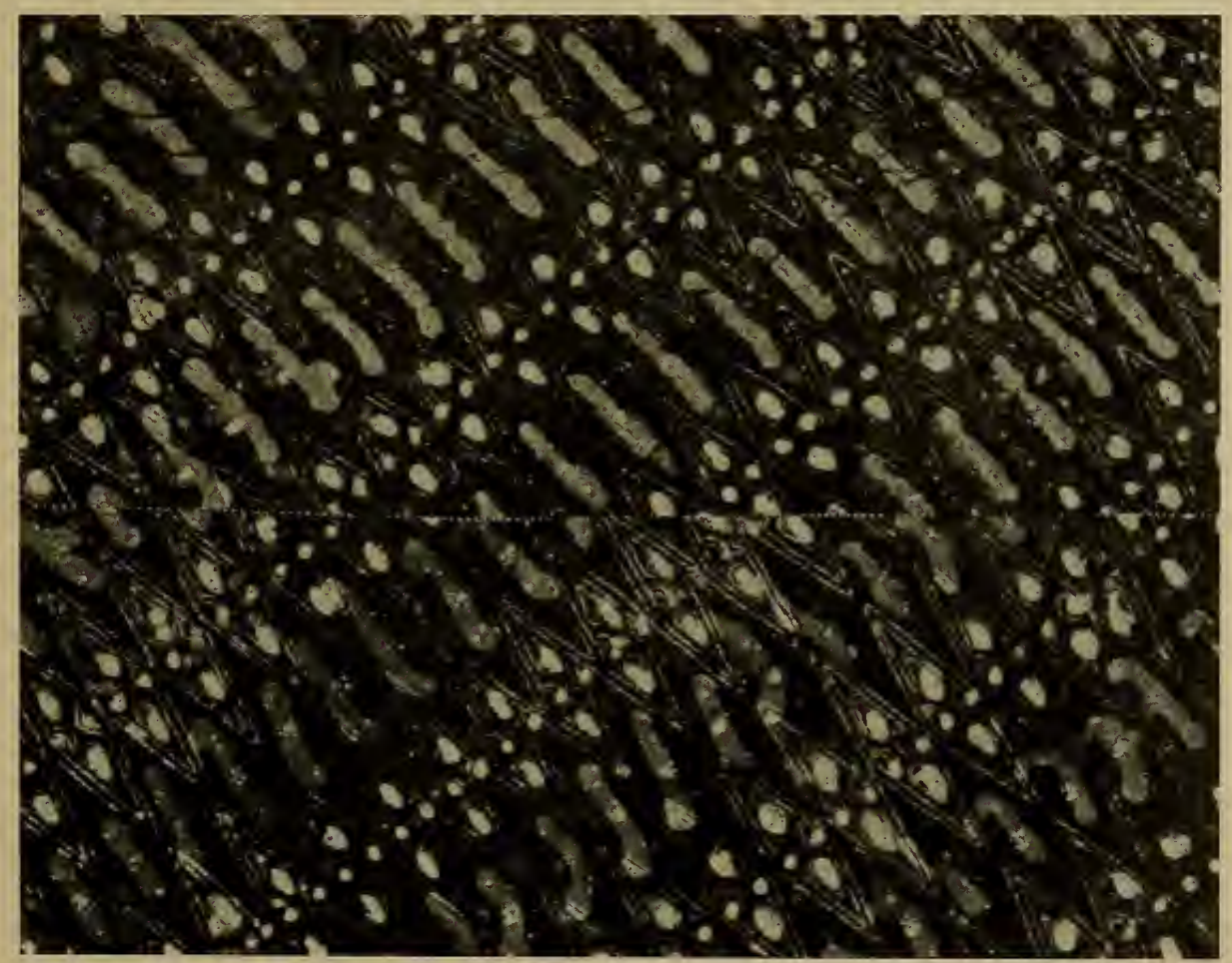


FIRST LESSONS IN BATIK

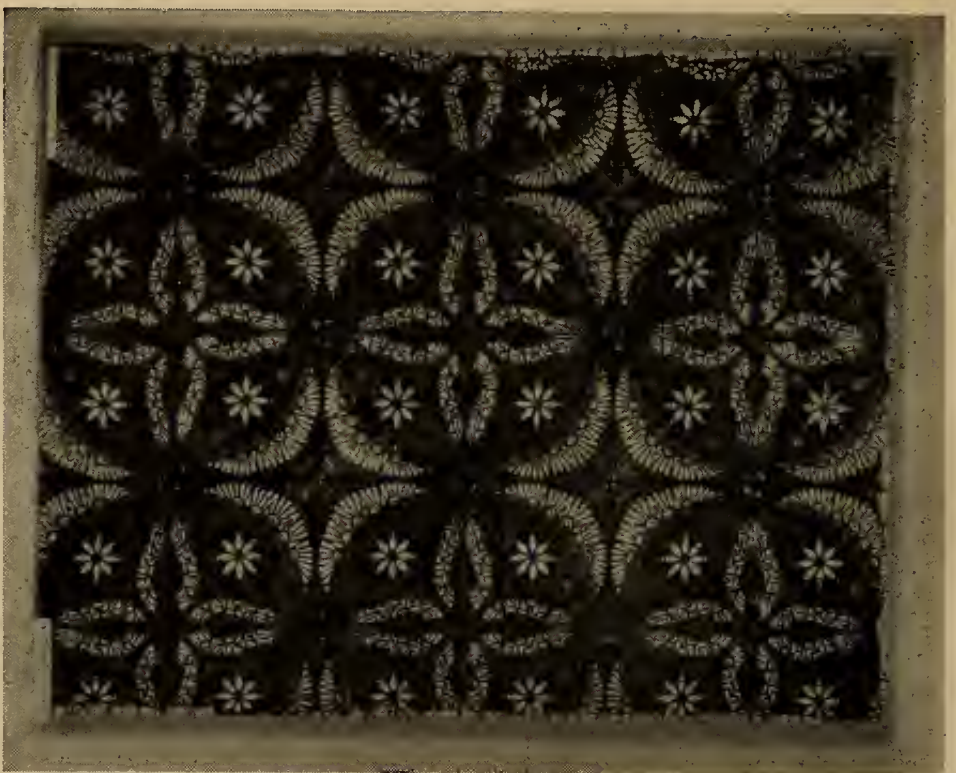

A Javanese Batik design from the Metropolitan Museum, New York

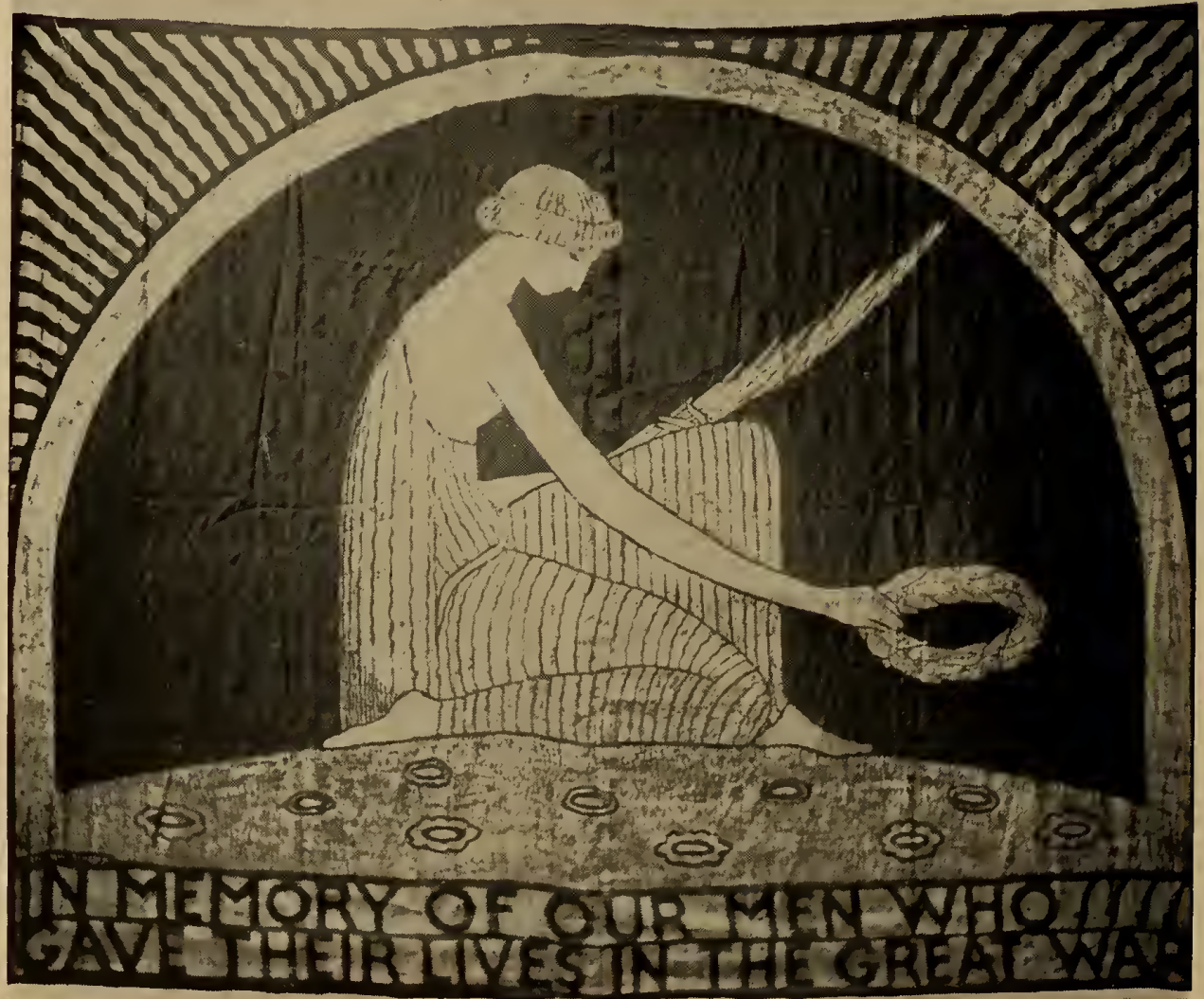

A Batik Memorial Hanging, by Jean Paul Slusser 


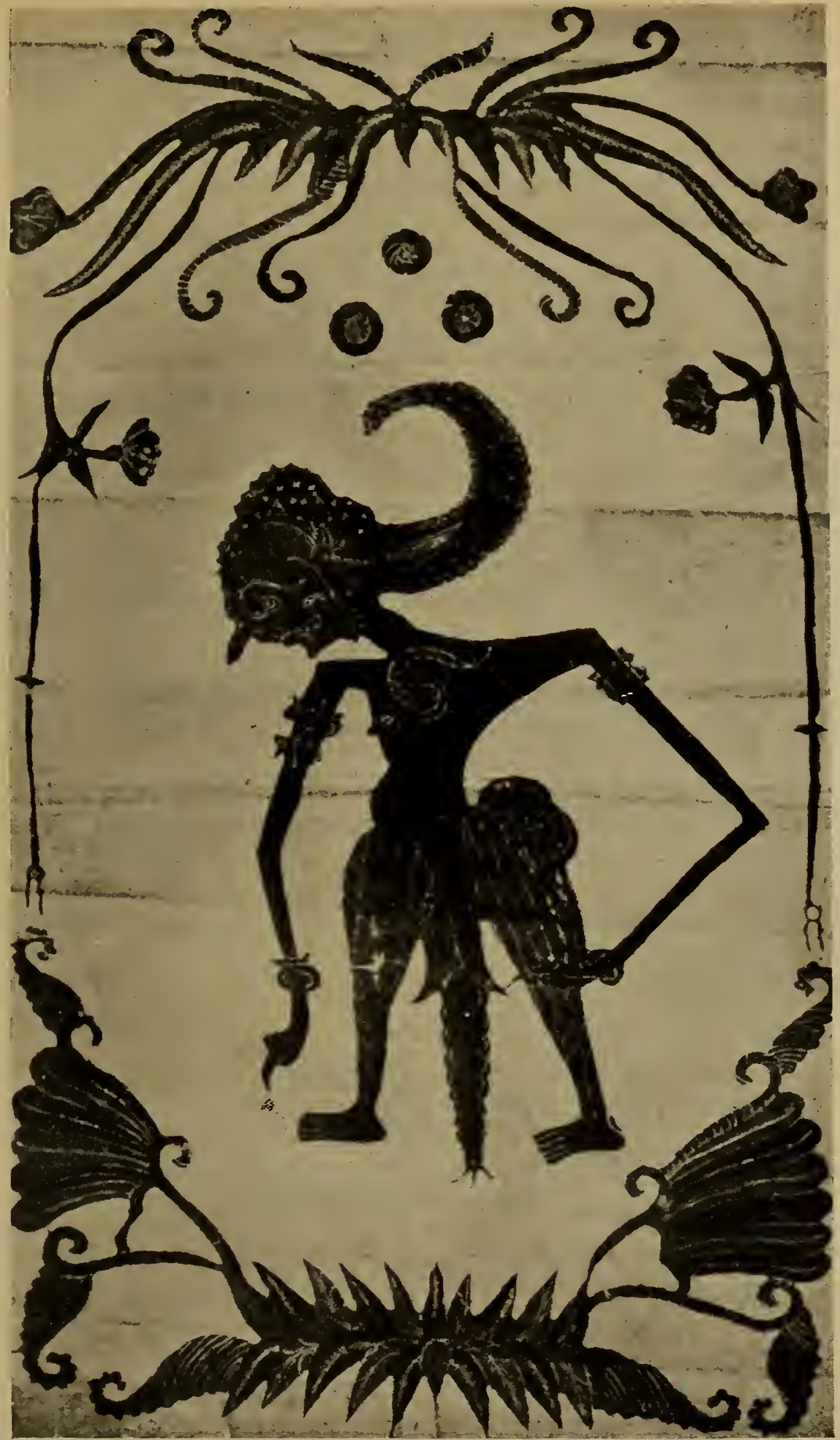

An unusual piece of Samarang Batik in the American Museum of Natural History, New York 


\section{CHAPTER VI}

\section{COLOR AND HOW TO USE IT}

7 OR those who have not had an opportunity of studying color, the following explanation of the theory of mixing colors may not be amiss.

Yellow, red, and blue are called the standard or primary colors. From these we make the three binary or secondary colors, orange, green, and violet.

Orange is produced by mixing red and yellow.

Green is produced by mixing blue and yellow.

Violet is produced by mixing red and blue.

These primary and binary colors are thought of as though they were arranged in a circle.

Divide the circumference of a circle in six equal parts. Draw three diameters through the points found. Begin at the top with yellow. Onesixth of the distance to the left, we place orange, at the next diameter's end place red. At the bottom of the circle opposite yellow is violet. Passing upward toward the right blue is opposite orange, and continuing upward, green is opposite red. The colors at opposite ends of the three diameters are called complements.

Yellow is the complement of violet and violet of yellow.

Orange is the complement of blue and blue of orange.

Red is the complement of green and green of red.

The outside of the circle in the cut represents the full strength of the pure color. The addition of different amounts of white and black is indicated by the inner circles, the center standing for pure white or pure black. The circle may be subdivided to suggest many gradations from the full color through the tints to white and by the addition of black through the shades to black. This system of gradation is a help in determining the contrast of tints, but is more useful in helping to determine related harmonies up and down the scale from black to the pure color and then through the tints to white.

Red, with one part of white added, would be indicated by the second circle. Its complement would be the green found on the second circle, which has an equal amount of white mixed with it, producing a tint. The same arrangement holds true with regard to black. Each circle represents also one portion of black added to the standard color, producing a shade. There is an almost indefinite number of these tints and shades, depending upon their location within the color circle.

It is found that equal parts of the primary colors red, yellow, and blue make neutral grey. Any binary color plus a primary color makes grey. For instance, a binary green, which is made of the two primaries yellow and blue, added to a primary red produces grey.

In the same way, a binary orange, which is a combination of primary red and yellow, added to blue makes grey. 


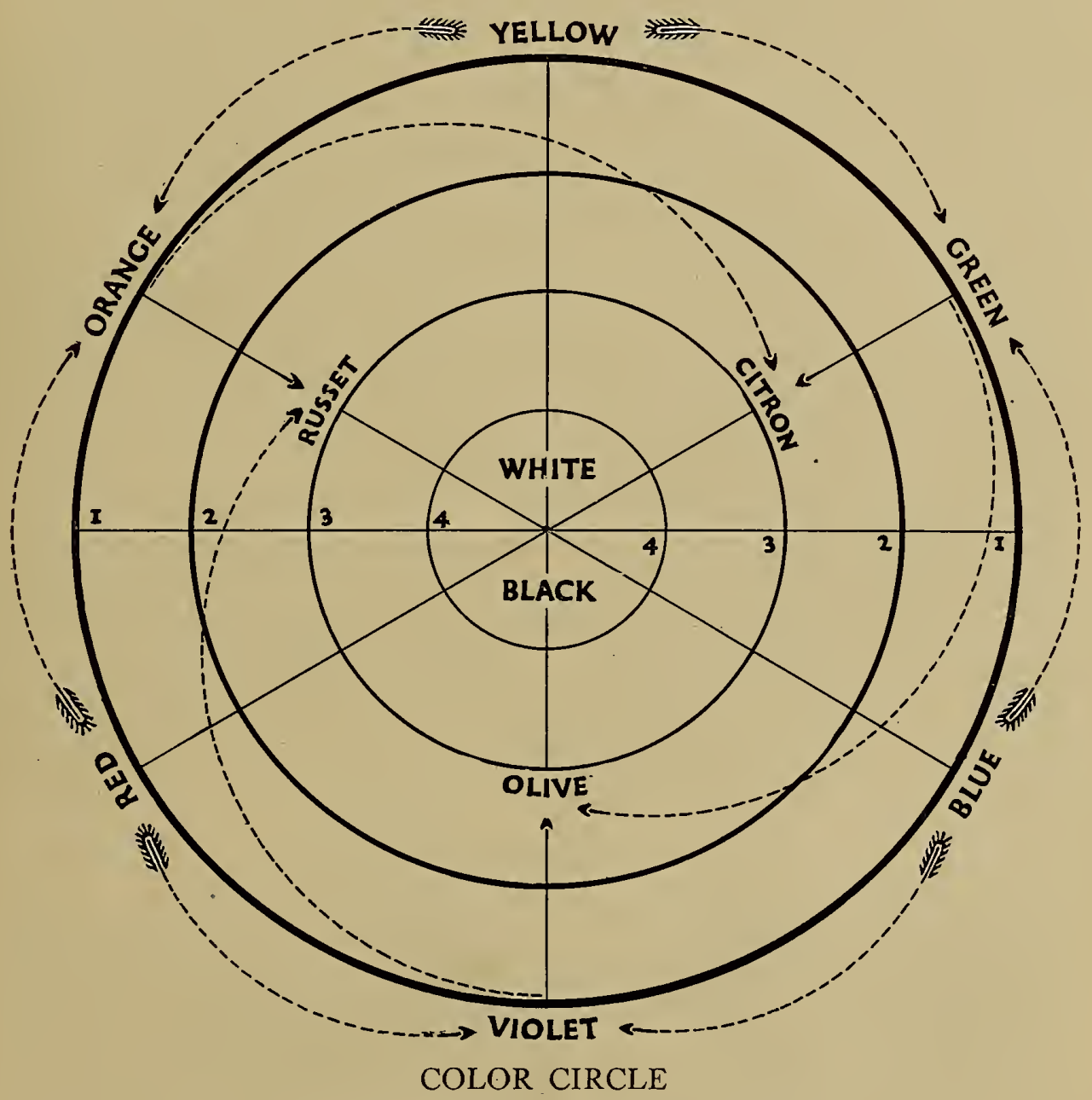

For explanation of this "Color Circle," see page 50 
A binary violet, which is primary red and blue, added to yellow makes grey.

Colors may be softened or greyed by adding a little black or brown dye or by adding the complementary color. A bright green, for instance, is softened either by adding a little black or brown or the complement of green, which is red.

Dyes are mixed in much the same manner as paints and it is necessary to know the action of one color upon another. Especially must one know how grey is produced so as not to produce this effect when such a result is undesirable and yet avoid too vivid combinations. In mixing dyes both brown and black are valuable to tone down the clear colors. There need be no fear of producing a muddy color by adding black or brown dye to the colors, as is produced by adding black paint, because the black dye is made up of particles of other colors.

Valuable help in reproducing color combinations is found in keeping a record of the amounts and colors used, the weight or size of material dyed, and the length of time the goods is in the dye bath.

If commercial dyes are used, follow the directions given exactly as on the package.

"Top dyeing" means to dye over another color.

The material may be a light blue. Over this or on top of this, a green is dyed, giving a blue green result.

In dyeing one color over another the result naturally depends upon the strength of the first as well as upon that of the succeeding dyes. As yellow is nearest white in value, it is wise to dye yellow first if other colors are to be added. If the yellow is weak the other dyes will be very little affected by it as they are much stronger. If a strong yellow has been used first, the following modifications may be expected:

\section{COLOR TABLE FOR TOP DYEING}

Orange over yellow will give orange yellow.

Red over yellow will give red orange.

Blue over yellow will give green.

Green over yellow will give yellow green.

Violet or magenta over yellow will give grey.

Brown over yellow will give yellow brown.

Black over yellow will give grey.

If a blue dye is to be used first, the following suggestions may help. Accordingly as the blue used is strong or weak, it will appear in the resulting combination strongly or weakly. The top dye used over it will equally of course count in the resulting combination according as it is strong or weak. Having these two points in mind we can say:

Red over blue will give purple.

Violet over blue will give blue violet.

Gieer over blue will give blue green. 


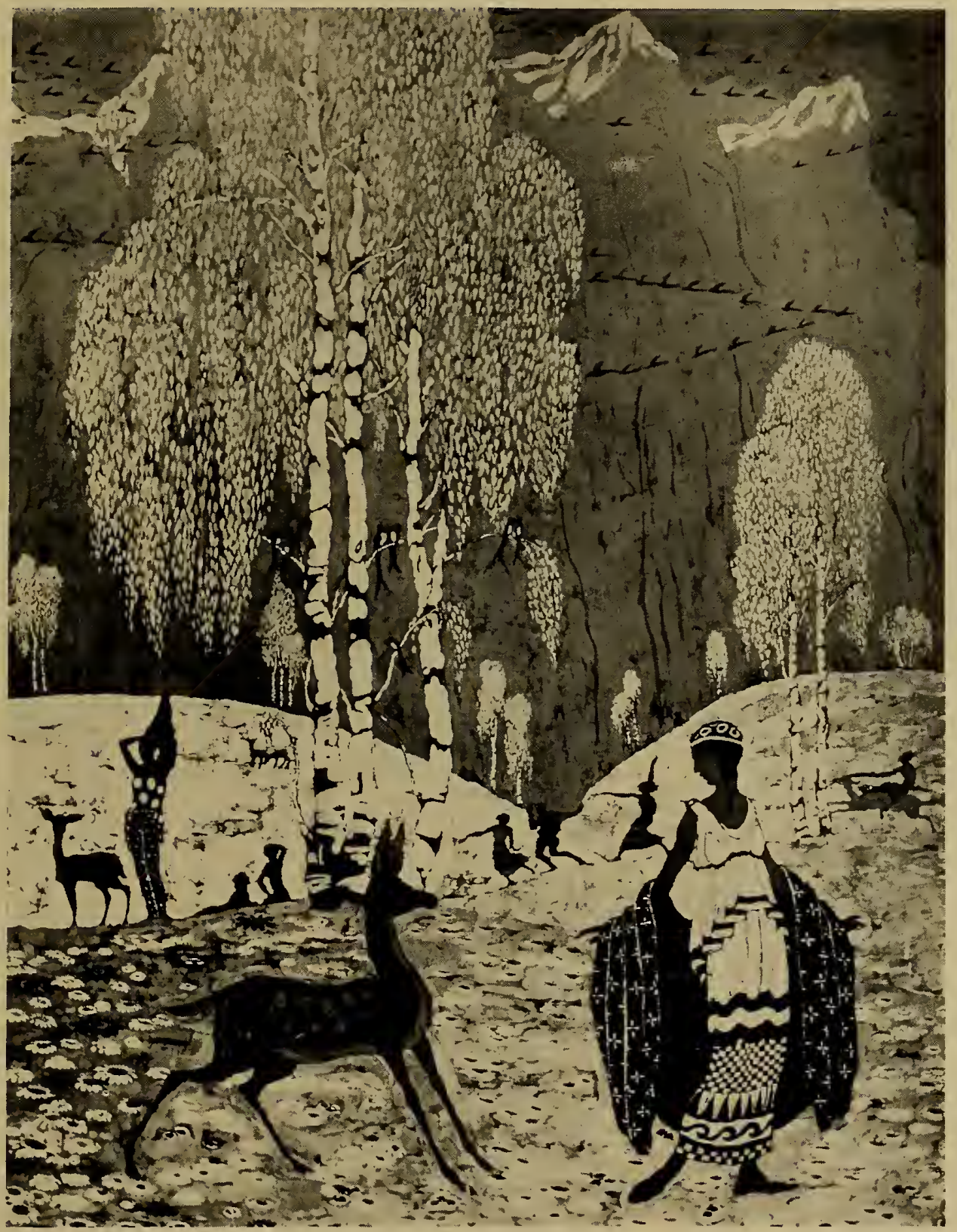

"Spring." A Batik Wall Hanging, by C. Bertram Hartman and Peter Mijer 
Yellow over blue will give green.

Brown over blue will give dark brown.

Black over blue will give blue black.

With red as the basic color, and with the strength of color in mind as suggested before, we find that

Orange over red will give orange red.

Yellow over red will give orange.

Green over red will give dark grey, green or red.

Blue over red will give violet.

Violet over red will give red violet.

Brown over red will give red brown.

Black over red will give grey red.

The following mixtures of dyes are valuable:

Yellow, orange and blue with yellow predominating make gold.

Orange and green with orange predominating give russet shades.

Orange, green and red give orange brown.

Orange, blue and magenta give bronze.

In studying out the color scheme of any piece it is desirable to refer to the Color Chart for contrasts, related colors and combinations that are not familiar.

If a perfect balance of contrast of any tint of a color is desired, the contrasting tint must show the same proportion of white in its make-up; but the contrast may be made more decided by choosing a lighter contrasting tint.

Yellow has the tendency to come nearer the observer and it adds warmth and brilliancy to all its combinations with other colors. Red is less brilliant than yellow, but it is the most intense and positive of all the colors. Blue is the retreating cold color. It shows its quality best by daylight. Blue and white are the strongest color contrasts excepting black and white.

Green, composed of the primaries yellow and blue, is capable of great variation from cool to warm according to the amount of either blue or yellow entering into it. Its contrast is red.

Orange is the most brilliant of the secondary colors. It is most useful when toned down to old gold and russet.

Violet is the darkest of the secondary colors. As it contains much blue it has a tendency to fade into a neutral brownish color by artificial light.

The tertiary colors russet, olive, and citrine are most valuable.

Russet is made up of orange and violet, which again are composed of yellow, blue, and red. Red being in both of these colors, russet evidently belongs to the red group of colors, and contains a smaller proportion of both yellow and blue. The contrast to russet is from deep green to blue grey for a very orange shade.

Olive is dominantly a blue color as it is made from green and violet, both of which contain blue. The contrast of olive is deep orange. 


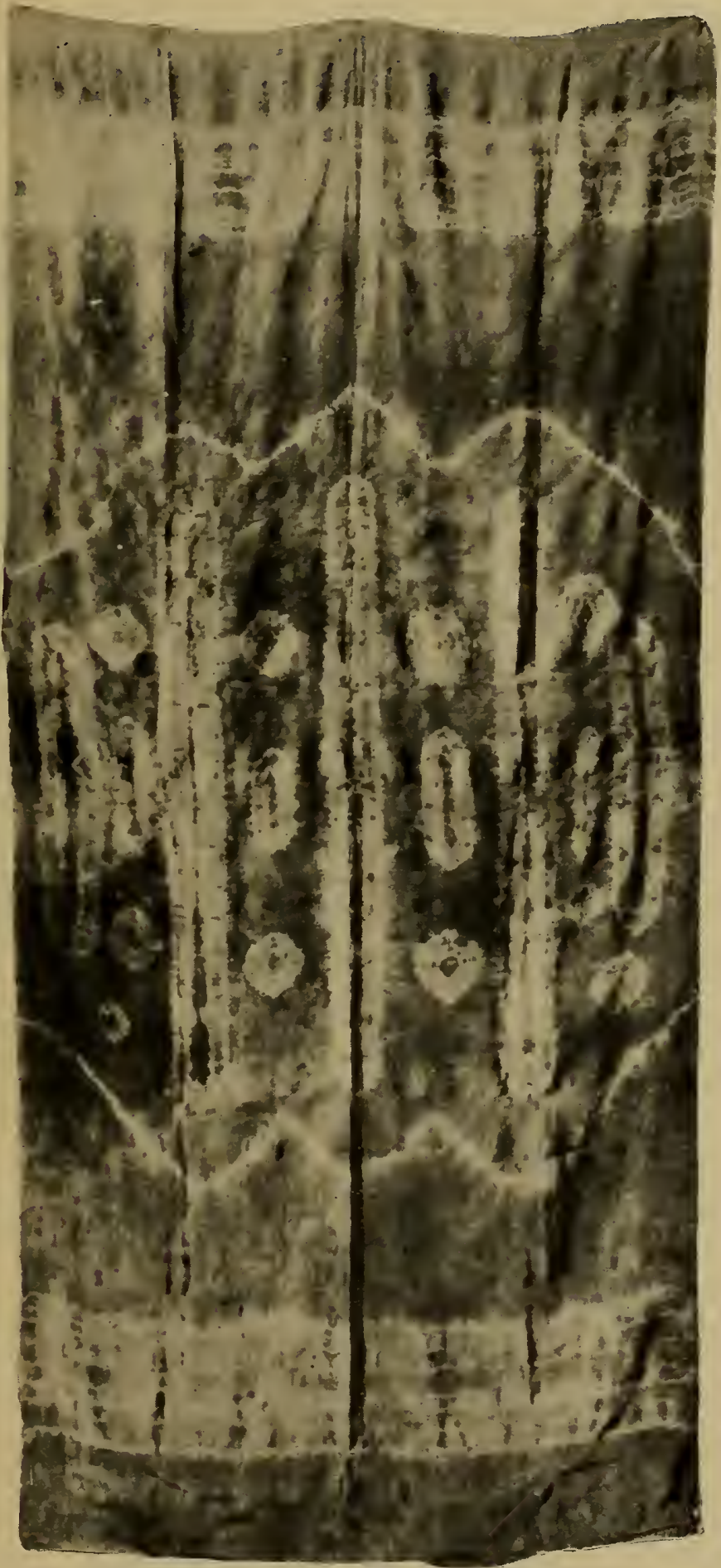

$A$ Scarf tied in bands across the ends. Designed by Helen R. Reed

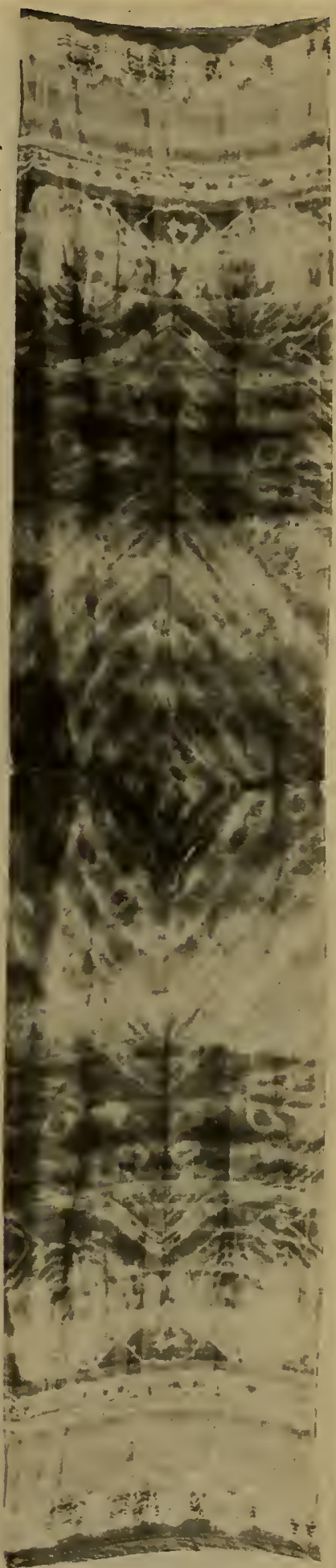

A Scarf, showing a combination of tied squares, circles and stripes. Designed by Helen R. Reed 
Citrine is a combination of orange and green, and therefore is made up of the primaries, two parts yellow, one red, and one blue. Yellow is in the largest amounts, red next, and blue least.

These three colors are exceedingly valuable to the decorator as each one has an enormous range of tints and shades and the whole group is very pleasing to the eye. There are a few other colors that are so generally used that they deserve special note.

First, brown, theoretically produced by a mixture of citrine and olive or red, blue and vellow. Practically several shades require the addition of black dye to produce brown. A bluish or purplish color according to its shade is its contrast.

Maroon is a red and brown whose contrast is shades of green.

Tints and shades of any full color also give harmonious combinations. The nearer the shade approaches black and the tint approaches white, the greater the contrast. The more closely related the two are the less the contrast.

In considering color combinations we also have the related or analogous group, from which to choose our color schemes. These are in every way more easily handled in dyeing work and are of greater use especially to the beginner.

A tint is secured in dyeing by reducing with water the full strength of the dye and also shortening the time of immersion.

A shade is secured by adding black. Between the full strength of the dye and white, however, lies the range of tints most easily used. Refer to the Color Chart for the complements of the tints and shades. These vary in the case of crimson, for instance, from deep crimson through rose to the palest pink tints. Each decided color step in this scale gives related tints that may safely be combined. If they are not far removed from each other in intensity, they give very little contrast, but may be at the same time a very pleasing combination. Considerable contrast may be secured by using tints that are considerably removed from each other in the color scale.

Still another group of color harmonies must be considered. This is the harmony of related colors. By this is meant the harmony of all colors of which blue, for example, forms a part. This group runs all the way from the purplish blues formed by adding red through all the different blues to blue greens made by adding yellow.

This grouping is especially useful in dyeing, as we can dye in one such group very effectively, starting with the yellow found in the blue green and working toward the red found in the violet blues.

For dyeing purposes we can really make just two color groups-the blue just given and the red. The red group starts with the red violets, which contain, of course, red and blue, and goes through the red group into the orange, which is red and yellow. 


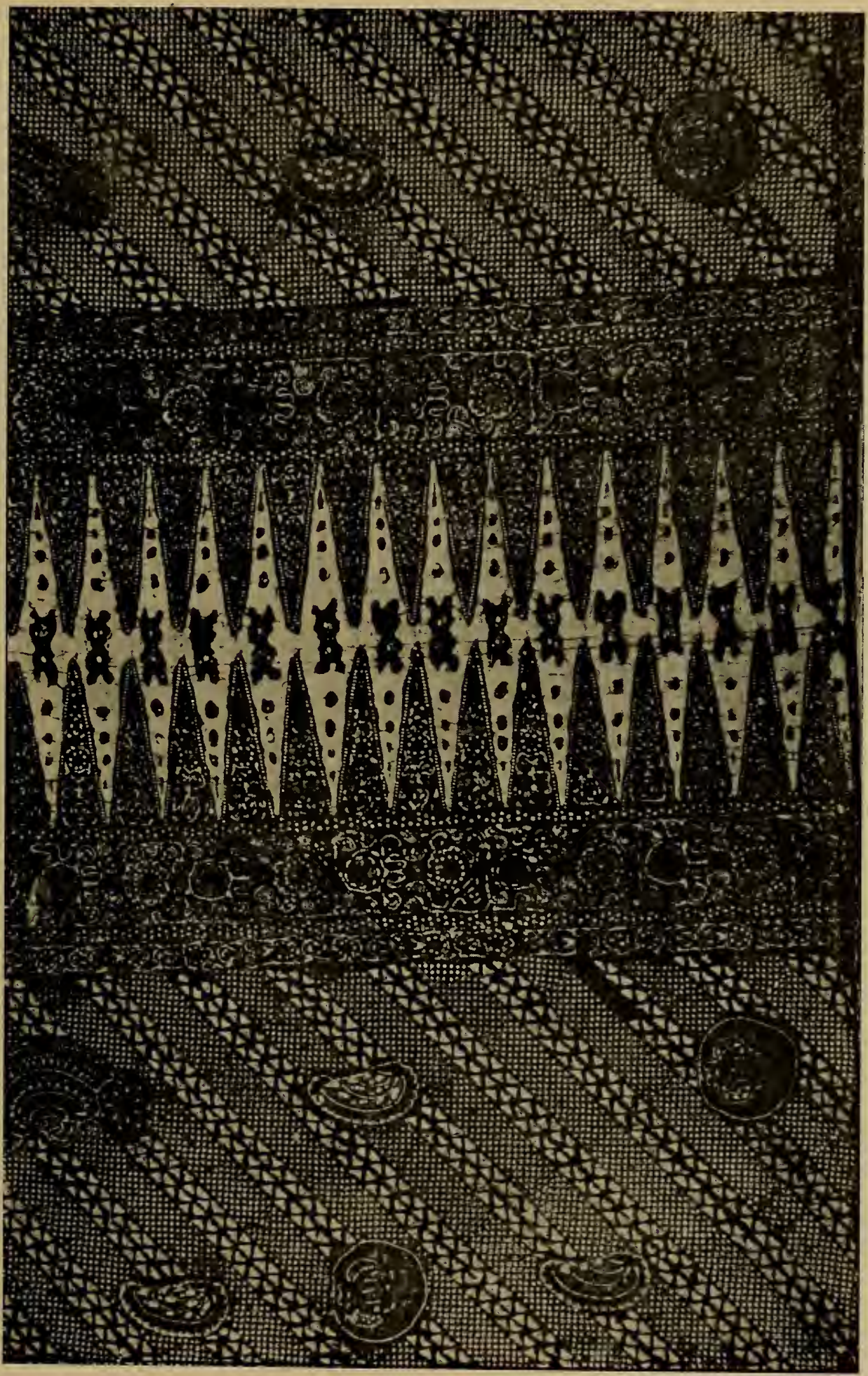




\section{PLEASING COLOR COMBINATIONS}

The following table of harmonizing colors is inserted as a guide for those who do not have a scientific knowledge of Color and its many harmonies:

Black harmonizes with crimson, lemon, yellow. Black harmonizes with scarlet, blue, green.

Black harmonizes with citrine.

Black harmonizes with olive.

Black harmonizes with salmon.

Black harmonizes with primrose.

Black harmonizes with corn color.

Black harmonizes with orange.

Black harmonizes with gold.

Black harmonizes with white.

White harmonizes with cerise.

White harmonizes with scarlet.

White harmonizes with orange.

Violet harmonizes with scarlet, blue, orange.

Violet harmonizes with scarlet, gold.

Violet harmonizes with corn color.

Violet harmonizes with gold.

Violet harmonizes with citrines.

Violet harmonizes with yellow.

Orange harmonizes with violet.

Orange harmonizes with blue, scarlet, green.

Orange harmonizes with purple, scarlet.

Orange harmonizes with crimson, blue.

Orange harmonizes with brown.

Orange harmonizes with violet.

Orange harmonizes with blue.

Dark Green harmonizes with crimson, blue, gold.

Dark Green harmonizes with gold.

Blue Green harmonizes with orange.

Green harmonizes with russet.

Green harmonizes with scarlet.

Green harmonizes with red.
Yellow harmonizes with violet, scarlet, blue.

Yellow harmonizes with brown.

Yellow harmonizes with deep crimson.

Yellow harmonizes with blue.

Yellow harmonizes with violet.

Crimson harmonizes with black.

Crimson harmonizes with violet.

Crimson harmonizes with corn color.

Crimson harmonizes with orange.

Crimson harmonizes with gold.

Crimson harmonizes with yellow, green.

Scarlet harmonizes with blue, grey.

Scarlet harmonizes with violet.

Scarlet harmonizes with blue.

Scarlet harmonizes with blue, green.

Red harmonizes with white.

Red harmonizes with grey.

Red harmonizes with blue.

Red harmonizes with gold.

Red harmonizes with green.

Blue harmonizes with brown, crimson, gold.

Blue harmonizes with orange, green.

Blue harmonizes with orange, black.

Blue harmonizes with black.

Blue harmonizes with white.

Blue harmonizes with chocolate brown.

Blue harmonizes with neutral grey.

Blue harmonizes with salmon.

Blue harmonizes with straw.

Blue harmonizes with corn color.

Blue harmonizes with gold.

Blue harmonizes with orange. 


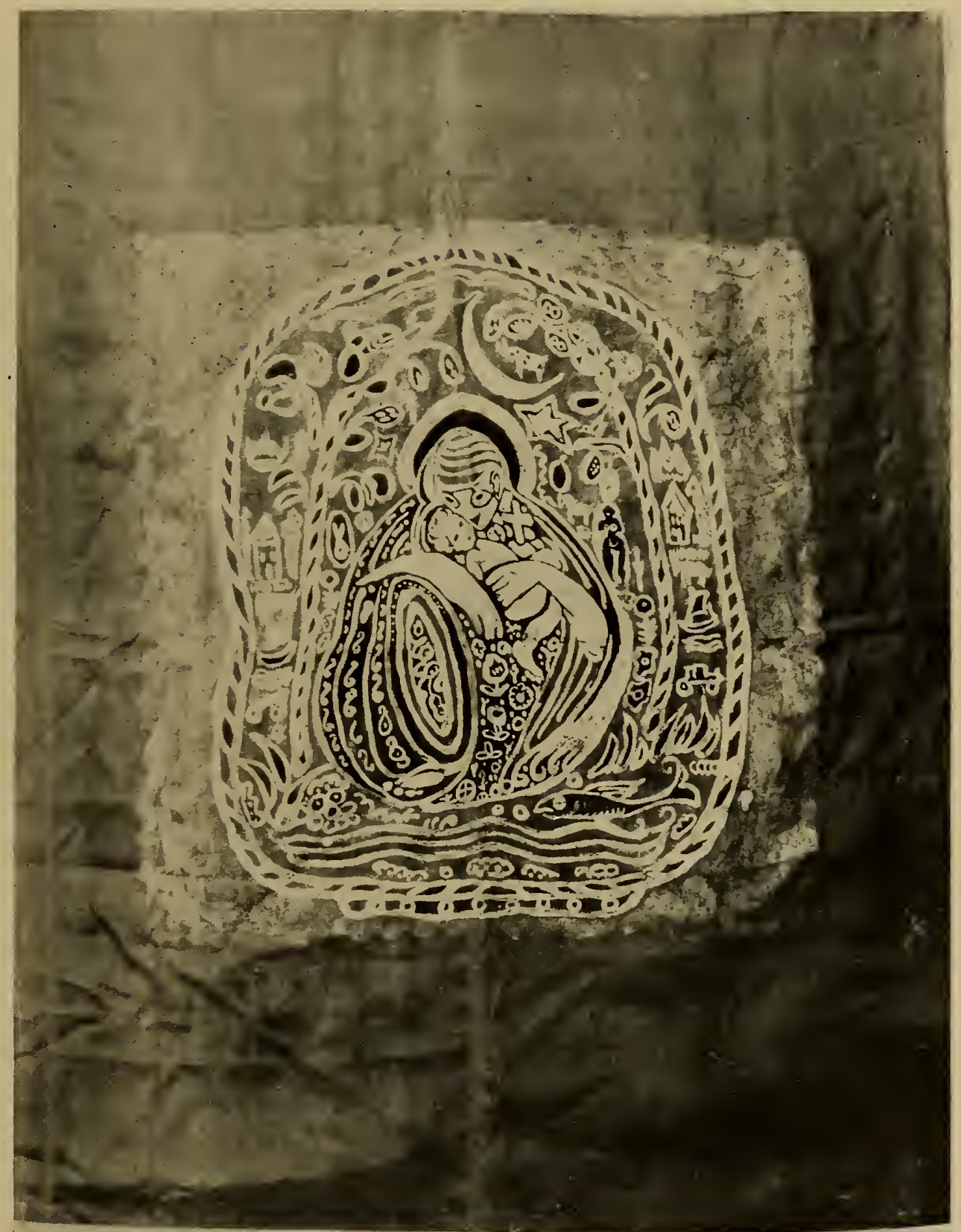

"The Madonna." A Batik Wall Hanging, by Helen R. Reed, Van Dyck Studios, New York 


\section{CHAPTER VII \\ “TIED AND DYED" WORK}

NOTHER new-old process that has been revived recently is "Tie-Dyeing." Its artistic possibilities are as yet hardly realized in this country. This is partly due to the difficulty that has been experienced in dyeing with a cold process and at the same time securing a strong fast color. This difficulty has now been met. The new "Bateeko Dyes" prepared for Batik work can be used on wool and silk in cold or tepid water. The dyes will wash so that permanent effects can now be secured. If the tying is firmly done, the goods can be dyed by boiling, so that ordinary dyes, that require boiling to set them, can be also used successfully.

This Tied and Dyed work is found among many primitive conditions and peoples. In old colonial days our grandmothers made their shaded wool by this method. They wrapped their skeins of woolen thread with corn husks and wound these around tightly with cord to give the necessary pressure. The portions covered with the husks retained the original color of the wool, while those exposed became the color of the dye bath into which they were dipped. Legend says that the ancient Greeks tied the borders of their robes to produce waving lines.

Two main variations in method of Tie-Dyeing are: First, the pattern is developed by tying the threads of warp or woof or both before weaving.

Second, parts of the goods are tied before dyeing in such a way as to protect spots of the cloth from the action of the dyes.

The first method is found in ancient Peruvian work, in central India, and in parts of the Philippines. It is a complicated process and requires a high degree of skill on the part of the weaver.

The second method was used to a large extent in central India, and a few examples are also known from Peru. Sir George Watt, in his "Indian Art of Delhi," gives such a clear description of Indian Tie-Dyeing, Knot-Dyeing, or Bandana work that it is worth quoting:

"The once famous Bandana handkerchiefs may be given as the best known example of Tie-Dyeing. The process is simple, but so laborious that it could only have been invented or practiced in a country where food was cheap and consequently human labor valued at an abnormally low figure. Tie-Dyeing may be described briefly as follows: The fabric is folded several times into half until reduced to a square or rectangular piece perhaps not more than one foot by a foot and a half in length and two or three folds in thickness. It is then dampened and pressed over a block which consists of a piece of wood with a mass of nails or pins fastened all over it in elaboration of some design. It is then taken off the block and given to a girl (the Bandhani) who purposely allows her thumb and forefinger nails to grow long with a view to their becoming an indispensable pair of pincers, by means of which minute particles of the cloth may be laid hold of readily. The raised up portions indicated by the block are seized and deftly tied by a string that may or may not have been coated with a 


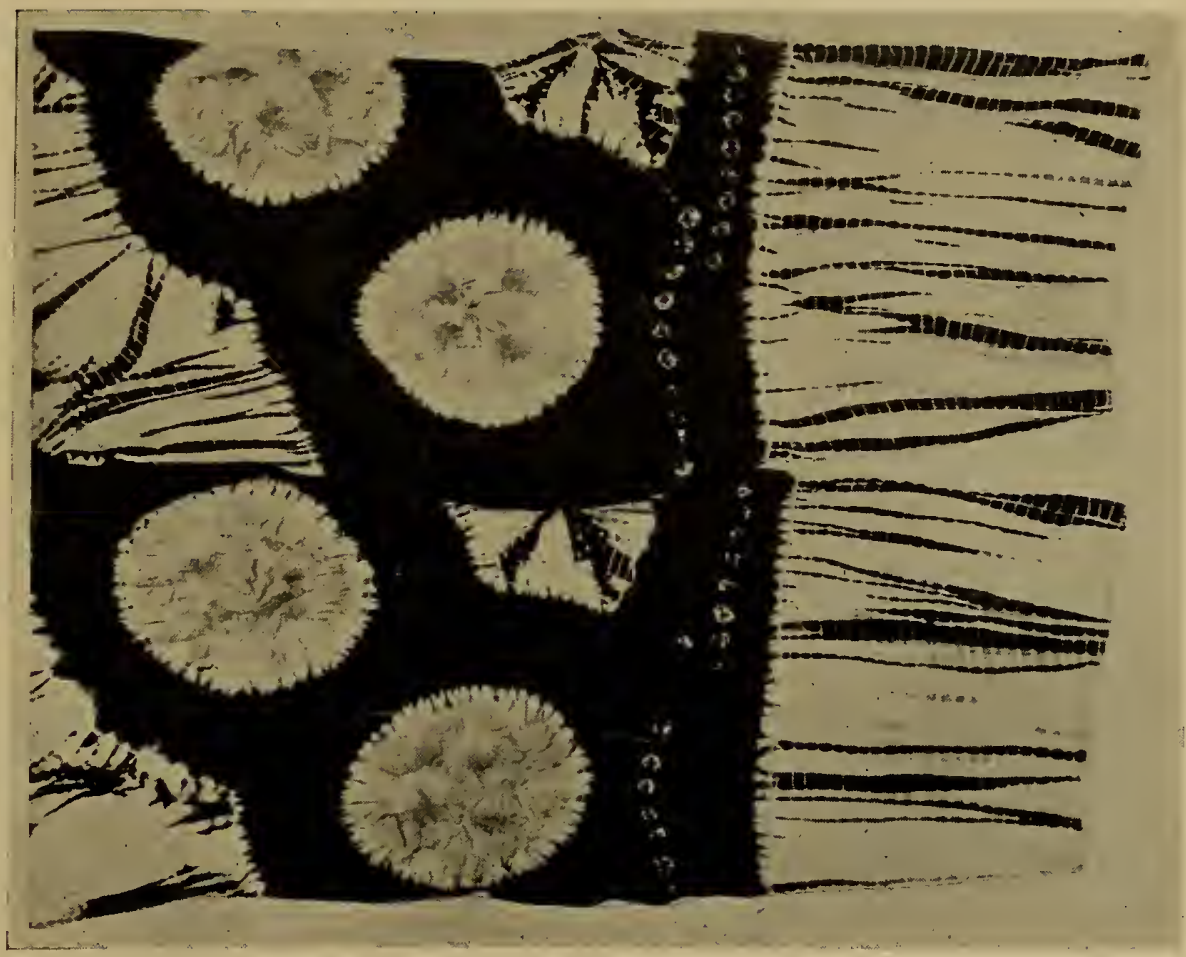

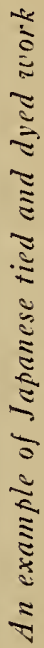

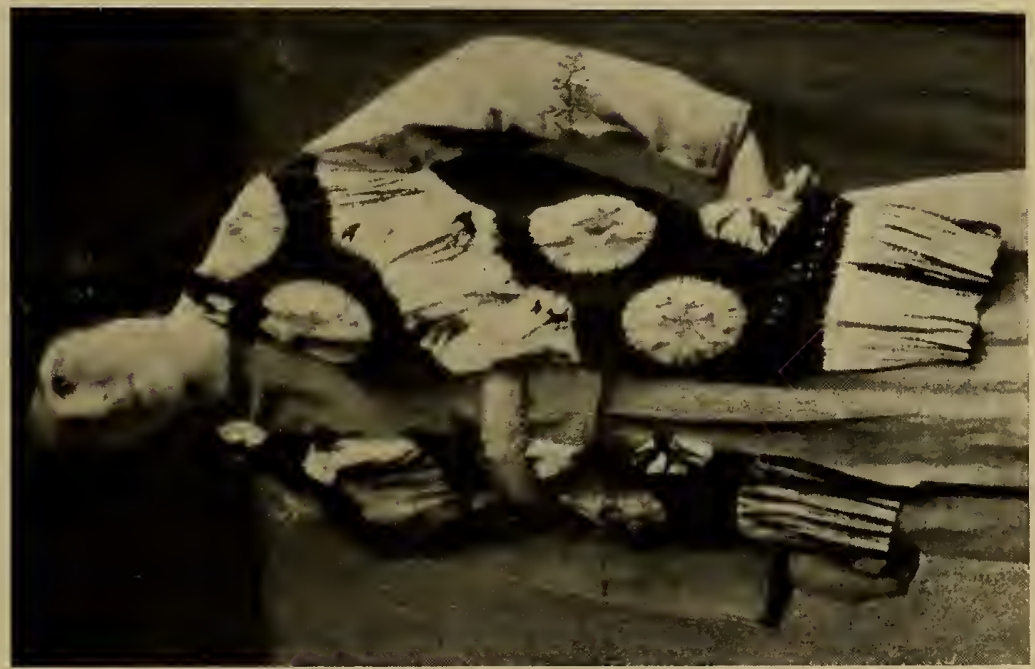


resist paste. Great skill is needed not only to securely grasp all the layers of cloth at once, but to so seize each portion that it may crinkle in a particular manner while being securely wound around and tied. Moreover, the thread is not cut into separate pieces at each tied point. It is carried from the one to the other and is merely held in position by the turn upon itself that is given just before being carried to the next point. In consequence, when the operation of dyeing has been completed, the thread may be readily unwound and used again and again.

"The Bandhani having finished her task, the fabric is given to the dyer, who begins by immersing the folded up and compactly tied cloth in the lightest shade that it is intended to be given, say yellow. When finished, it is handed to the Bandhani, who now impresses it upon a second pattern block, and proceeds to tie a still further series of raised up points. It is again dyed the next shade, say red, and if the pattern and scheme of color desired be thus completed, the threads are unwound and the fabric opened out, when it will be found to have a red field with a pattern in white and yellow points, repeated several times all over it.

"Instead of stopping with a red, a third series of points may be tied, and the fabric dyed black, when the pattern will appear in points of white, yellow and red on a black (or black brown) field. But should a still more elaborate design be contemplated, the tying and dyeing may be repeated indefinitely. For example, the first points tied may have been very large and the cloth so folded that when they are opened out they form perfectly circular white spots, squares, or star-shaped patches upon the first ground color. These may now be dealt with separately and be tied and retied until the circles, the squares, or the stars become variegated by concentric bands of color, or a final special spot may be given in the center of each by uncovering the tips so as to allow these portions of the tied up spaces to receive the desired tint; in fact, such exposed portions may be specially colored by means of a brush. But since the tying of points can never be absolutely complete, the very center of each bears the tiniest speck of the final field color.

"Instead of using a block to raise up the cloth at the desired points, the Bandhani may simply proceed to tie up portions according to a pattern that she has practiced until it has become second nature. In this way she will work rapidly and outline a bird, a horseman or a flower, and pass over certain points in the design that require to be tied at subsequent stages, while carrying on a heated controversy with her neighbor or attending to her infant child. And she will return again and again to the further elaborations of one piece after another with the certainty of action that speaks of intuition rather than training.

"But instead of circular, square or star-shaped spots, it may be desired to produce transverse bands or zigzag lines of one color or another. This is accomplished by folding the cloth lengthwise into, say, four folds, then tying at intervals by a series of patches of the desired breadth. If then dyed and subsequently opened out, it will be found to have a ground color 


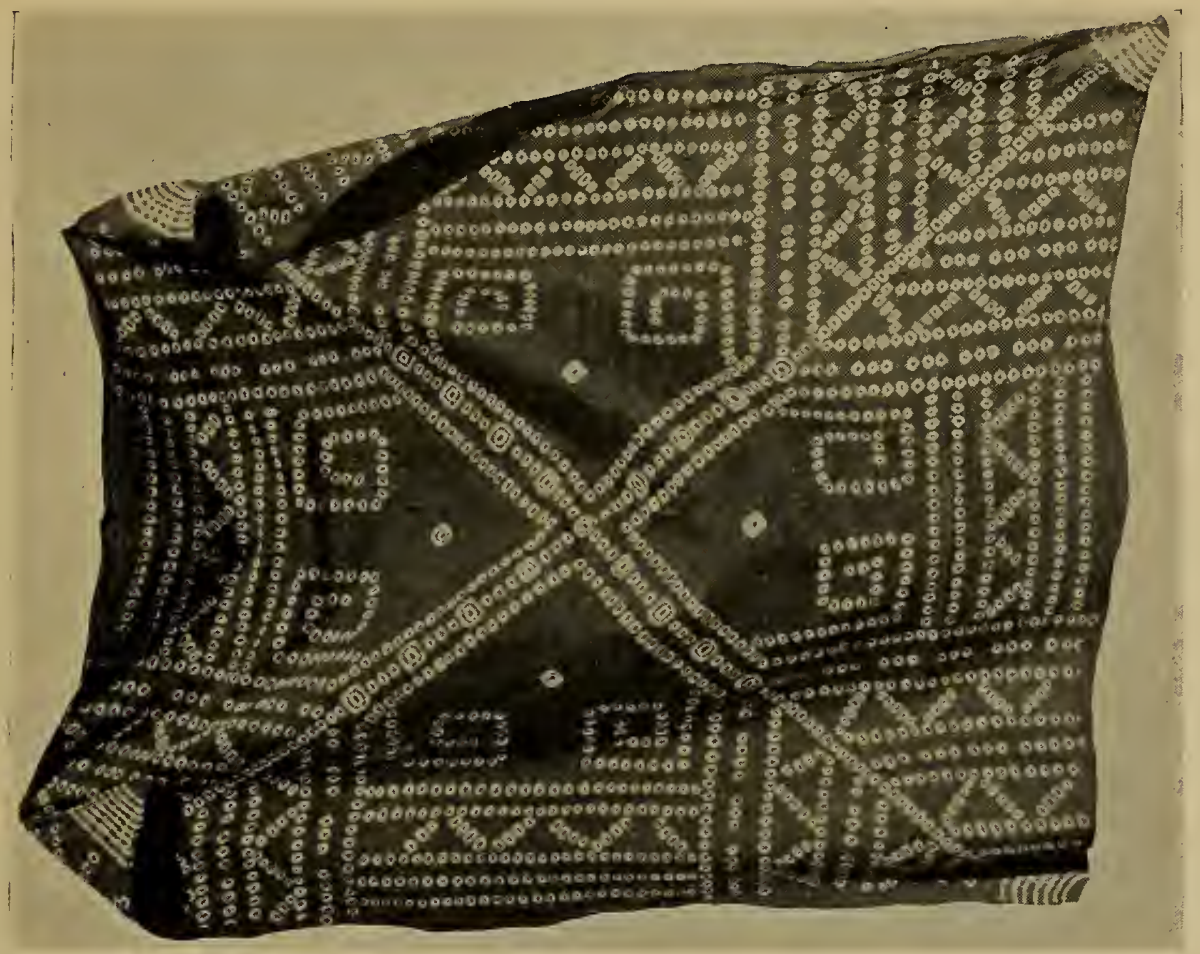

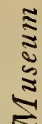

5

हु

5

से

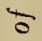

दे

$\leqq$

$\circlearrowleft \approx$

$+\frac{1}{3}$

2?

$\checkmark 0$

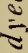

ह

$\frac{\pi}{2}$

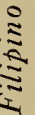
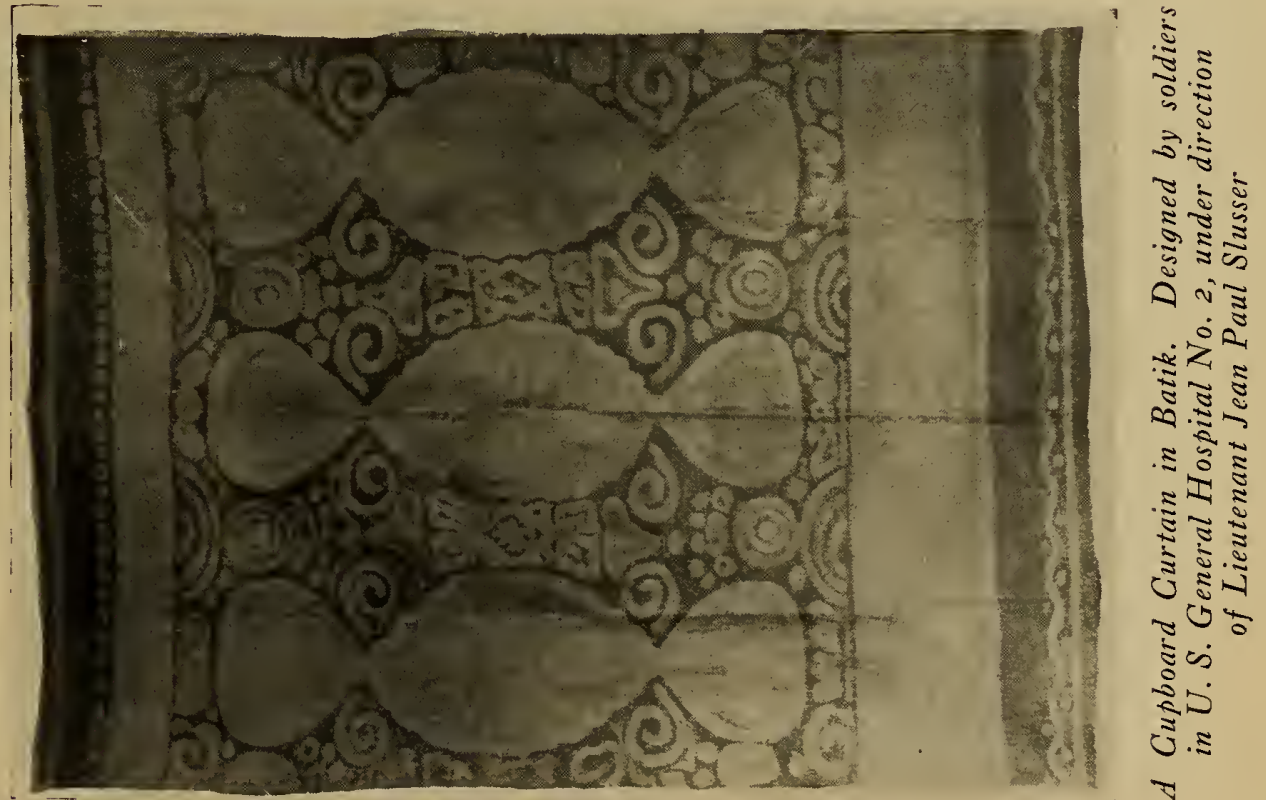
with zigzag transverse bands of white. Having obtained this result, the ordinary point tying may next be resorted to, with the result of producing a limitless series of effects."

This old process, although impossible as a manufacturing method under modern industrial condition, is full of suggestions for the art worker. The simplicity of the process is part of its charm. There is no long process of tracing around edges or smoothing curves. The whole thought goes to planning the shapes, spacing, and arrangement of the spots produced by the tying.

In working with a piece of cloth, all sorts of interesting design possibilities will develop.

In starting to experiment with this work, it is a good plan to take some soft cord, dip it first in any convenient wax, such as paraffin, and cool it, then take a few old pieces of soft cotton cloth and try arranging the folding and wrapping to find by actual experience how to make different shapes. To produce a "tied" square fold a piece of cloth on what is intended to be the two diagonals of the square. Fold on the first diagonal and then on the second, and then holding one end of the cord with the thumb of the left hand begin at the tip and wrap backward to the desired depth.

To make a circle, pick up a point of cloth and crease away from the point as evenly as possible. A shot or marble tied in the center will give a colored center with a light ring or border-square or round, as desired. If the cord is waxed, a single twist at the bottom of the tied spot will hold it firmly. One layer of waxed cord wrapping smoothly done will protect the cloth below perfectly.

In working with semi-transparent material the design can be first blocked in with charcoal on paper. Distances from edges, centers, etc., should be carefully measured with a ruler, tape line, or yard stick. The size of the spots to be protected should be planned carefully, then, laving the cloth over the plan, with either blue tailor's chalk or charcoal, mark the centers of squares and circles and lines for oblongs. With heavier material, after the piece has been planned on paper, draw the foundation lines that give the spacing directly on the cloth as before explained.

The necessary equipment includes jars for the dye, enamel pans, preferably, as acid corrodes metal pans in time, plenty of string, a cake of paraffin wax, and marbles, shot, etc.

The list of articles for which Tie-Dyeing is a suitable decoration is long: Pillow tops, scarfs, bags, table and bureau covers, curtains, bedspreads, blouses, lamp shades, middy ties, collars, aprons, etc.

A charming lamp shade can be made of a square piece of cotton crepe dyed gold first without tying, then tied to give a suitable group of orange brown spots and borders. 


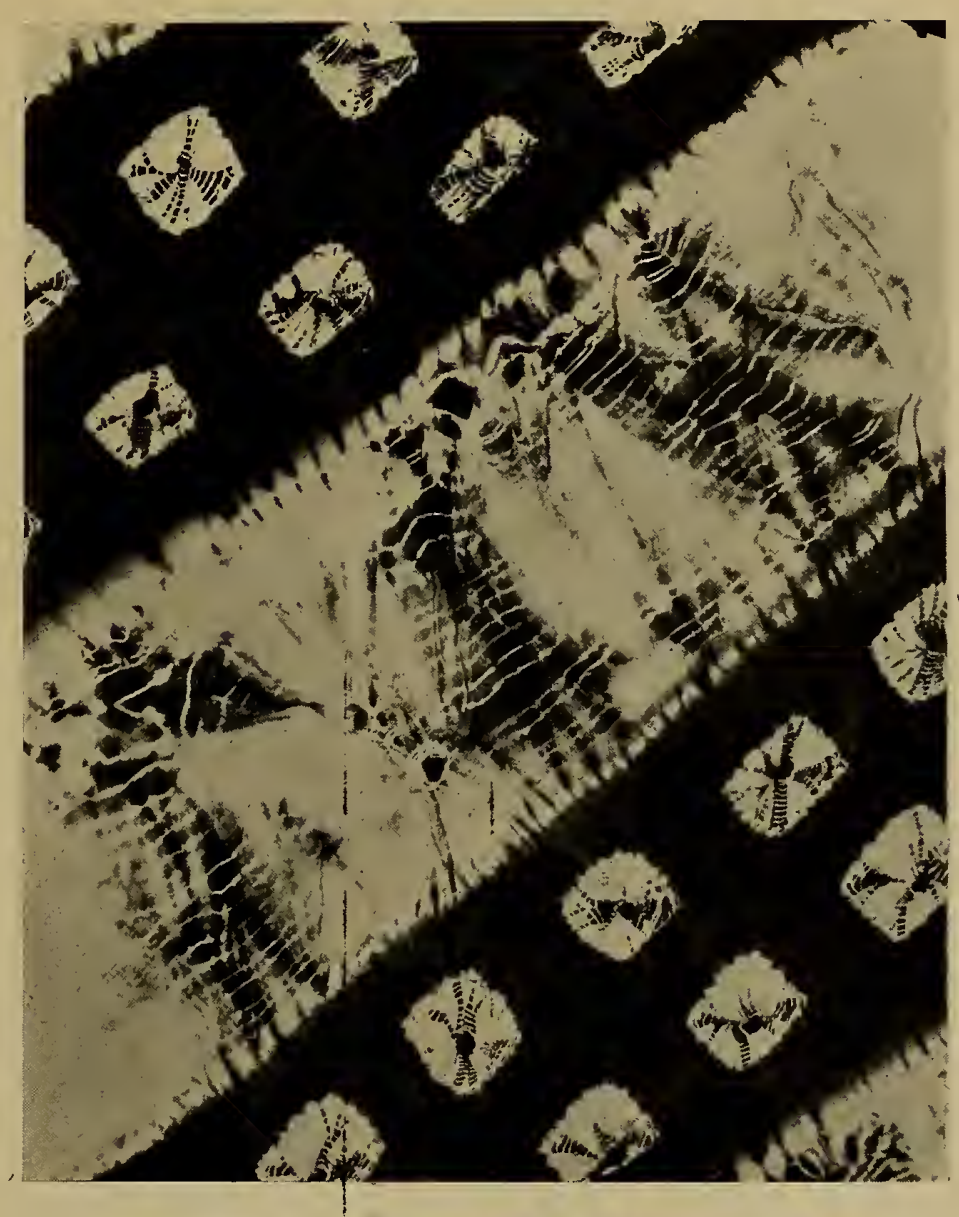

Tied and jyed work in diagonal stripes

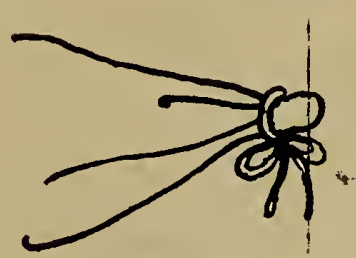

Fig 8

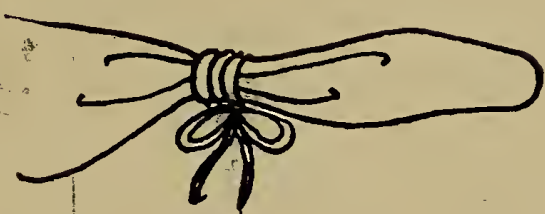

Fis 9

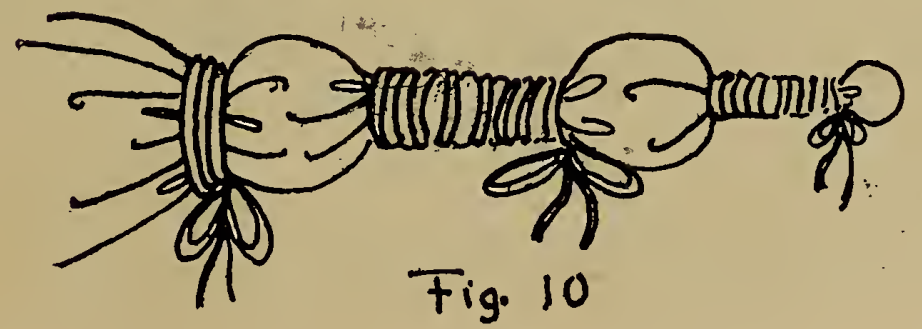

Figure 8 show's how to tie a small square or circle; Figure 9, for larger circles, and Figure 10 , for concentric circles 


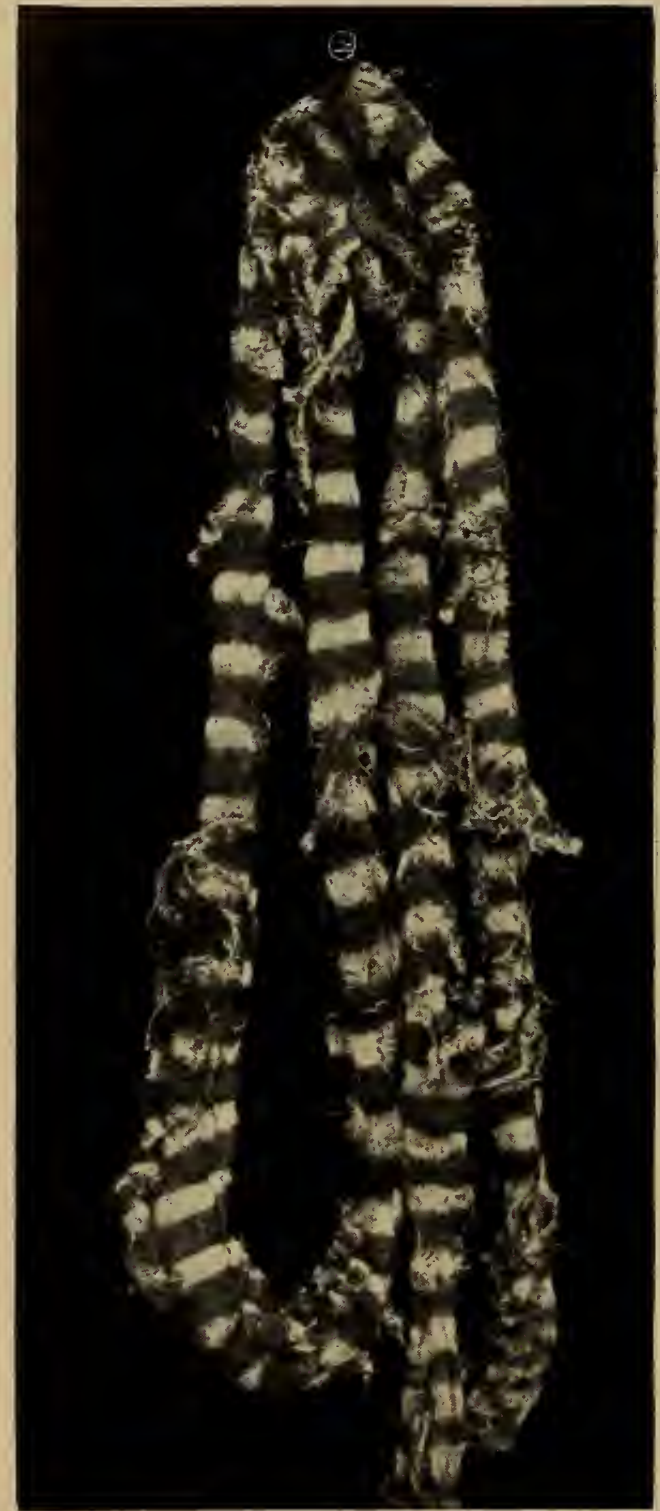

Showing a method of tie-dyeing used in Peru. Courtesy of the American Museum of Natural History, New York

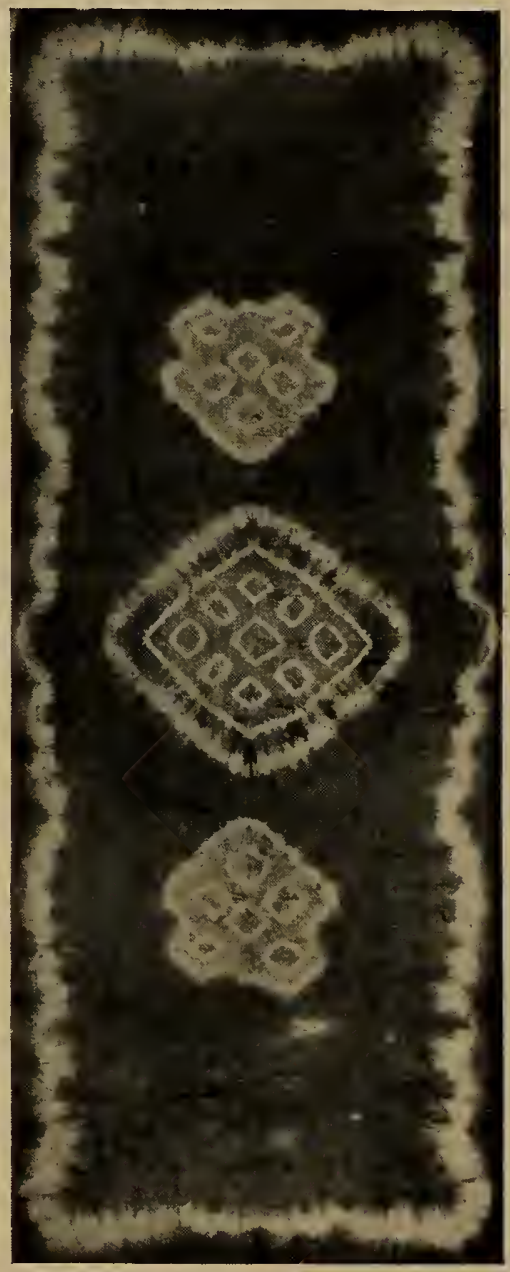

An example of modern tie-dyeing, by Amy Suisher, Athens, Ohio 


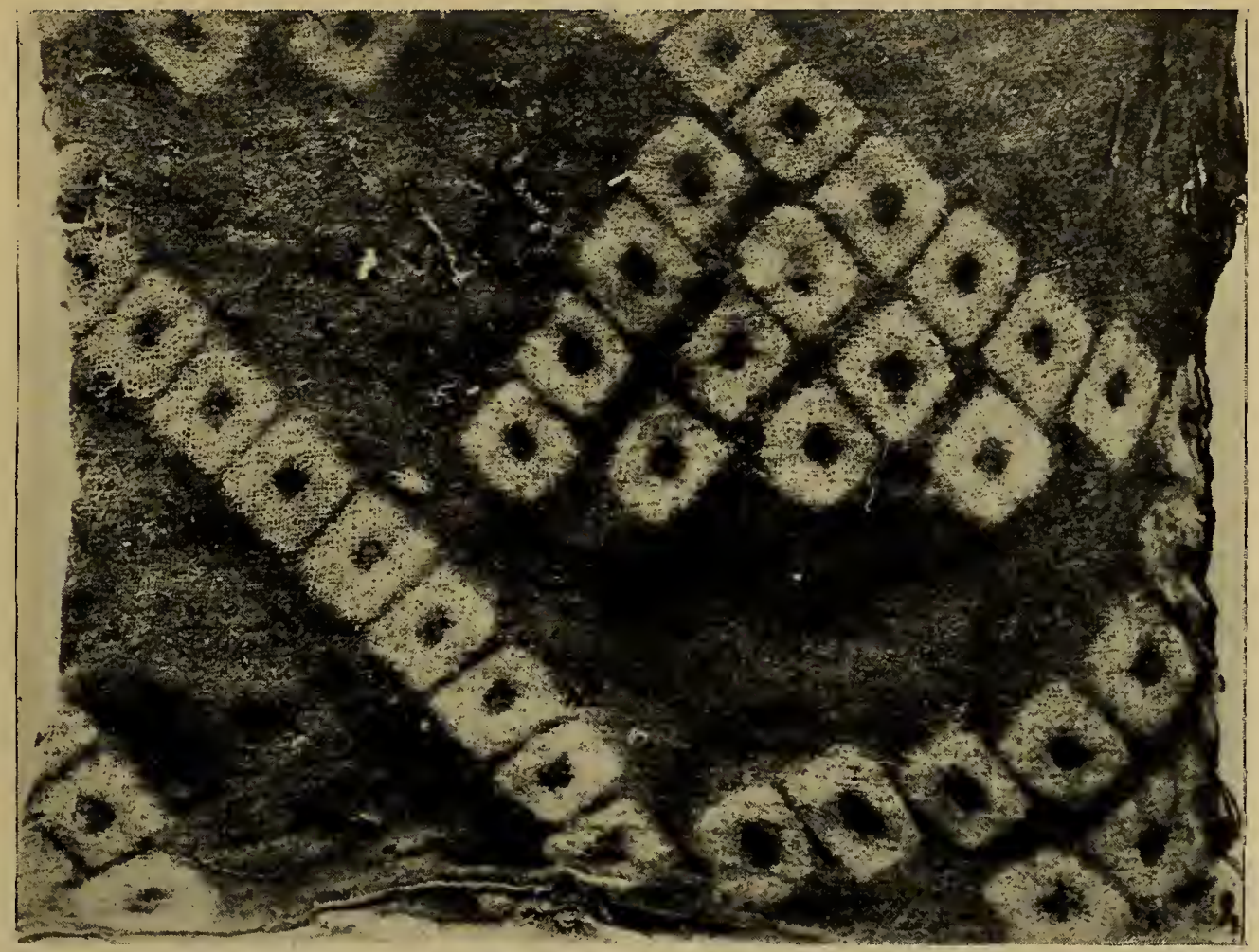

An example of tie-dyeing from an old Peruvian tomb. Courtesy of American Museum of Natural History, New York

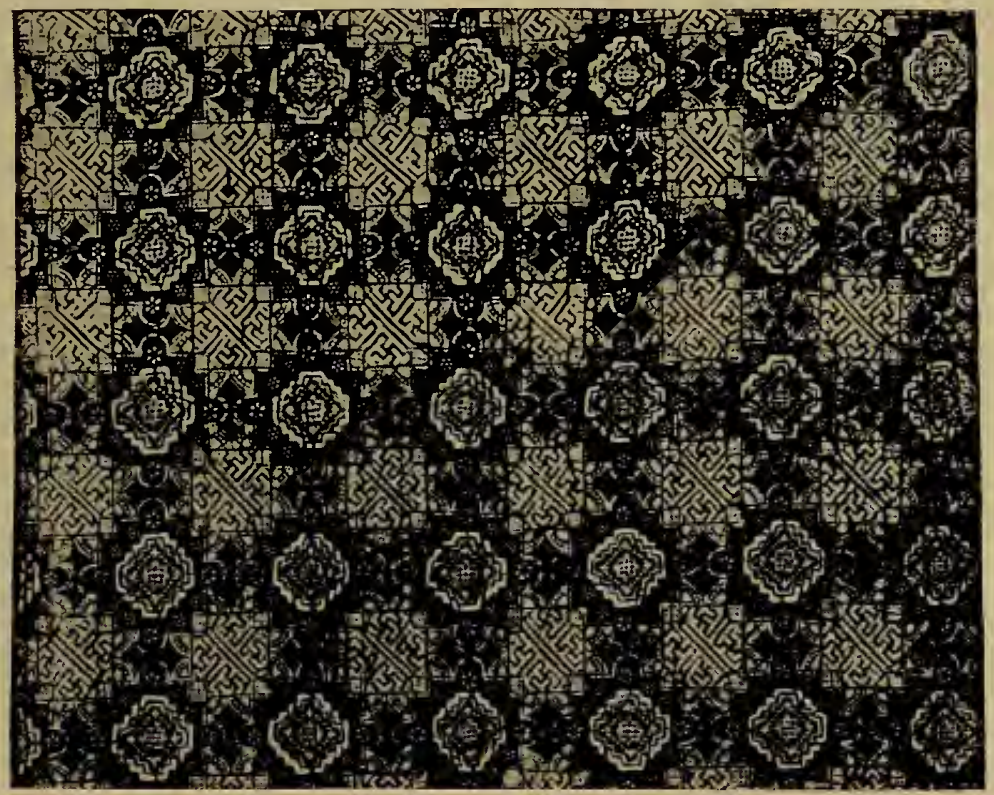

A Javanese Batik design. Courtesy of the Metropolitan Museum, New York 
FIRSTT LESSONS IN BATIK

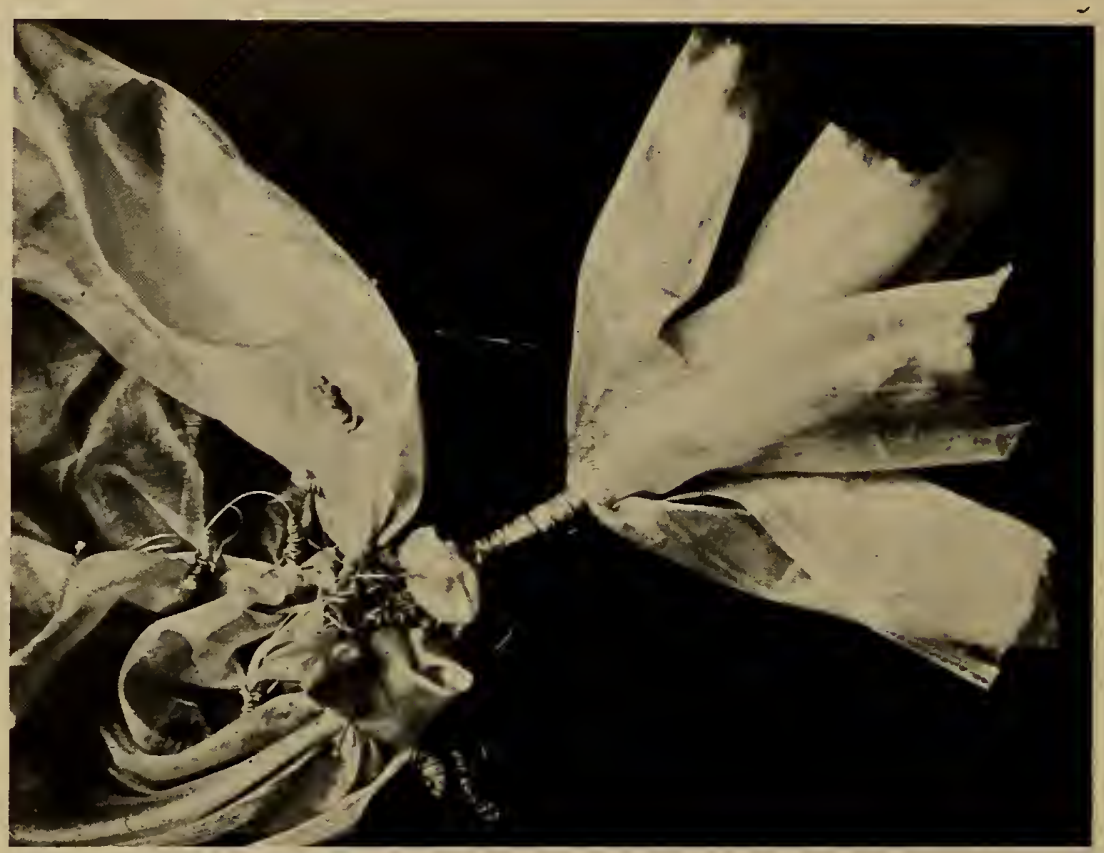

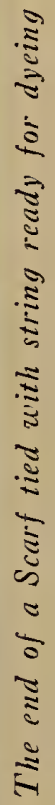

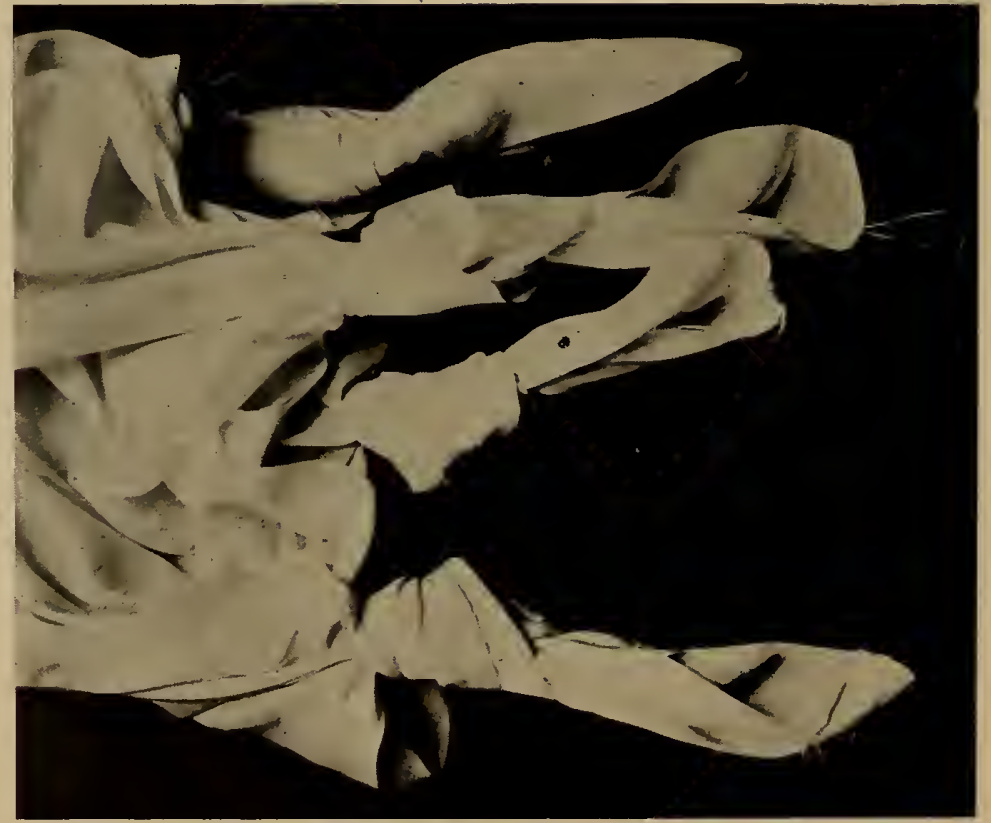

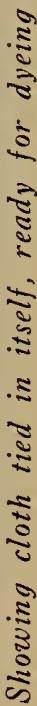




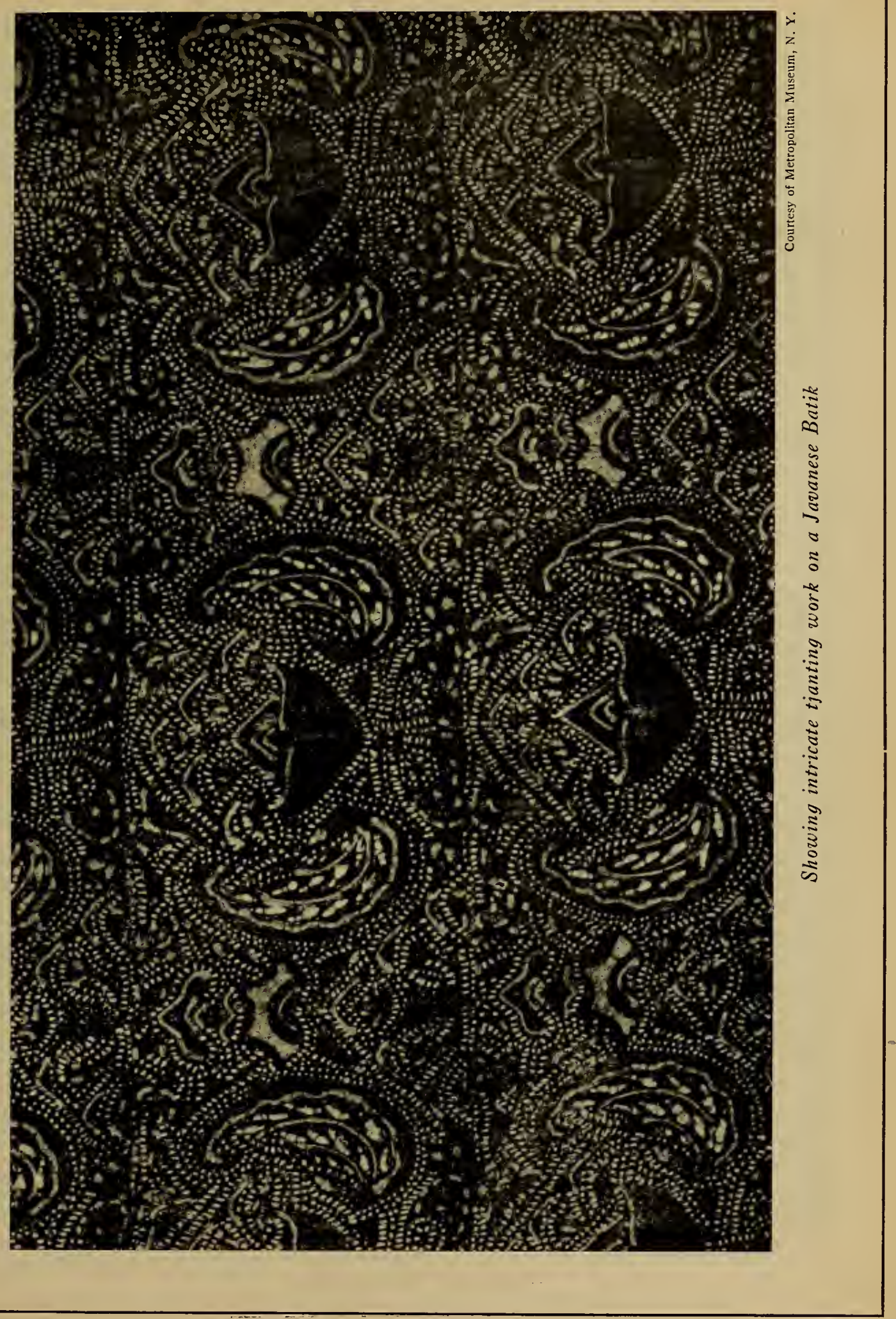




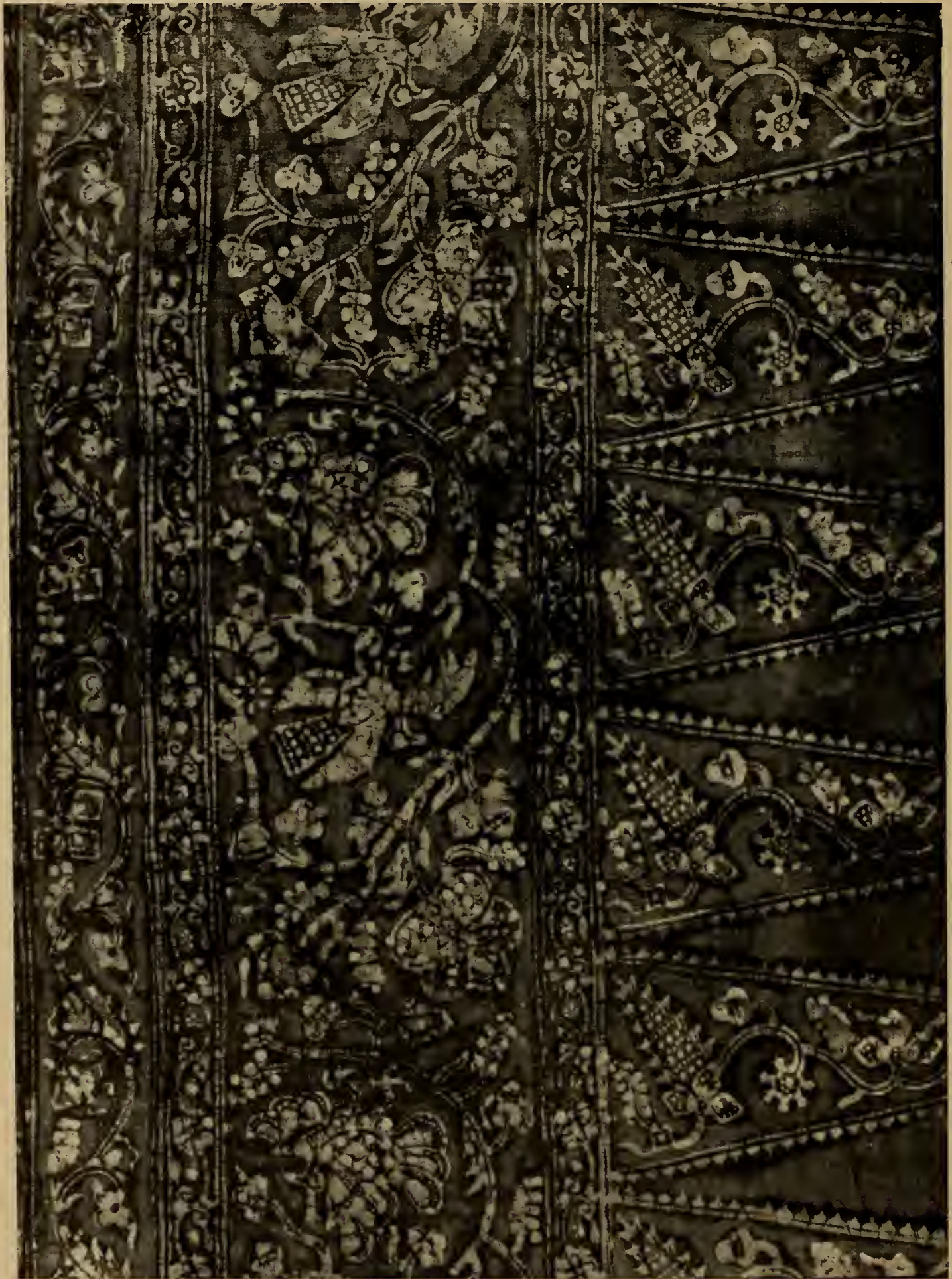




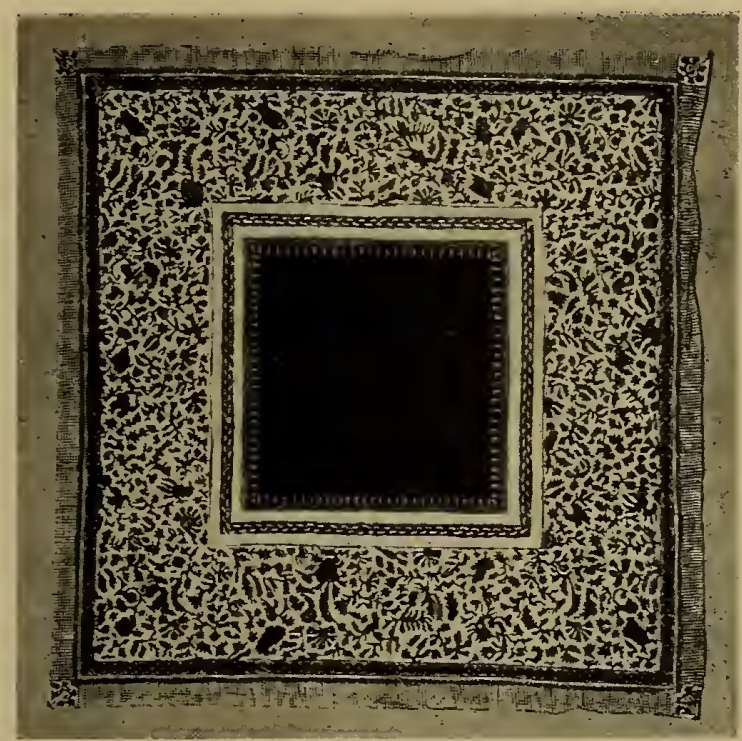

Javanese Batiks. Metropolitan Museum

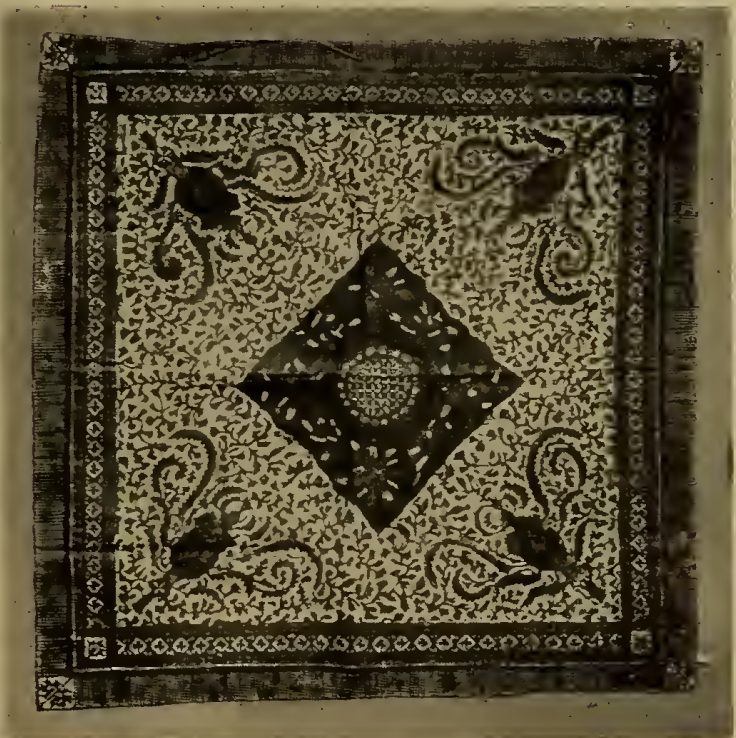

Javanese Batiks. Metropolitan Museum 
FIRST LESSONS I N B A T I K

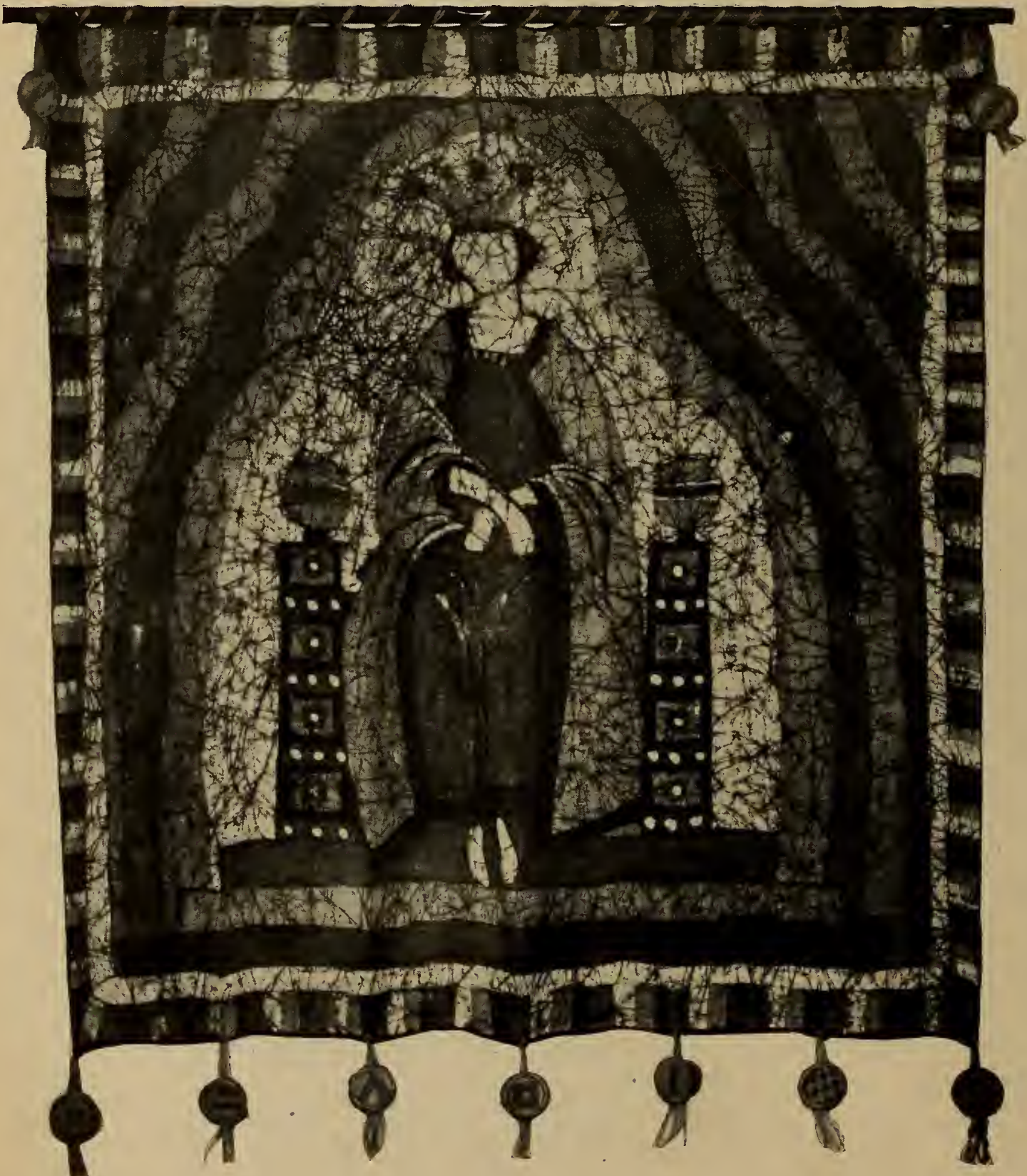

"The Oueen." A Batik hanging by Ilonka Karasz. Courtesy of Academy Art Shop and "Keramic Studio" 


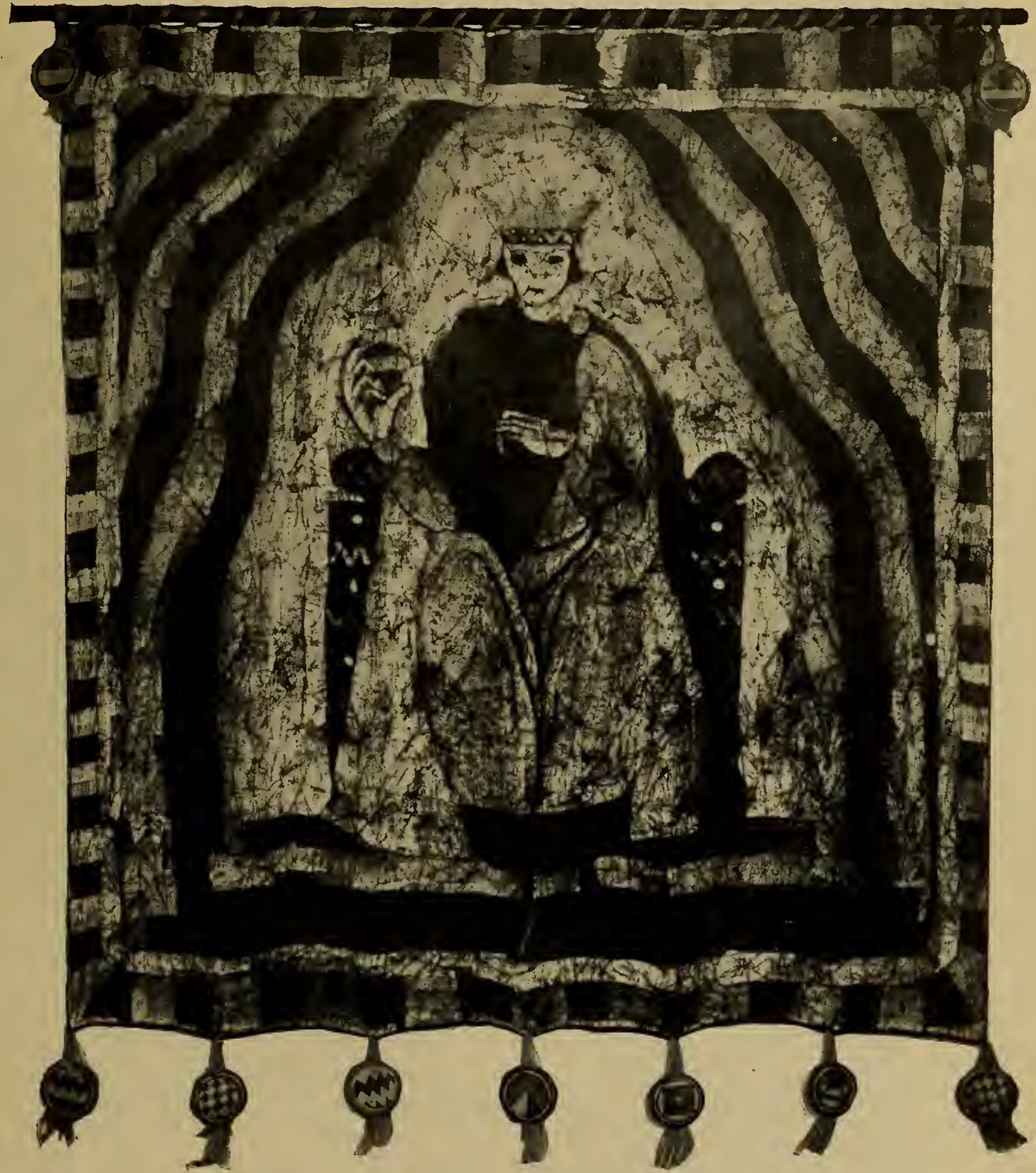

"The King." A Batik hanging by Ilonka Karasz. Courtesy of Academy Art Shop and "Keramic Studio" 


\section{CHAPTER VIII \\ DYEING SUGGESTIONS}

T $\mathrm{N}$ the past, in dyeing under our American conditions, very little attention has been paid to the durability of the dyes. Unless the dye is specially prepared to be used with the cold process which is necessary to keep the wax from melting, the colors will not be fast and the work therefore only transient. This lack of durability has often discouraged careful work. For this reason, great care should be used in the choice of dyes.

The requirements for good Batik dyes are-

1. They must be easily applied.

2. They must be used cold, as the wax melts at $128^{\circ}$ Fahrenheit or $60^{\circ}$ Centigrade.

3. The colors must be sufficiently fast to allow the wax to be removed without injury to the color.

4. The colors must not fade in light or in sun.

Many commercial dyes that are prepared to be used hot can be used somewhat successfully cold. There will be more or less loss of brilliancy and fastness of color, however. These dyes should be used in a much stronger solution than indicated by the directions on the packages.

The most satisfactory results, however, are obtained by using colors prepared especially for the cold process, such as the "Bateeko Dyes." They are exceedingly strong and for that reason exact directions for mixing from the powdered form are impossible, as a tiny speck of the powder will modify the color mixed. For exact measurements it is recommended that each package of the Prang Bateeko Dyes be dissolved in $1 \mathrm{~T} / 2$ cups of water; that is, about 20 tablespoonfuls, and that the amount of each color used in mixing be taken with measuring spoons from this solution. A pint fruit jar is good to hold the mixture.

The extensive use of dyeing as a means of printing textiles dates from the Igth century, when the modern chemical dyes were discovered. There is still a prejudice among some people against the use of chemical dyes for art work. This seems to be based upon the undisputed fact that in the early days of the dye industry some of the colors were so crude and harsh that people fell into the delusion that all harsh colors were due to chemical dyes. The chemists in the meantime have been improving these products until now one can depend upon the manufactured dyes for as beautiful colors as were ever obtained by the older methods. They are so much more easily applied that it is largely for experimental purposes and as a means of keeping alive a craft of our ancestors that the old processes are ever used.

Some brands of dyes are completely dissolved by stirring in hot water. Some need to be boiled and strained to be perfectly clear from specks. They must be thoroughly dissolved. Most dyes are used with either salt, vinegar or acid. Use whichever is recommended by the makers of the dyes 


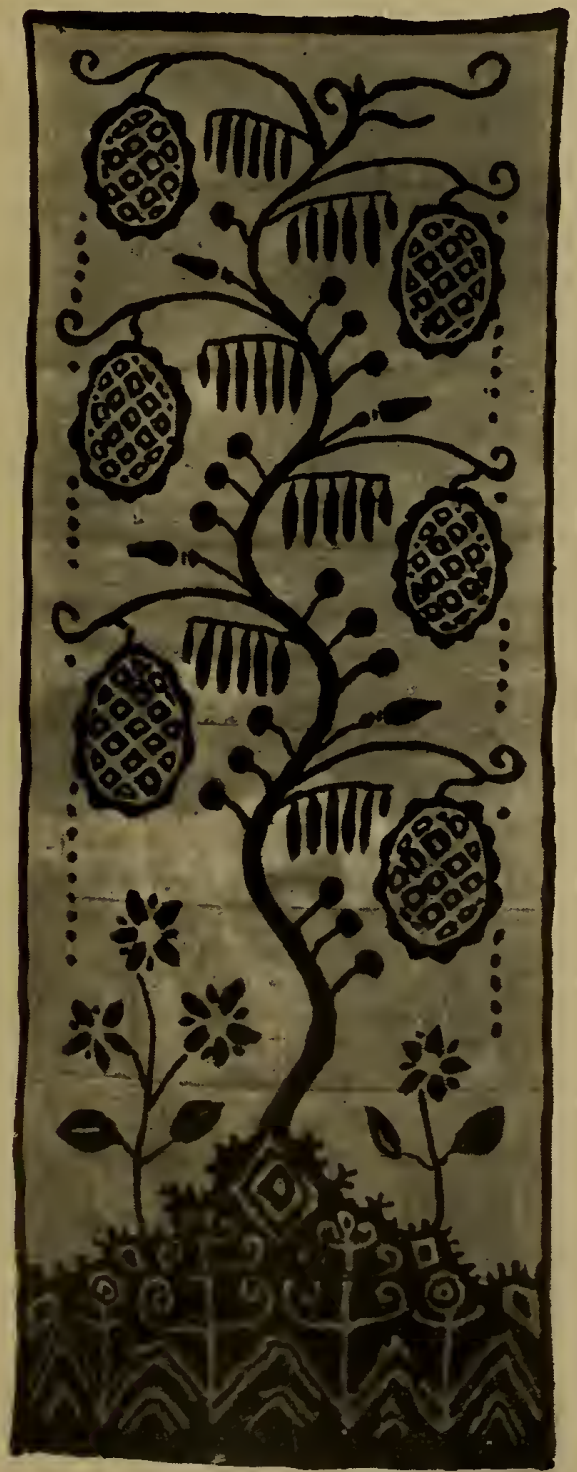

A decorative Batik Hanging by Jean Paul Slusser, using the Javanese "Tree of Life" motif

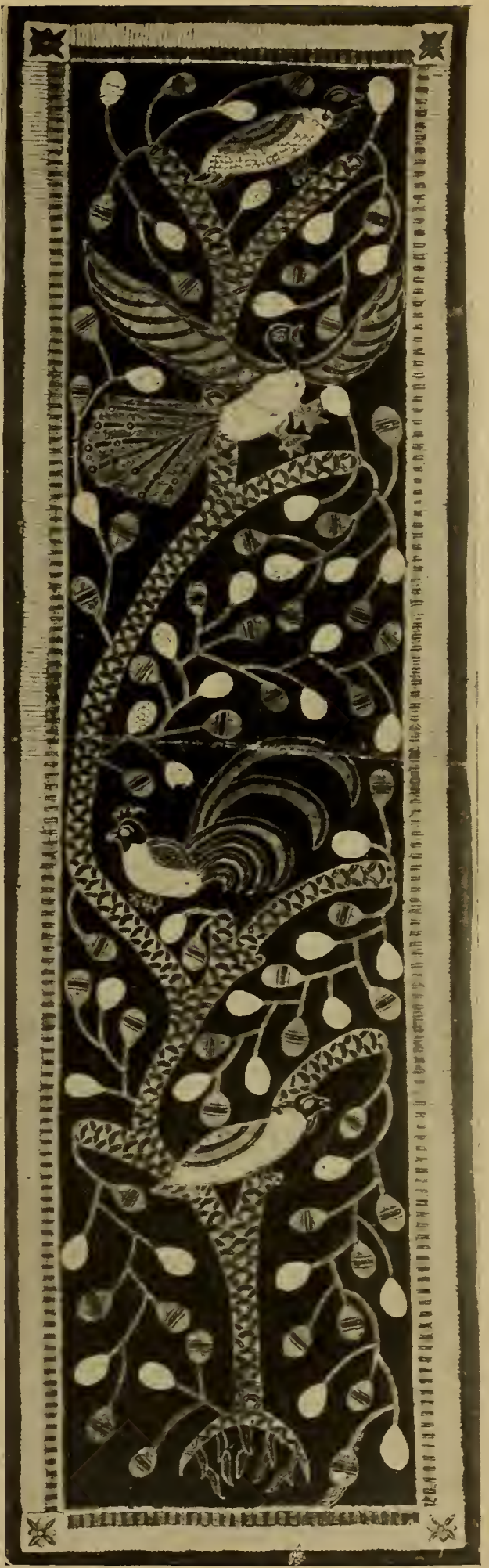


used. For Batik the acid is generally added to the water in which the cloth is to be dipped. Dyes will all work a trifle better in lukewarm than in cold water. Several dippings in a weak dye will give a more permanent color than one dyeing in a strong color.

Dyes vary in their tendency to dye evenly or in spots, and if the worker finds herself using a color having a tendency to streak, this can be overcome by especial care in keeping the piece continually moving while in that color.

To secure an even color it is necessary to keep a gentle motion so as to prevent the dye from settling in any part and to keep all the cloth equally wet, so that it is necessary to have a vessel large enough to keep the cloth entirely under the water and moving freely.

In using any metal pan one should not let dye containing acids stand in it, as the metal will corrode. An enamel pan with a flaw will allow the acid to eat a hole in it in two weeks' time (as the writer found). Dye need never be thrown away. If it dries to a powder or crystal on the bottom of the pan, set the pan away, and when the color is wanted again add warm water as at first and dissolve again. Sometimes as the dye stands in a pan day after day, if it is in constant use, some color may settle on the sides or a film may gather on top of the pan which will streak or spot the cloth if not noticed. Simply strain the dye into a clean vessel and continue to use it as long as any color remains.

When the worker can produce a piece of Batik or tied-and-dyed with a dye that will last, there is no excuse for careless work. And a piece of the work should receive the time and care in making that its beautiful possibilities deserve.

Batik dye cannot be used hot as the wax would melt. If used very cold the wax tends to crack and the color will creep under the wax. If too hot, that is, over 128 degrees Fahrenheit, the wax melts and the design is blurred or lost. The best temperature for the dye bath is between 90and I Io degrees Fahrenheit. As 98 degrees is blood heat, if no thermometer is convenient, water that feels the temperature of the wrist will be all right. Use plenty of water to float the cloth. Allow it to move freely without crowding in the basin. Put only enough dye in the water to color the water distinctly. The cloth will absorb the dye color from the water and leave the water clear, if only enough dye has been used. If much dye remains in the water after the work is finished it shows that more dye was used than was necessary. If more dye is to be added, remove the cloth from the water and add in small quantities.*

It is not only waste of dye to use a strong solution, but a more durable fast color is secured by allowing the goods to remain in the dye bath until there is a thorough union between the dye and the fiber of the cloth. This union cannot be obtained in a few minutes sufficiently to stand much rough usage. "Make haste slowly" must be the motto of the dyer who wishes

*Mairet's "Vegetable Dyes" will give all the formulas necessary for experimenting in that line if any readers are interested. 


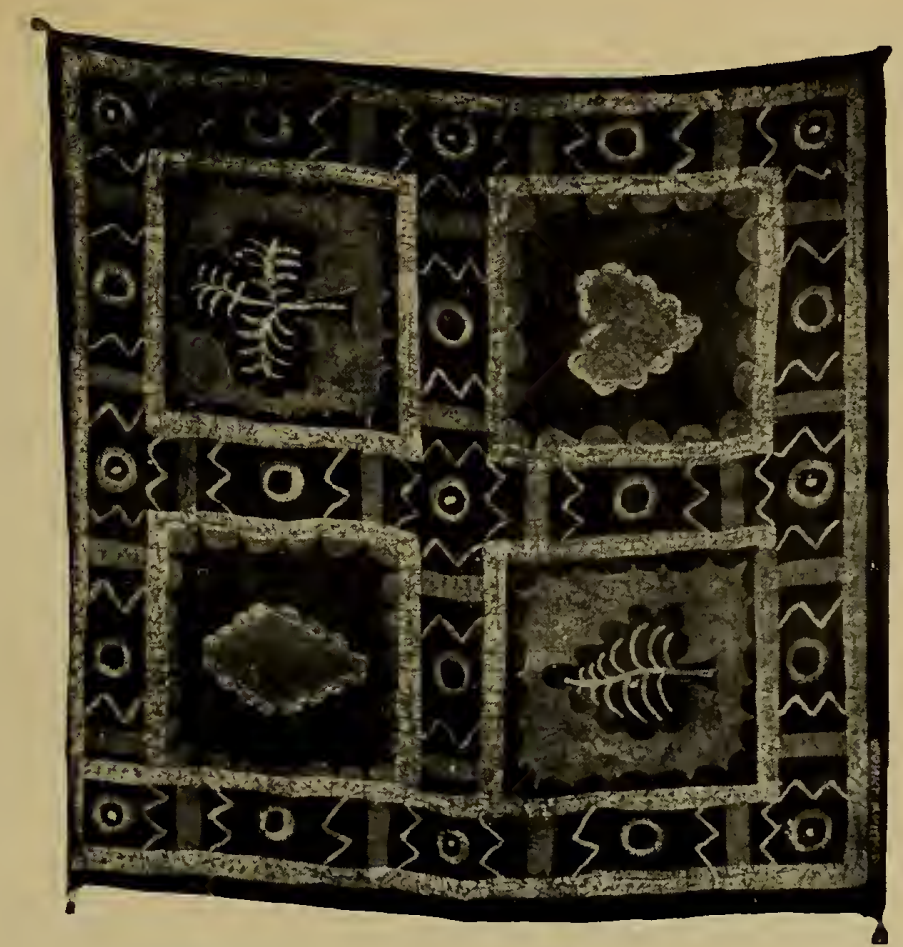

Batik by Ilonka Karasz. Courtesy Academy Art Shop, New York

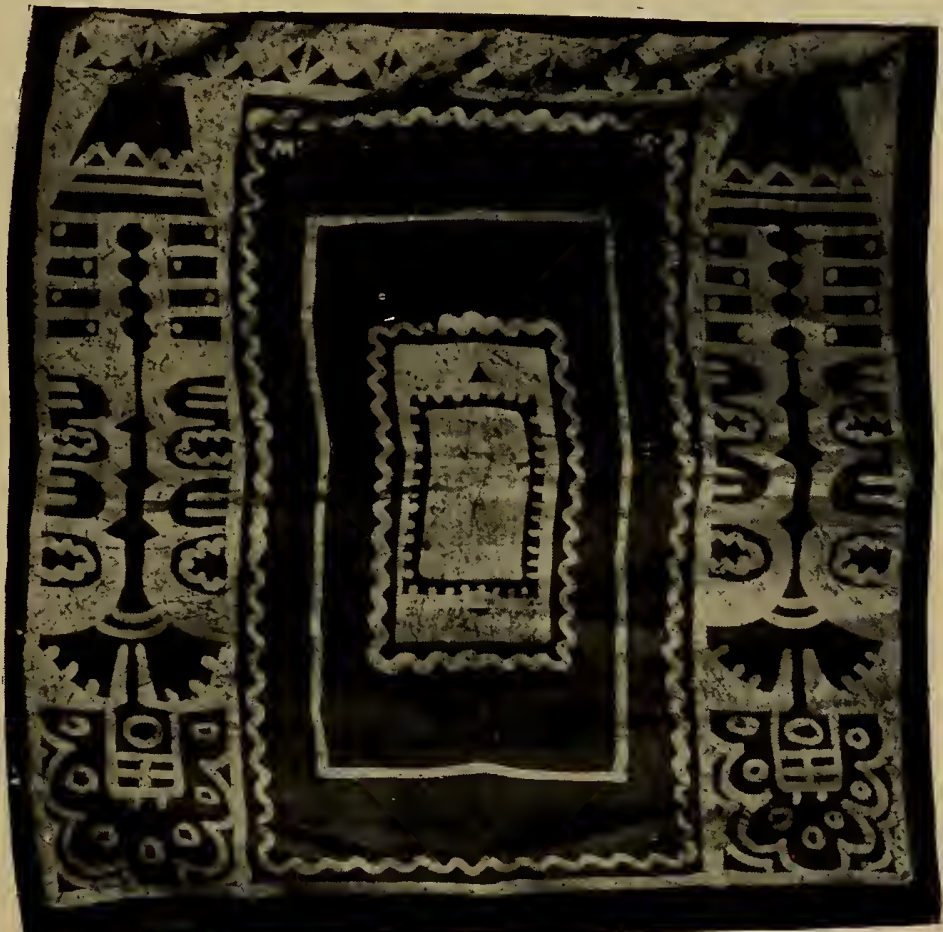

Batik by Winold Reiss. Courtesy Academy Art Shop, New York 
a permanent color. Remember the time required in the old indigo and turkey red processes.

Therefore, it is better to allow at the very least twenty minutes for the dyeing. An hour is better for a slow color like black. Some colors, such as black, brown and yellow, unite with the fiber of the cloth more slowly than others, so that more time must be allowed for these. Blue dyes very quickly and easily, but must be given time to set in the fiber to become thoroughly permanent. These time suggestions are for the "Bateeko Dyes" in powder form.

There is also a great difference in materials used, as to the rapidity with which they will absorb the dye. Wool and silk absorb the dye easily and quickly, cotton, linen and hemp much more slowly. Therefore, the time allowed for dyeing must be increased to get deep colors in cotton, linen and hemp.

The closeness of the weave and the hardness of the twill must also be considered. A very loose porous silk or cotton crepe will dye in a few minutes, while a firm muslin will require perhaps half an hour to an hour to produce a strong fast color.

The material should be free from starch or sizing of any kind before it is put into the dye.

After the goods has been stirred in the bath for five to ten minutes, more dye can be added if necessary. Be sure to remove the material from the dye bath before adding more dye. As color always seems darker when it is wet, it is difficult to tell exactly when you have as deep a color as you desire, but holding the material up to the light gives a fairly good idea of the way the color will look when dry. To get a deep shade of a special color it is always better to work up to the color desired by steps, that is, to dye a light tone of the color desired, examine this and if it is the desired shade continue until the desired depth of color is reached.

After dyeing, rinse thoroughly in cold water, drain the water out on an old towel or sheet and hang it on a waxed line or cord to dry. It is best to wax the line so that the line does not tear off the wax on the cloth where it is pinned up.

The remaining problem of dyeing is the most interesting of all, viz.: the effect of one dye on another, and of dyeing one color over or on top of the preceding color.

In this "top dyeing," we must remember that the final color will be the combination of the color already on the material and the dye color which is being added. If we have a brilliant yellow scarf, we cannot dye it a blue unless in some way we can remove the yellow, but we can dye it any color of which yellow forms a part, such as orange, orange red, mahogany, green of all kinds, browns, greys, and black. All these colors contain yellow and can be dyed over yellow by adding the other colors which make the desired combination. A pale yellow can be neutralized by dyeing with weak magenta and then dyeing blue. 


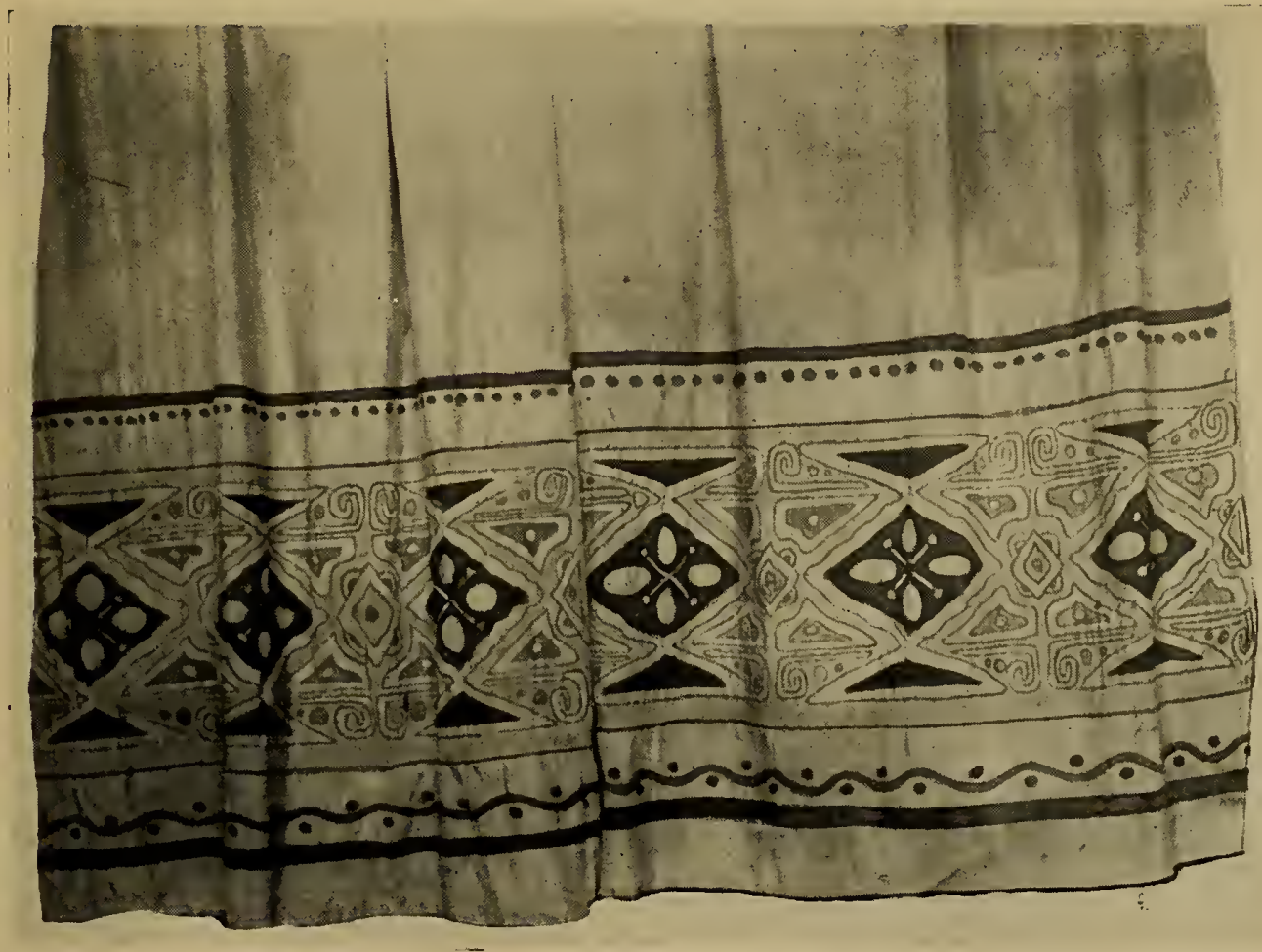

A Window Curtain decorated in Batik. Designed and executed by soldiers in the Commercial Art Class at U.S. General Hospital No. 2, under the direction of Lieutenant Jean Paul Slusser

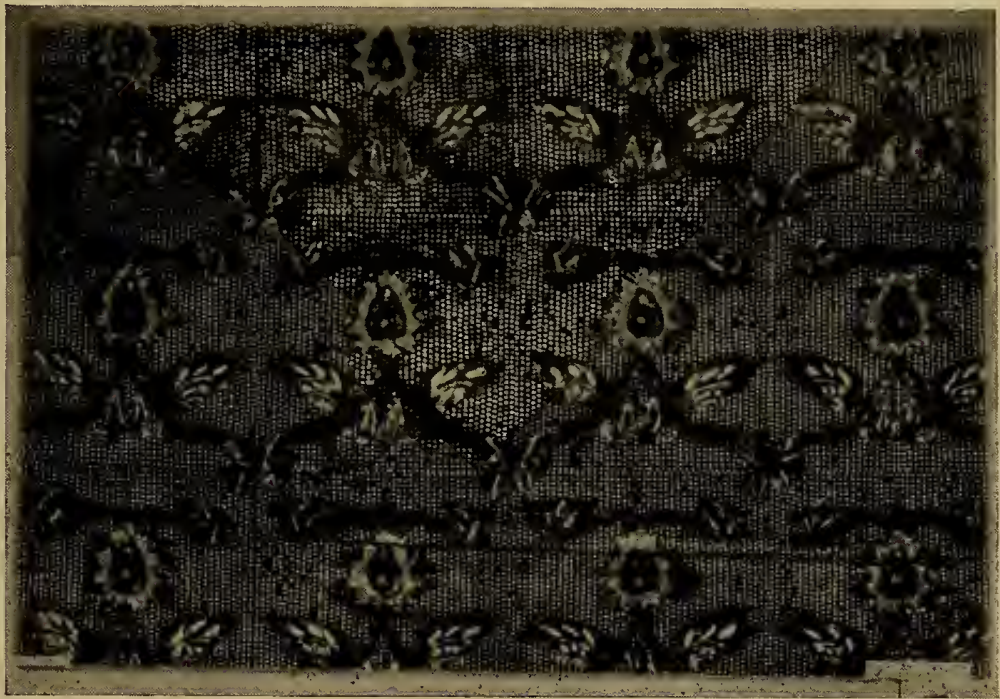

Javanese Batiks. Courtesy of the Metropolitan Museum, New York 
For instance, to make a medium grey green over a yellow, both blue and red must be added, the blue making green when dyed over yellow and a little red making the color grey. In dyeing a strong color over a weak and greyish color the original color will seem to have very little effect.

The amount of each color used depends upon the result desired. Therefore, analyze the color you wish to produce. Decide what proportion of each color there seems to be in the shade desired, and mix the dyes accordingly. Dye the light colors first, and the darkest last. Remember a color may be darkened or modified, but cannot be lightened, except by removing the dye with ammonia or washing soda.

In dyeing for Batik, the safe thing is, of course, to depend upon several weak dye baths of rather clear colors, as there is danger of producing too grey and muddy a color if strong baths are used before there is a good understanding of the result of the color combinations. If at all uncertain of the result of a color combination, dye a piece as a trial first.

In dyeing, to secure a red and green in the same piece, the colors of the "blue group" discussed in the previous chapter should be dyed first entirely. Then with washing soda or ammonia the color on the spots where the red group of colors is desired can be removed. This bleaching process had better be reserved for advanced work, and in the beginning stages color combinations not requiring it should be used. The soda and ammonia both affect the wax and after using them the waxing should be looked over carefully and ragged edges re-waxed.

When a small spot of a contrasting color is wanted on such a place as the wings of the bird on the velvet bag on page 42 , the method of removing the color by ammonia is the one to use.

With thin silk the wax can be so entirely removed with a hot iron and papers that a piece can be re-waxed for contrasting colors. With heavy cloth or velvet, the wax could not be so completely removed by this method that the next dyeing would be satisfactory. Gasoline is the best method of removing the wax in such a case. Every particle must be removed in order to have the next dye bath satisfactory.

For that reason it is best to remove all the wax possible in the first gasoline bath and rinse in clean gasoline before dyeing again.

In dyeing textiles in large quantities with the "Bateeko" Powder Dyes as is required for costumes, draperies, etc., the directions as to size of receptacle, time of dyeing, stirring, etc., are the same as for smaller work.

While these dyes are very rapid in their action when used in only tepid water, they are naturally still more rapid when used hot. The user, therefore, has the choice of the hot or cold process, according to her convenience. If the dye is used hot the material must be stirred constantly. If used in tepid water it must be kept in motion only sufficiently to keep the color from settling in the folds and making dark spots or streaks.

Always rinse out all the loose color thoroughly in cold water before hanging up to dry. Hang the pieces so they do not touch anything. 


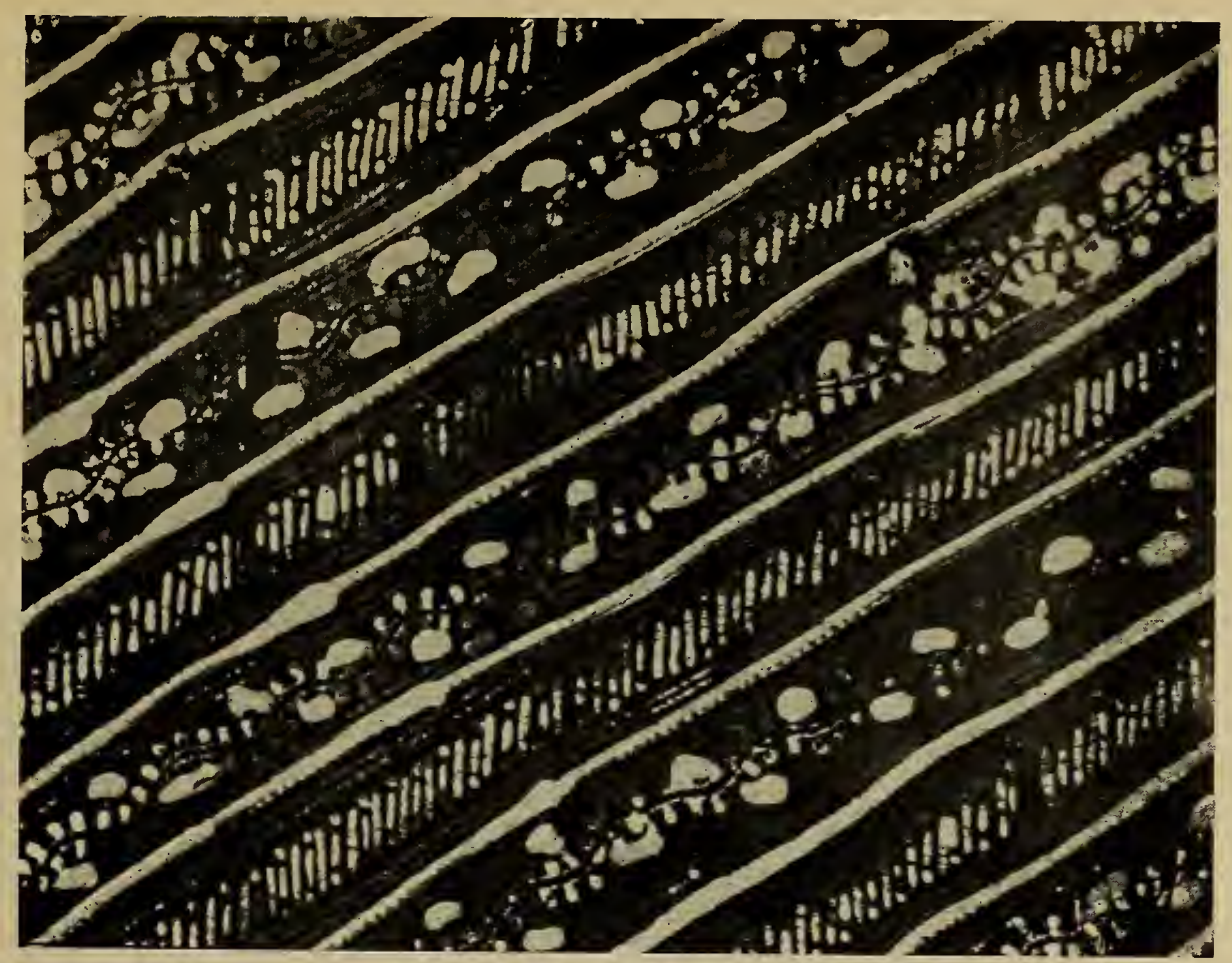

A section from a Javanese Batik from Metropolitan Museum, New York

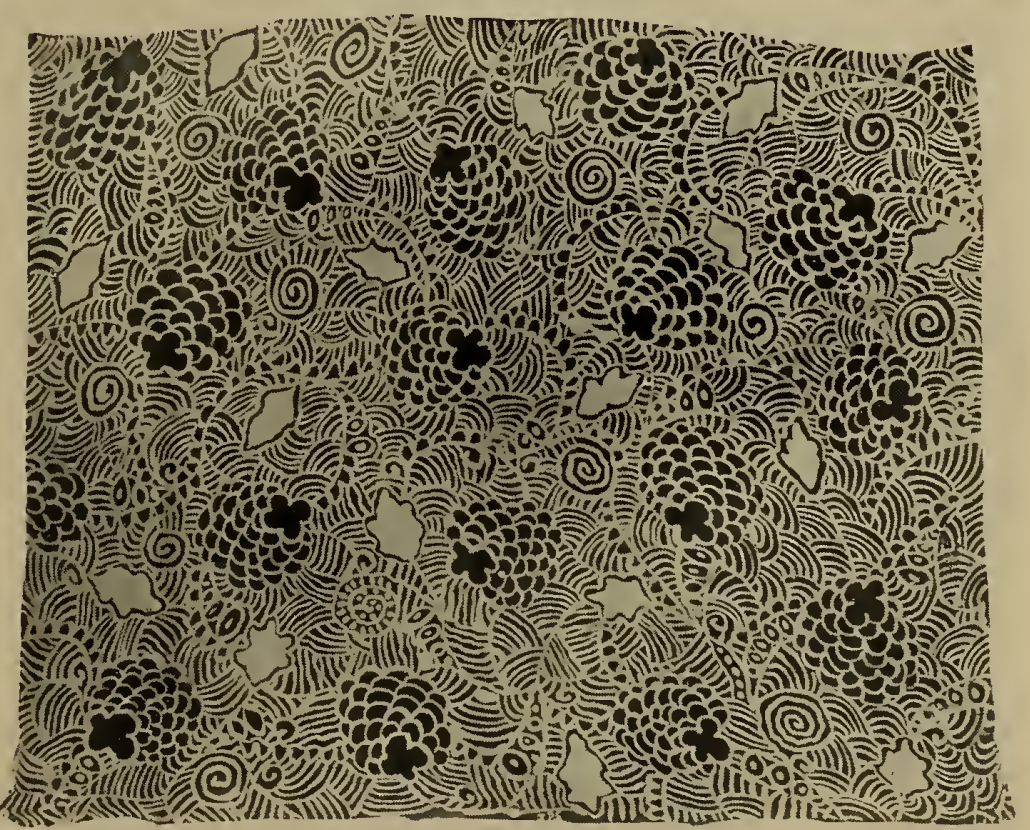

An all-over design in Batik that was practically improvised as the work u'as done. By Jean Paul Slusser 
If working constantly with dyes, rubber gloves are a convenience. However, even with gloves one sometimes stains the hands. Ammonia or washing soda will help remove the stain.

Practically any container that is large enough can be used. The best is perhaps a copper tub; enamel ware is excellent. Wooden tubs are used by professional dyers somewhat. Galvanized iron is all right, unless the dye containing acid stays in it so long that the acid affects the iron.
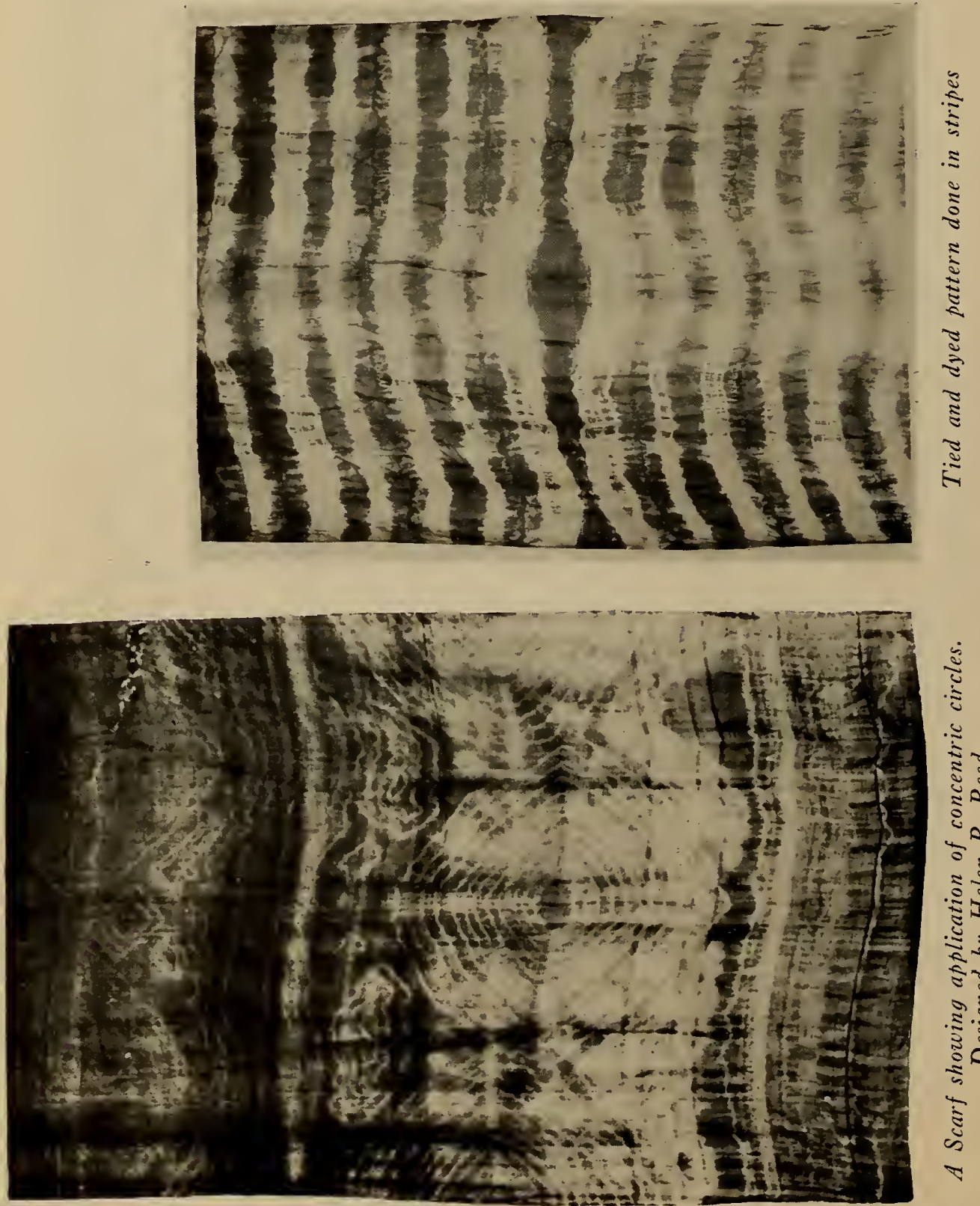

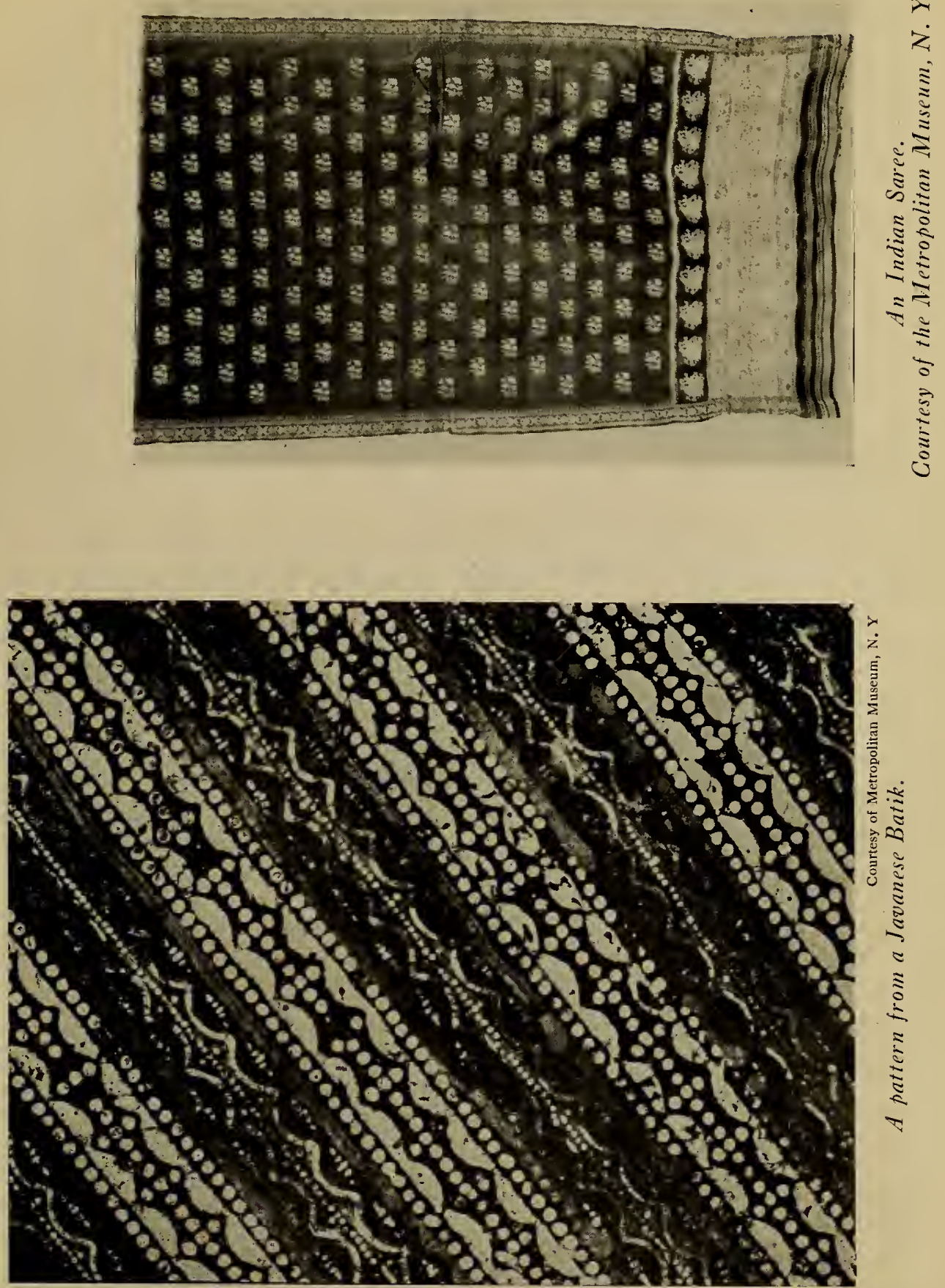


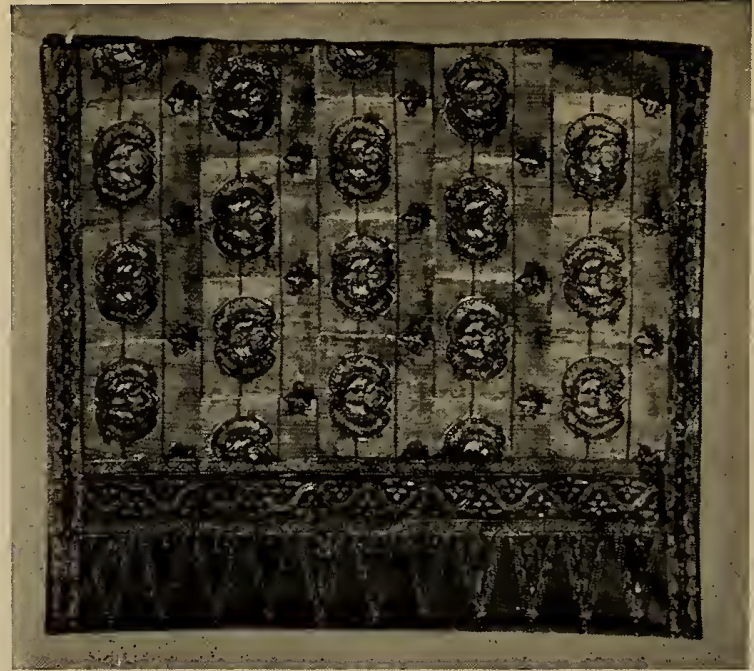

A pattern from a Javanese Batik.

Courtesy of the Metropolitan Museum, New York

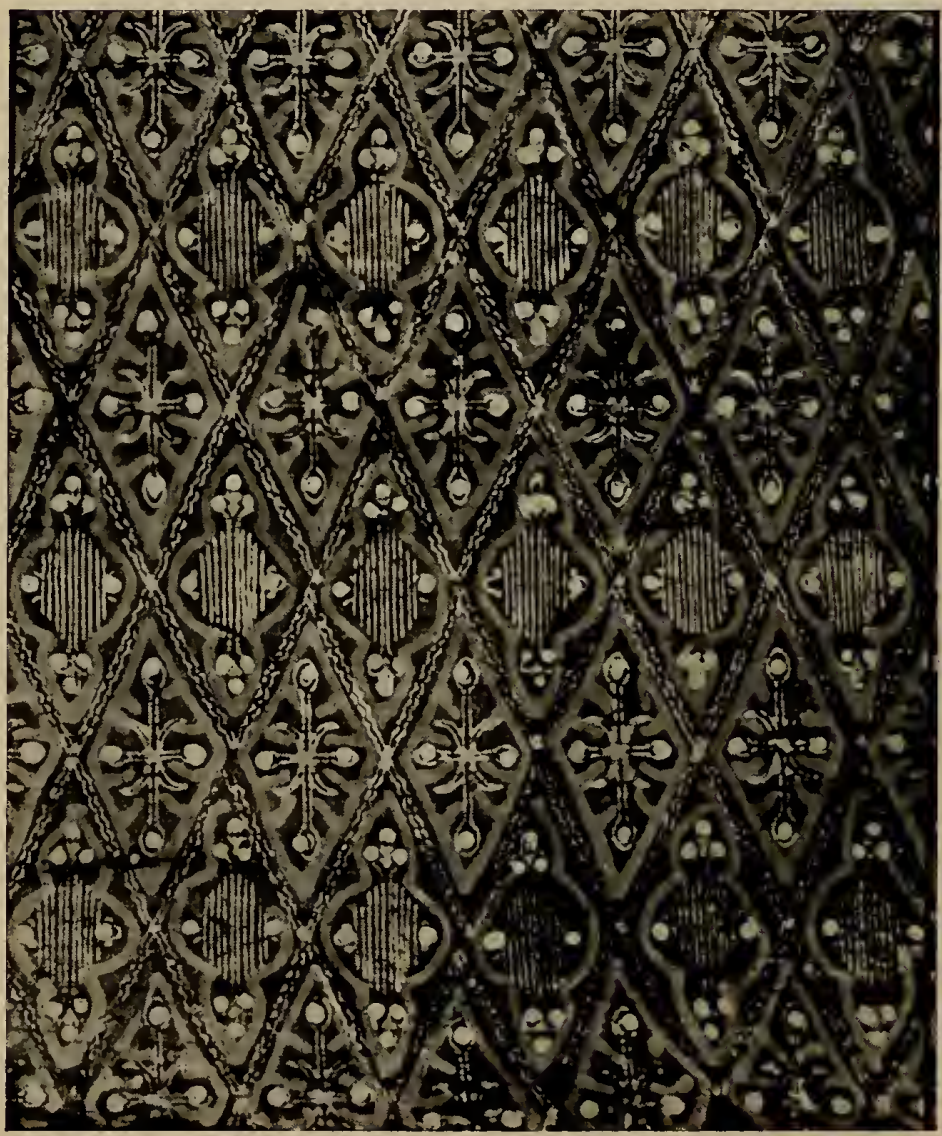

Courtesy of Metropolitan Museum, N, Y.

A pattern from a Javanese Batik 

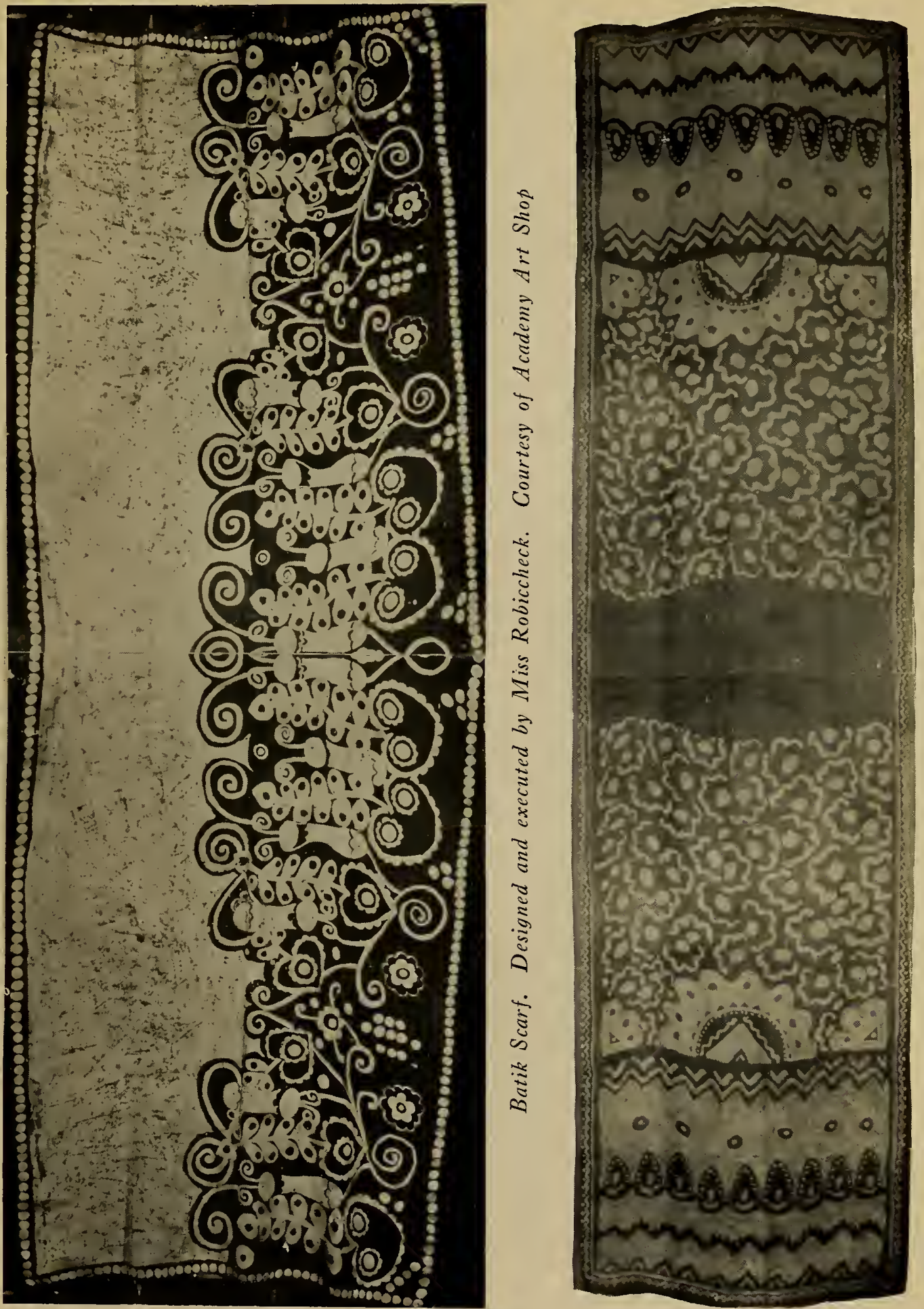

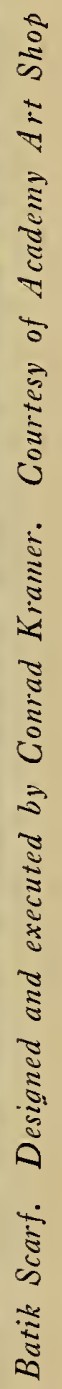


FIRST LESSONS IN B A TIK

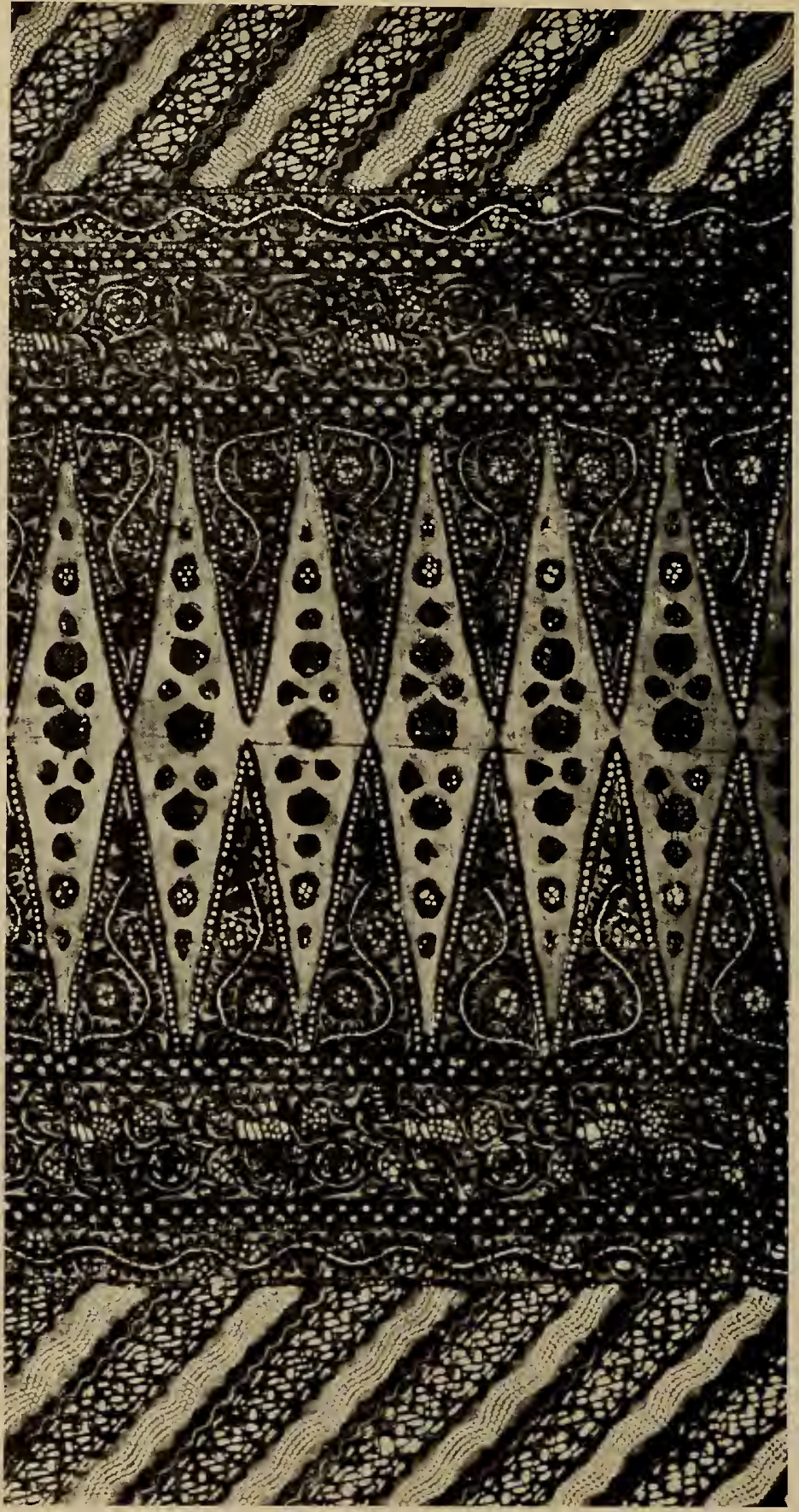

A Javanese Batik pattern 


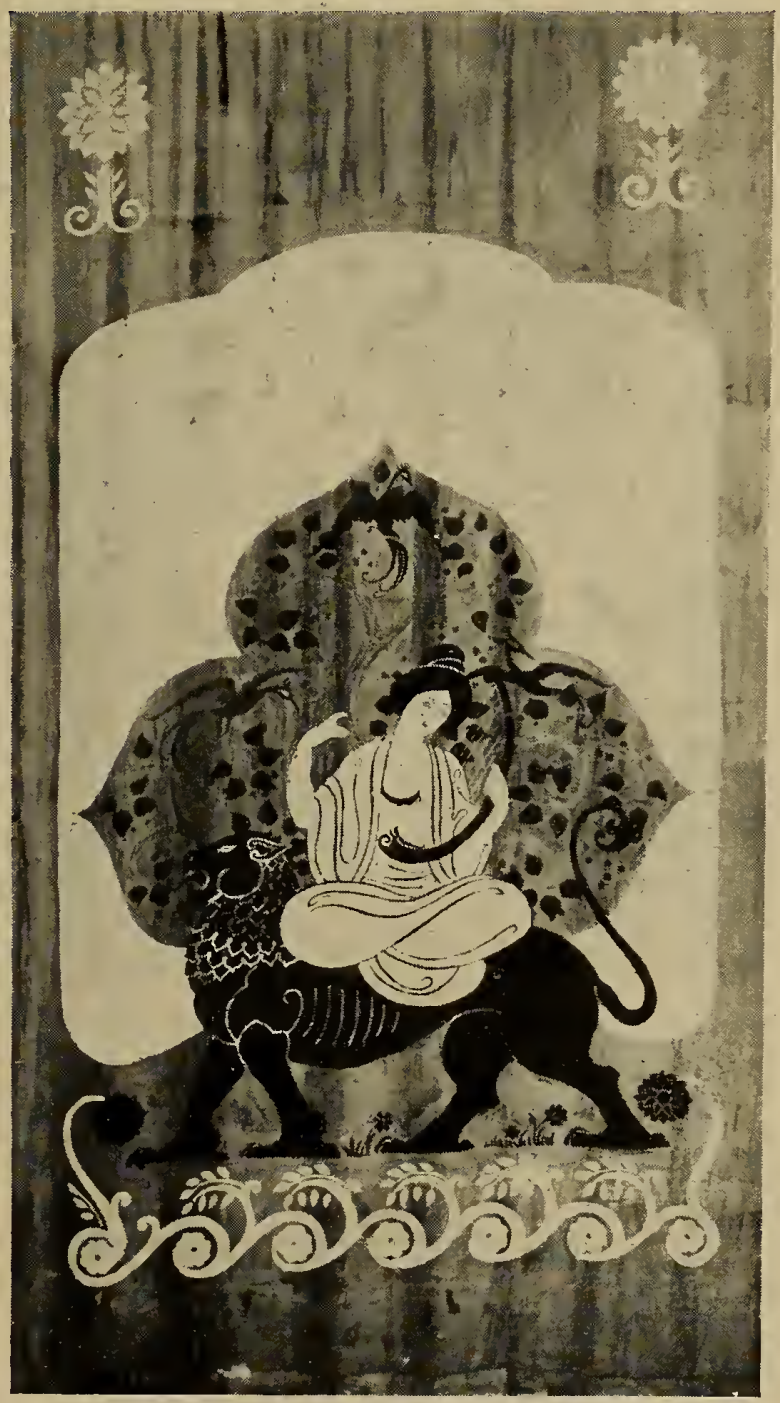

A modern Batik wall hanging 


\section{PRANG "QUARTO ART BOOKS"}

"THE THEORY AND PRACTICE OF COLOR"

By BONNIE E. SNOW and HUGO B. FROEHLICH

The most authoritative work on "Color" issued in this country. Illustrated with hand-painted "Color Charts" of great value. Large quarto, price, $\$ 4.00$; by mail, $\$ 4.25$.

\section{“ART SIMPLIFIED” (Revised Edition) \\ BY PEDRO J. LEMOS and JOHN T. LEMOS}

A book of practical instruction in Art for advertisers, commercial artists, teachers and students. Twenty-two full-page plates, 175 pages. Price, $\$ 4.00$; by mail, $\$ 4.25$.

\section{"LETTERING"}

By THOMAS WOOD STEVENS, of Carnegie Institute, Pittsburgh

The standard work on the subject for students and artists. One hundred ten full-page plates. Large quarto, price $\$ 3.00$; by mail, $\$ 3.25$.

\section{"CARTOONIST'S ART"}

By J. CAMPBELL CORY

The secret of the art told by a successful cartoonist, with many examples of the work of other prominent artists. Price, $\$ 2.00$; by mail, $\$ 2.25$.

\section{“CONSTRUCTIVE ANATOMY"}

By GEORGE B. BRIDGEMAN

Teachers in Anatomy in Art Schools, Colleges, Normal Schools and High Schools will find this book invaluable as a Text Book on the subject. Price, $\$ 7.50$; by mail, $\$ 7.75$.

\section{"PENCIL SKETCHING PORTFOLIOS" \\ By GEORGE W. KOCH}

These "Pencil Sketching Portfolios," Nos. 1 and 2, contain drawings which have been specially designed for students of pencil technique. Each Portfolio contains 15 plates. Price, each, $\$ 1.00$; by mail, $\$ 1.25$.

\section{"TWELVE GREAT PAINTINGS"}

By HENRY TURNER BAILEY, Director Cleveland School of Art

Interpretations which cannot fail to stimulate interest in the world's masterpieces. Large quarto, price, $\$ 3.00$; by mail, $\$ 3.25$.

\section{"WITH PEN AND INK"}

By JAMES HALL

Complete instructions for work in this medium, with 21 full-page plates and 21 problems. Large quarto, price, $\$ 3.00$; by mail, $\$ 3.25$.

\section{"A SHORT HISTORY OF ART"}

By DE FOREST and CAFFIN

The most comprehensive single volume on the subject, comprising 758 pages with 289 illustrations. Price, $\$ 4.00$; by mail, $\$ 4.25$.

\section{"EXERCISES IN DESIGN" \\ By ELIZABETH G. BRANCH}

Suggestions to teachers accompany each of the 70 full-page plates, $7 \times 11$ inches in size. Quarto, price, $\$ 3.00$; by mail, $\$ 3.25$.

\section{"FIRST LESSONS IN BATIK"}

\section{By GERTRUDE C. LEWIS}

A practical handbook, giving full information for "Batik" dyeing and "tie-dyeing" on various fabrics. Beautifully illustrated. Price, $\$ 1.50$; by mail, $\$ 1.60$.

\section{"PERMODELLO MODELING"}

\section{By BONNIE E. SNOW and HUGO B. FROEHLICH}

Gives full directions for innumerable uses of "Permodello," the permanent Modeling Clay, which sets like concrete without firing. Beautifully illustrated. Price, $\$ 1.50$; by mail, $\$ 1.60$.

THE PRANG COMPANY, Publishers, NEW YORK, CHICAGO 






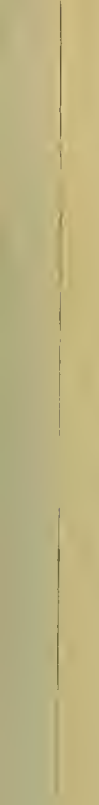





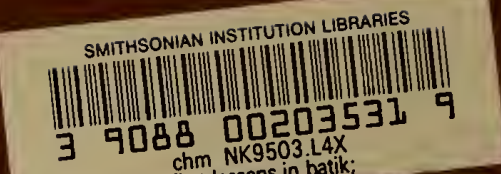

chm NK9503.L4X

First lessons in batik. 